\title{
WestVirginiaUniversity
}

THE RESEARCH REPOSITORY @ WVU

Graduate Theses, Dissertations, and Problem Reports

2010

\section{A case study of Universal Design for Learning applied in the college classroom}

Marie E. Leichliter

West Virginia University

Follow this and additional works at: https://researchrepository.wvu.edu/etd

\section{Recommended Citation}

Leichliter, Marie E., "A case study of Universal Design for Learning applied in the college classroom" (2010). Graduate Theses, Dissertations, and Problem Reports. 4625.

https://researchrepository.wvu.edu/etd/4625

This Dissertation is protected by copyright and/or related rights. It has been brought to you by the The Research Repository @ WVU with permission from the rights-holder(s). You are free to use this Dissertation in any way that is permitted by the copyright and related rights legislation that applies to your use. For other uses you must obtain permission from the rights-holder(s) directly, unless additional rights are indicated by a Creative Commons license in the record and/ or on the work itself. This Dissertation has been accepted for inclusion in WVU Graduate Theses, Dissertations, and Problem Reports collection by an authorized administrator of The Research Repository @ WVU.

For more information, please contact researchrepository@mail.wvu.edu. 
A Case Study of Universal Design for Learning Applied in the College Classroom

Marie E. Leichliter

Dissertation submitted to the College of Human Resources and Education

at West Virginia University in partial fulfillment of the requirements

for the degree of

Doctor of Education

in

Technology Education

\author{
Neal Shambaugh, Ph.D., Chair \\ Cindy Beacham, Ph.D. \\ Ugur Kale, Ph.D. \\ Jaci Webb-Dempsey, Ph.D \\ Pamela Whitehouse, Ph.D. \\ Department of Technology, Learning, and Culture \\ Morgantown, West Virginia \\ 2010
}

Keywords: Universal Design for Learning, active learning, Scientific Teaching, case study, pedagogy, learner-centered, student perceptions

Copyright 2010 Marie E. Leichliter 


\begin{abstract}
A Case Study of Universal Design for Learning Applied in the College Classroom
\end{abstract}

Marie E. Leichliter

As the landscape of education and the demographics of the postsecondary classroom continue to evolve, so too must the teaching practices at our nation's institutions of higher education. This study follows an instructor who has evolved to incorporate Universal Design for Learning (UDL) techniques into her classroom, even though prior to participation in this research study, she had not heard of UDL. UDL is a flexible framework used to design curricula that enable all learners to acquire knowledge, skills, and motivation to learn. This qualitative, descriptive case study addressed how and to what extent UDL techniques are being implemented in the college classroom and what student's perceptions of how these UDL techniques affect their learning. Data were collected over the course of a semester via field-based observations, semi-structured interviews, a survey, and a review of course materials. The case study participants included 38 students and an assistant professor at an institution of higher education in West Virginia. Results indicated that the instructor was implementing many UDL techniques in her classroom and that the majority of students both acknowledged and positively received these techniques. The data gathered during this study also revealed that the implementation of UDL in the college classroom is more than mere theory; the application of the UDL framework and principles are practical. Neuroscience suggests that no two students learn the same way or experience the same event with identical observations; responses are as unique as our fingerprints or DNA. As educators, our instruction must meet the needs of unique and diverse learners. UDL assists instructors to meet a diversity of needs through a single curriculum design. Research studies indicate that UDL is "best practice" teaching. 


\section{Acknowledgements}

It is my pleasure to acknowledge some of the colleagues, friends, and family who contributed to this work. I would like to express my gratitude to each of the individuals who aided me during the many stages of my dissertation work. I appreciate all the guidance, feedback, time, and support that you have given me. I would never have been able to complete my dissertation without the support and guidance of a few important individuals.

I would like to express my deepest gratitude to my advisor and dissertation committee chairperson, Dr. Neal Shambaugh, for his excellent guidance. He is truly a man with a mentor's spirit. I thank all of my committee members, Dr. Cindy Beacham, Dr. Pam Whitehouse, and Dr. Jaci Webb-Dempsey, for their time and valuable feedback. Special thanks goes to Dr. Ugur Kale, who was willing to join my defense committee at the last moment.

I would like to thank Dr. Keith Garbutt, my current supervisor, without whom I would never have discovered the world of Scientific Teaching or met the instructor with whom I was able to complete my research. For this introduction, and for all the support he has provided me throughout the entire process, I thank him.

I would also like to thank Ms. Jeanne Grimm at The West Virginia University Center for Excellence in Disabilities. My experience at WVATS has forever imprinted me with a life perspective and I will always be thankful for the guidance I received. Jeanne introduced me to UDL.

I would like to thank Dr. Michelle Withers, one of the finest and most supportive educators I have ever met. Additionally, I would like to express thanks to Dr. Susan Fisher, a creative entomologist who uses UDL to teach her students the "Art of Science" and taught me about her exciting work.

Thank you to all of my friends and family members who have supported me. To my parents whose unconditional love and support throughout this entire process inspired me; I could not have done this without you. Thank you from the bottom of my heart. I love you. A very special thanks to Richard Krause, a mentor, best friend, and confidant, who always pushed me to achieve my goal and many times reminded me about the light at the end of the tunnel.

Finally, I would like to thank the Lord above for the all these remarkable people. I believe each person we meet in our lifetime alters us in some manner. I am a better person having known all of the people on this page.

This study is dedicated to all the future researchers who will continue delve into the vast expanse of knowledge that Universal Design for Learning can provide the world of education. I know we are only at the beginning. 


\section{List of Tables}

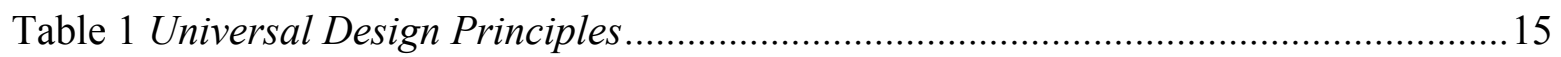

Table 2 Principles of Universal Design for Instruction .................................................. 17

Table 3 Performance Indicator Categories ............................................................... 19

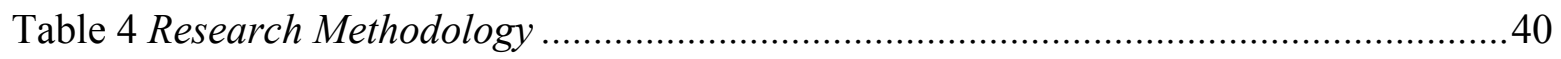

Table 5 Krippendorff's (2004) Components of Content Analysis.......................................51

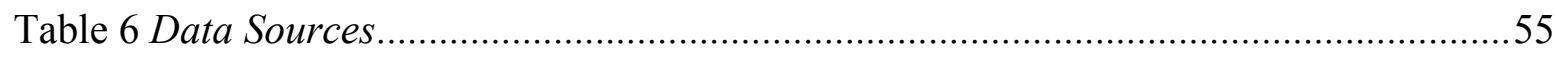

Table 7 How and to What Extent are UDL Techniques Being

Implemented in the College Classroom .....................................................................64

Table 8 BIOL 593 Student Interview Questions ...................................................... 74

Table 9 Instructor Interview Questions ............................................................ 80

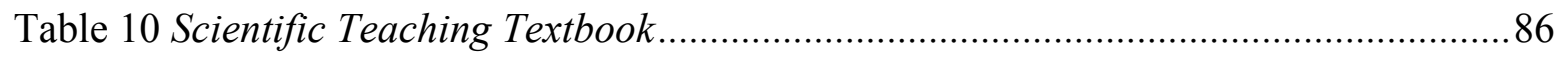

Table 11 BIOL 115 E-mail Survey Questions..............................................................99

Table 12 BIOL 115 Student Demographics ........................................................... 101

Table 13 Underrepresented Populations in 2009 at the Institution

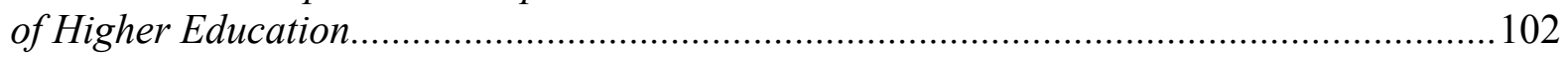

Table 14 What Are Students' Perceptions of How UDL Techniques

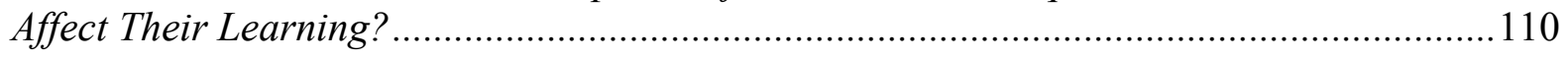

Table 15 Summary of Instructor's implementation of UDL Techniques

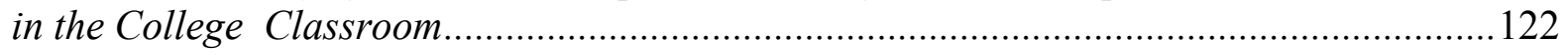

Table 16 Summary of Student Perceptions of UDL Techniques and

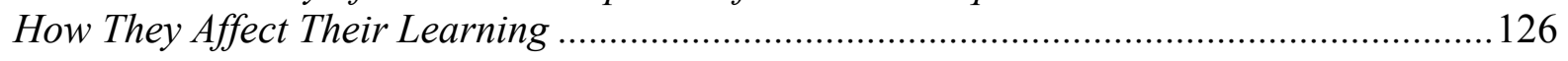

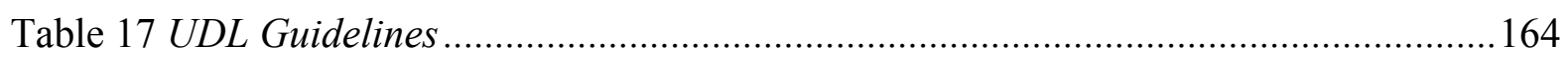

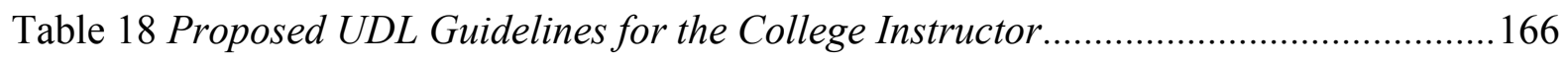




\section{Table of Contents}

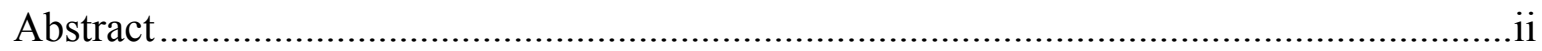

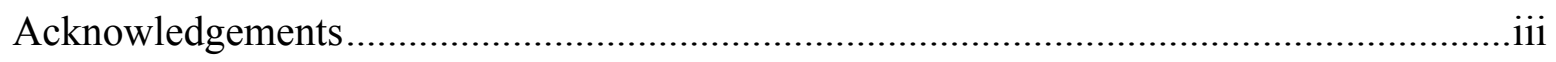

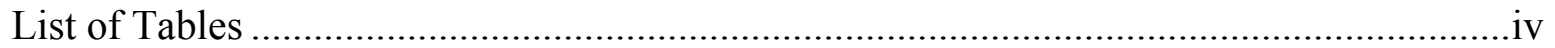

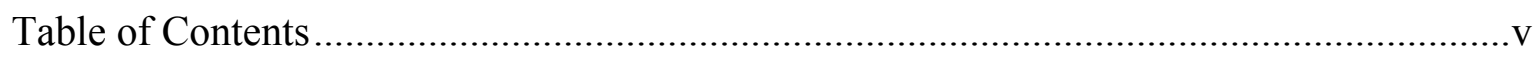

Chapter One: An Introduction to Universal Design for Learning ....................................

Significant Shifts in Student Demographics .................................................

NCLB, IDEA, and $21^{\text {st }}$ Century Skills......................................................... 4

Legislative Prescription for Universal Design for Learning...............................

Universal Design for Learning: A New Paradigm in Education ...........................9

Purpose of Studying Universal Design for Learning in the College Classroom .......11

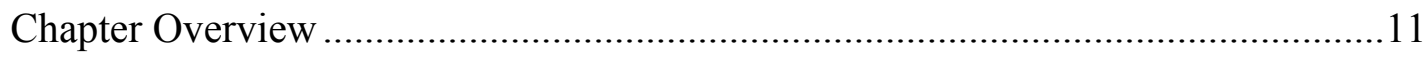

Chapter Two: A Review of Literature ........................................................................ 13

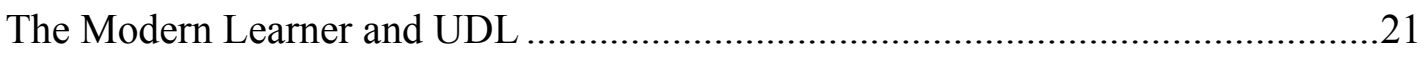

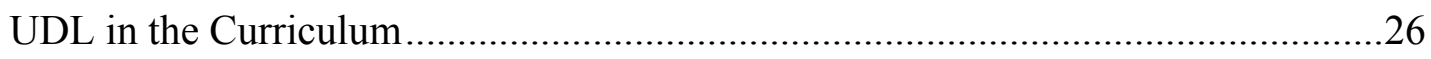

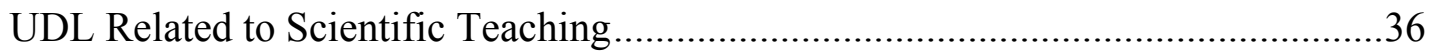

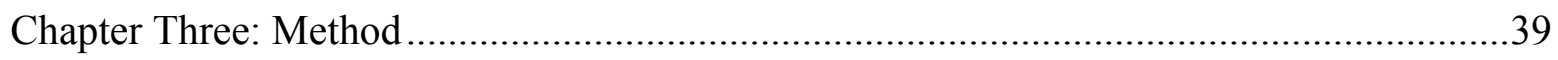

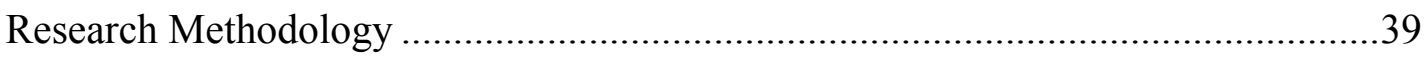

Units of Analysis and Participant Selection .................................................... 40

Data Source Description and Collection Procedures .........................................42

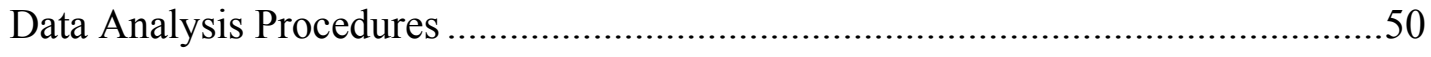

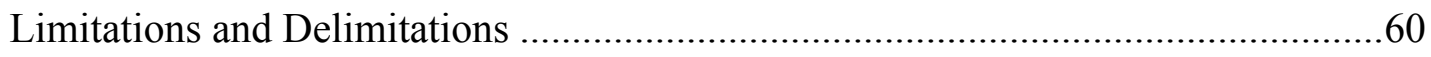


Chapter Four: Results .62

Research question: How and to what extent are UDL techniques

being implemented in the college classroom?

Research question: What are students' perceptions of how UDL

techniques affect their learning?

Summary of Results

Chapter Five: Conclusions

Interpretations

Significance of the Study

Recent Literature 156

Implications 158

Recommendations for Best Practices in Teaching 160

Limitations

Suggestions for Future Research

References

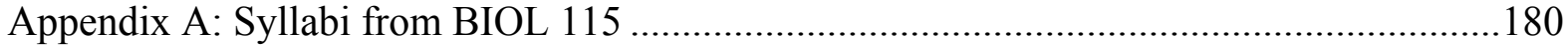

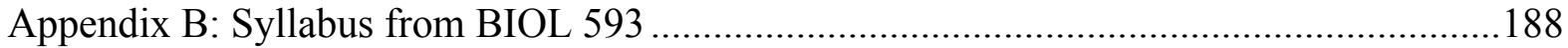

Appendix C: Interview Questions for the Instructor .............................................. 193

Appendix D: Interview Questions for BIOL 593 Students............................................ 194

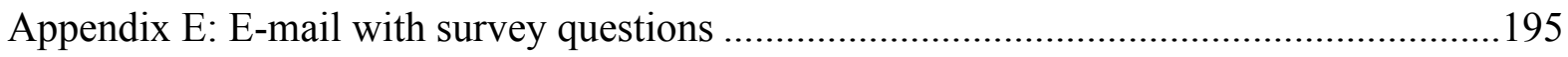

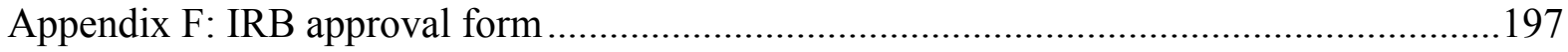




\section{Chapter 1}

\section{An Introduction to Universal Design for Learning (UDL)}

\section{A Case Study of UDL Applied in the College Classroom}

As the landscape of postsecondary education continues to transform, educators are in a constant search for new approaches that will reach an ever-changing population of students. One contemporary model being applied in the college classroom is Universal Design for Learning (UDL). UDL is an instructional design model, or design template, that provides a framework for flexible teaching techniques that present students with choices and alternatives in materials, tools, contexts, and supports they can utilize to gain greater understanding of instruction and to be more successful learners. As UDL is a modern method of instruction, further investigation is warranted to examine the use of UDL in higher education.

The proposed case study explored the following: (a) how and to what extent UDL techniques are being implemented in the college classroom, and (b) what are the student perceptions of how UDL techniques affect their learning. The study investigated the various UDL techniques being implemented in a college classroom where the primary pedagogy is a constructivist approach, identified student perspectives of this use, and discussed possible outcomes of using the UDL techniques.

Instructors of higher education are being expected to meet the widely divergent needs of an increasingly diverse student body. As we move toward the ideal of inclusion and success for all learners, UDL may be an evident solution. As a contemporary instructional design method, UDL's application in and impact on higher education should be investigated. 


\section{Significant Shifts in Student Demographics}

Societal changes in culture and technology have lead to amendments in legislation and developments in education that have profoundly altered the student composition of the traditional classroom. Many of today's college classes include: students with a multitude of cultural backgrounds, students from under-represented groups, international students for whom English is a second language, students who may not have proficient literacy skills, non-traditional students of varying ages and experiences, students with behavioral, emotional, motivational, physical and learning disabilities, students with chronic illnesses, academically-gifted students, and those students often referred to as typical (Rose \& Meyer, 2002).

Institutions of higher education have experienced a rapid transformation of their student populations. Growth in technology and the birth of an information age have resulted in economic and social changes that have drastically affected enrollment numbers at colleges and universities throughout the United States (Scott, McGuire, \& Shaw, 2003). High school students have come to realize that a college degree is virtually a requirement to obtain even an entry-level position in any professional field. In 2004, 94 percent of the students surveyed in an educational research study conducted by the United States Department of Education Office of Educational Technology stated that they planned to continue their education after high school and 88 percent of those students stated the belief that attending college is critical to success in life (U.S. Department of Education, 2004). Many adults who have been employed for years in an occupation are becoming aware that a postsecondary education is necessary for advancement, or they are deciding to return to school for a complete change in career. In the year 2000 , over " 15 million students enrolled in postsecondary education" (Scott, McGuire, \& Shaw, 2003, p. 369). 
Enrollment numbers continue to increase and traditionally underrepresented groups are quickly shifting student demographics at American colleges and universities.

According to a 2000 study conducted by the Educational Testing Service of the National Center on Education Statistics, researchers predict that enrollment at American institutions of higher education will continue to increase over the next 15 years by 19 percent and minority students will represent 80 percent of the total growth (Lords, 2000, as cited in Scott, McGuire, \& Shaw, 2003). As the population of the United States continues to grow more diverse, classrooms too will become increasingly diversified in heritage, culture, and spoken language. The research gathered in 2004 by the United States Department of Education Office of Educational Technology indicated that of the 50 million students enrolled in the K-12 education system, 30 percent of the population was comprised of minority students - "representing the largest and most diverse student body in our history" (p. 16). This diverse population of students has already begun to progress into postsecondary education, and these numbers are expected to continue to increase.

In addition to minority students, adult students of nontraditional age have been increasing in number over the last couple of decades (Scott, McGuire, \& Shaw, 2003). According to the United States Department of Education National Center for Education Statistics, a nontraditional student is defined as an individual who meets any or all of the following characteristics: a student who (a) has delayed their enrollment in postsecondary education, (b) attends only part-time, (c) works full-time while enrolled in study, (d) is financially independent when determining financial aid eligibility, (e) has dependents that are not a spouse, (f) is a single parent, (g) or does not possess a high school diploma (2007). A study done in 1998 revealed that almost 40 percent of the student population surveyed were 25 years of age or older (Scott, McGuire, \& Shaw, 
2003). Recent research studies indicate that the proportion of students over the age of 25 "may exceed 50\% by 2012" (O’Donnell \& Tobbell, 2007, p. 313). The adult student population brings a diverse set of experiences, backgrounds, knowledge, and special needs related to being a nontraditional learner for which educators must be prepared.

Educators at postsecondary institutions should also be ready for a dramatic increase in students with special needs related to disability. In addition to social and economic trends, government legislation and subsequent changes in the special education systems of K-12 schools

have drastically affected the number of students with disabilities who graduate from high school and decide to pursue a college degree. According to a research survey conducted during the fall 2000 semester, 66,197 full-time freshman attending public and independent colleges and universities reported having a disability. This number represented 6 percent of all freshman enrolled during the fall 2000 semester (Henderson, 2001). During the 2003-2004 college year, a similar study conducted by the United States Department of Education National Center for Education Statistics revealed that 11 percent of the undergraduate population reported a disability (2006). The number of students with disabilities in the college classroom rose 5 percent in only a four-year period. According to the National Dissemination Center for Children with Disabilities, more than 6 million children with disabilities are currently in the K-12 public school system (2007). If public education transition services for students with disabilities continue to improve, as they have over the last five years, postsecondary institutions can anticipate sustained growth in the numbers of students with disabilities.

\section{NCLB, IDEA, and $21^{\text {st }}$ Century Skills}

Transition services, planned activities and training sessions that help a student progress from high school to a vocation or postsecondary education, have improved as a direct result of 
government legislation. Amendments to the Individuals with Disabilities Education Act (IDEA) in 1997 placed great emphasis on the transition of students with disabilities into the higher education system (Scott, McGuire, \& Shaw, 2003).

While many of the mandates in the IDEA are relatively recent, the legislation itself is not new to the education system. In an effort to protect the civil rights of children with disabilities in the K-12 public school system, the Education for All Handicapped Children Act was passed in 1975. This legislation was renamed the Individuals with Disabilities Education Act (IDEA) in 1990 to reflect significant expansion and revision. Since this time, the IDEA has been reauthorized in 1997 and again in 2004. The current IDEA requires that schools educate students with disabilities in classrooms among their peers without disabilities to the greatest extent possible (2004).

In addition to IDEA regulations, educators must also comply with No Child Left Behind Act (NCLB) mandates. The NCLB Act of 2001 requires inclusive classrooms where all students are to receive equal access to education and are to demonstrate adequate yearly progress based upon state academic achievement standards. Due to NCLB legislation, schools are held accountable for how diverse demographic groups, including minority students and those with disabilities, achieve in comparison to their peers enrolled at the same school (NCLB, 2002). NCLB legislation has established 2014 as the deadline when "achievement gaps between different socio-economic backgrounds must be identified - and closed - so that all children regardless of race and income level can read and do mathematics at grade levels" (U.S. Department of Education, 2004, p. 13). The basic premise of NCLB is "that all children can learn" (U.S. Department of Education, 2004, p. 13). 
The practice of inclusion, or the mainstreaming of children with special needs into classrooms of their peers, and the significance placed on accountability measures have generated much angst among education professionals. Implementing these government accountability mandates is a challenge for both administrators and educators who do not consider themselves trained in how to meet the needs of diverse student learners and who are unwilling to learn new methods of instruction.

New education mandates like NCLB and the IDEA necessitate that K-12 public school educators and administrators discover methods to meet new standards-based goals and objectives if they are to continue receiving government funding. In an effort to encourage school officials' endeavors to implement new programs and meet these mandates, the federal government established discretionary and formula grant awards through the Department of Education. Schools throughout the United States are receiving government monies to increase and update their educational technology, provide professional development for administrators and educators, and to implement new instructional design methods that will allow all children to learn in an inclusive classroom environment (U.S. Department of Education, 2007).

In alignment with NCLB standards and accountability measures, an advocacy group known as The Partnership for $21^{\text {st }}$ Century Skills has generated a list of core skills that today's students need for success in their careers, to act as informed citizens, and to serve as leaders in their communities. The Partnership for $21^{\text {st }}$ Century Skills is an advocacy group comprised of individuals representing both education and industry who believe that a profound gap exists between the knowledge and skills learned in the classroom and the knowledge and skills needed in the community and for employment. Proponents for $21^{\text {st }}$ Century Skills argue that curricula should focus on the following: (a) core subject areas as identified by No Child Left Behind 
(NCLB), (b) learning and innovation skills, (c) information, media and technology skills, and (d) life and career skills (Partnership for $21^{\text {st }}$ Century Skills, 2004). The philosophy of $21^{\text {st }}$ Century Skills is gaining momentum in the field of education and nine states, including West Virginia, currently have statewide initiatives to implement these changes in their curricula. The principles used to integrate $21^{\text {st }}$ Century Skills into the classroom are reflective of NCLB and also resemble those used for Universal Design for Learning (UDL).

\section{Legislative Prescription for Universal Design for Learning}

When one familiar with Universal Design for Learning (UDL) reads the language in the No Child Left Behind (NCLB) Act, the governmental mandate seems a prescription for the implementation of UDL. NCLB describes a new, more flexible instructional design model that embraces the use of instructional technology to provide multimodal education experiences and opportunities for students (U.S. Department of Education, 2004).

The four main purposes of the NCLB act are: (1) to hold schools accountable for the education of all students, (2) to increase flexibility in education to help schools reach established goals, (3) to provide options for parents if their children are enrolled in low-performing schools, and (4) to encourage research on what is most effective for student learning (U.S. Department of Education, 2004). According to the U.S. Department of Education, "this single piece of legislation has fundamentally altered the education landscape. Its premise - that all children can learn - is profound in its simplicity but multifaceted in its implementation" (2004, p. 13).

The premise that all children can learn, the first and foremost purpose for NCLB, is the keystone around which the instructional design model known as Universal Design for Learning (UDL) has been built. UDL is an instructional design model used to generate curricula that are 
accessible by all students, or the largest audience possible, to ensure student success and participation (Rose \& Meyer, 2002).

As proposed in NCLB, UDL is fashioned around the philosophy that education must be flexible if a wide audience is to be reached. UDL designed curricula offer multiple ways for learners to acquire and access knowledge, multiple means for demonstrating what they have learned, and multiple methods to increase learner interest, motivation, and challenge level (Center for Applied Special Technology, 1999).

The UDL model of instruction seeks to generate curricula and materials that are better suited to reach a multitude of diverse learners and learning styles. By addressing the issue of diversity at the level of curricula development, educators can more effectively reach a greater number of students while monitoring built in assessment measurements to meet the standards mandated by NCLB and IDEA. Scholars studying the UDL approach to education indicate that it can provide a more flexible method for instruction that will lead to more effective learning and therefore a reduction in low-performing schools or classes (Center for Applied Special Technology, 1999).

Also in compliance with the purposes of NCLB legislation, individuals from an organization known as the Center for Applied Special Technology (CAST) are working with K12 schools, colleges and universities, and other partners in education to assist these institutions in their implementation and evaluation of UDL. Members of CAST's staff conduct professional development and research activities to gather information about what methods and strategies are most effective for student learning. These staff members are working with select schools and postsecondary institutions throughout the United States to help establish UDL as the method to reach students who are traditionally left in the margins (Rose \& Meyer, 2002). 


\section{Universal Design for Learning: A New Paradigm in Education}

Universal Design for Learning (UDL) was first conceived by the Center for Applied Special Technology (CAST) in the early 1990's as an application of the universal design movement in architecture to the field of education (Center for Applied Special Technology, 1999). The initial universal design movement was developed to ensure "the design of products and environments that are usable by all people, to the greatest extent possible, without the need for adaptation or specialized design" (The Center for Universal Design, 1997). Scholars at CAST viewed the basic principles of universal design and envisioned how these guidelines might also apply to the design of classroom and curricula.

The UDL model of instruction provides a blueprint to help educators generate curricula that utilize technology and include flexible methodology, materials, and assessment to make education more effective for and inclusive of all students (Center for Applied Special Technology, 1999). In the past, educators have always been taught to focus on fixing an individual student's ability to learn. UDL, on the other hand, shifts the focus from the individual student to the curriculum itself. Educators are asked to recognize that the barrier to learning is not inherent in the capabilities of their students, but instead presented by inflexible educational materials and design (Rose \& Meyer, 2002).

The UDL model promotes three vital assumptions. First, all learners are unique and therefore have different needs for instruction. Every student in every classroom, regardless of ability level, should be provided with an equal opportunity to become involved with the curriculum. Next, instruction must be designed with all students in mind. Curricula should not need to be adjusted and tweaked as an after-thought for each individual student. Rather than adapting the curricula, educators can focus on the generation of materials and activities that 
reduce barriers to learning. Educators should prepare their lessons with built in flexibility that will increase overall effectiveness by allowing every student to access materials. Through the use of educational technology, educators can provide students greater accommodation and access to the curriculum. Media and interactive technologies offer students a plethora of ways in which to learn and subsequently demonstrate their acquired knowledge. Finally, and imperative for UDL, instructional design must be flexible. No instructional design can account for every variable, thus, educators must be willing to make modifications as they become necessary to assist learners through the education process. The UDL framework is constructed with the assumption that all students can learn, although they may learn in different ways and at different rates (Rose \& Meyer, 2002).

Universal Design for Learning (UDL) should not be viewed as a method to "dumbdown" the curriculum or to teach to the least common denominator. Instead, UDL can be used to present challenges that will present themselves to each student at their level (Orkwis, 1999). UDL is the intersection where many education initiatives like "integrated units, multi-sensory teaching, multiple intelligences, differentiated instruction, use of computers in schools, performance based assessment, and others" (Rose \& Meyer, 2002, p. 4) meet and merge into one model. UDL is a framework upon which many other constructivist pedagogies can hang. Used with other approaches, like differentiated instruction or active learning at the front end of design, the UDL model will save institutions and instructors a great deal of time and frustration at the back end (Rose \& Meyer, 2002).

Proponents of UDL do not want educators and administrators to view this instructional design model as a burden or impossible task, but instead want them to recognize the added value UDL can present with a little initial investment. UDL is an instructional design model that can 
create instruction to teach students more than merely facts; UDL can be used to teach students how to learn (Rose \& Meyer, 2002). As the composition of the classroom becomes more diverse and accountability mandates continue to challenge educators, UDL provides an instructional design model to meet both learner needs and education standards.

\section{Purpose of Studying Universal Design for Learning in the College Classroom}

Universal Design for Learning (UDL) is currently being implemented at a limited number of K-12 public schools and at a small number of colleges and universities throughout the United States as a potential method to reach an ever-more diverse student population. Studies regarding the use of UDL at the K-12 level of education indicate growing interest and legislative support for UDL nationwide (Müller \& Tschantz, 2003).

While research has been conducted on the effects of UDL use in K-12 education, scant literature exists with regard to how UDL works in the postsecondary classroom. As a relatively new paradigm in the field of education, UDL remains a well-kept secret that should be explored and studied. If UDL works in practice as well as it reads in theory, every educator and education professional should be made aware of this instructional design method.

This descriptive case study addressed the following questions: (a) How and to what extent is UDL being implemented in the college classroom, and (b) what are students' perceptions of how UDL techniques affect their learning? The study provided valuable insights about what UDL techniques are being employed in higher education, and the impact various UDL strategies have according to student learners and the faculty member involved in the study.

\section{Chapter Overview}

This chapter outlined the history and development of Universal Design for Learning (UDL) and discussed the value of research in this relatively new area of education. Chapter 2 
presents a review of pertinent UDL-related literature and discusses results from related research studies conducted on the use of UDL in K-12 schools. Chapter 3 details the research study to be conducted and outlines the proposed methodology to be used. Chapter 4 analyzes the results from the research conducted, and Chapter 5 provides a summary of interpretations and conclusions and suggests future research questions to further explore the use of UDL in postsecondary education. 


\section{Chapter 2}

\section{A Review of Relevant Literature}

As a more diverse student population pervades the world of postsecondary education, institutions of higher education will need to evolve. Curriculum design is one vital facet of education that must be revised to meet the ever-changing needs of the modern student body. Universal Design for Learning (UDL) is an instructional design model that proponents claim has the power to transform traditional curricula into designs that are flexible enough to meet the widely divergent needs of exceedingly diverse audiences.

The construct of Universal Design for Learning (UDL) emerged from the earlier Universal Design movement that began in the field of architecture. In 1998, three universal design pioneers, Molly F. Story, James L. Mueller, and Ronald L. Mace, from the Center for Universal Design at North Carolina State University published The Universal Design File: Designing for People of All Ages and Abilities to introduce the concept of universal design to the world. Their volume on universal design is organized into four chapters that present a brief history of universal design, information on human abilities, the principles of universal design, and case studies related to the use of universal design.

The term "universal design" was coined by Ronald L. Mace, architect and founder of the federally funded Center for Accessible Housing, now known as the Center for Universal Design at North Carolina State University. Universal design is "the design of products and environments to be usable to the greatest extent possible by people of all ages and abilities," (Story, Mueller, \& Mace, 1998, 2). According to Story, Mueller, and Mace, the idea for universal design had roots in demographic, legislative, economic, and social climate changes (1998). 
Since the beginning of the 20th century, vast advances in medicine and technology altered the demographics of the United States. People are living longer lives. The conventional family structure no longer consists only of mom, dad, sisters, and brothers. Increasingly, households are comprised of generations from infants to senior citizens residing together in the same home. At the dawn of the 20th century, senior citizens and individuals with disabilities were true minorities as the average lifespan was only 47 years. "The average lifespan has increased to 76, largely due to healthier living, better medicine, and vaccines and sanitation that have virtually eliminated many killer infectious diseases" (Story, Mueller, \& Mace, 1998, p. 6). The United States Census Bureau estimates that by the year 2020, over seven million people will be over the age of 85 (Story, Mueller, \& Mace, 1998).

Parallel to these demographic shifts, the Civil Rights Movement and the Disability Rights Movement influenced social climate and federal legislation like the Architectural Barriers Act of 1968, Section 504 of the Rehabilitation Act of 1973, the Education for Handicapped Children Act of 1975, the Fair Housing Amendments of 1988, the Americans with Disabilities Act of 1990, and the Telecommunications Act of 1996 (Story, Mueller, \& Mace, 1998). People began to recognize a need for products and services that are conceived for everyone regardless of ability level. Universal design standards give rise to no-step entrances, wider doors, larger rooms, and additional features that allow maximum use and access for everyone. For example, a slightly wider door would enable a mother with a baby stroller, a toddler in a walker, and an individual using a wheelchair to utilize the same entrance.

A team of engineers, environmental designers, and architects at the Center for Universal Design established seven principles for the universal design of products and environments (Story, Mueller, \& Mace, 1998). Table 1 describes each of the principles of Universal Design as 
they apply to a lever door handle. The use of lever handles on doors and faucets is an example of universally designed products that suit a wide spectrum of human needs. For individuals with hand mobility limitations, such as arthritis, traditional doorknobs and turn-style handles can be difficult if not impossible to maneuver. Levers, on the other hand, allow the user to utilize any part of their body to open the door or turn on the faucet. While the lever is well suited to individuals with disabilities and an aging audience, the same lever handle is also appropriate for someone who does not have a free hand due to carrying heavy bags, pushing a baby stroller, or multitasking.

Table 1

Universal Design Principles

\begin{tabular}{ll}
\hline Principle & Description \\
\hline Equitable use & A device, product, service, etc. should be \\
useful and marketable to everyone, or as \\
wide an audience as possible. The lever is a \\
perfect example of a universally designed \\
device. A wide range of users with many \\
personal characteristics and levels of ability \\
can use the lever handle.
\end{tabular}




\begin{tabular}{ll}
\hline & $\begin{array}{l}\text { without a high risk of injury or danger to } \\
\text { the user. The lever handle poses little, if } \\
\text { any, threat for danger. }\end{array}$ \\
\hline Low physical effort & $\begin{array}{l}\text { A device, product, service, etc. should not } \\
\text { cause serious strain for users. The lever can } \\
\text { be manipulated with very little physical } \\
\text { strain on the user. }\end{array}$ \\
\hline Size and space & $\begin{array}{l}\text { A device, product, service, etc. should } \\
\text { allow users enough space to approach, } \\
\text { manipulate, and use. When positioned } \\
\text { correctly on the door, the lever handle is } \\
\text { reachable by most audiences. }\end{array}$ \\
\hline
\end{tabular}

The Center for Universal Design (1997)

While other articles and short documents can be found that discuss universal design, Story, Mueller, and Mace's 1998 work remains the authoritative example cited by all others in the field.

Since its inception, universal design has spread from the field of architecture into the manufacture of products, web design, engineering, and education. As the authors of "Universal Design and Its Application in Educational Environments" note, "a perusal of the current literature that pertains to UD in educational settings quickly results in an 'alphabet soup' jumble of terminology: UD, UDL, UDI, UID, UDE,” (McGuire, Scott, \& Shaw, 2006, p. 172). Universal Design (UD) has transformed into Universal Design for Learning, Universal Design of/for Instruction, Universal Instructional Design, and Universal Design in Education.

In Universal Design in Education, Frank Bowe, a professor of counseling, research, special education and rehabilitation (CRSR) in Hofstra University's School of Education and Allied Human Services, defines Universal Design in Education (UDE) as "the preparation of curriculum, materials and environments so that they may be used appropriately and with ease, by a wide variety of people" (Bowe, 1999). Bowe wrote his text to be used as a handbook for instructors involved in every level of education from kindergarten through advanced university 
programs. Much of his initial work was reflected in the ideas and writing of the scholars that followed him.

Educators at the University of Connecticut were the first to use the term Universal Design for Instruction (UDI) to describe the application of the seven basic principles of Universal Design to the educational environment. After some additional research was done, two additional principles were added to their list (see Table 2)(Faculty Ware, 2002). These nine principles focus heavily on physical access to and usability of the environment and technology.

Table 2

Principles of Universal Design for Instruction $\odot$

\begin{tabular}{ll}
\hline Principle & Definition \\
\hline Equitable use & Instruction is designed to be useful and \\
& accessible by people with diverse abilities. \\
& Provide the same means of use for all \\
& students; identical whenever possible, \\
& equivalent when not. \\
\hline Flexible use & Instruction is designed to accommodate a \\
& wide range of individual abilities. Provide \\
choice in methods of use.
\end{tabular}




\begin{tabular}{ll}
\hline Size and space & $\begin{array}{l}\text { Instruction is designed with consideration } \\
\text { for appropriate size and space for approach, } \\
\text { reach, manipulation, and use regardless or a } \\
\text { student's body size, posture, mobility, and } \\
\text { communication needs. }\end{array}$ \\
\hline A community of learners & $\begin{array}{l}\text { The instructional environment promotes } \\
\text { interaction and communication among } \\
\text { students and between students and faculty. }\end{array}$ \\
\hline Instructional climate & $\begin{array}{l}\text { Instruction is designed to be welcoming } \\
\text { and inclusive. High expectations are } \\
\text { espoused for all students. }\end{array}$ \\
\hline
\end{tabular}

Scott, McGuire, \& Shaw (2001)

Individuals at The Center for Applied Special Technology (CAST), researchers, educators, and administrators devised the term Universal Design for Learning (UDL) to create a purposeful distinction between UDI and UDL. David Rose and Anne Meyer, co-executive directors of CAST, recognize the need to maximize physical access to technology and environmental spaces, but they are equally concerned with cognitive access to learning and how the brain functions (Rose \& Meyer, 2002). If a student can sit at a desk, or use a computer, because physical access has been considered, but cannot understand the material that is being delivered, learning is not taking place. Researchers at CAST believe that the curriculum itself can be a barrier to student learning. UDL focuses on providing learners with multiple means of representation, expression, and engagement.

Working in tandem with CAST's definition of UDL, researchers at Washington University’s Disabilities, Opportunities, Internetworking, and Technology (DO-IT) program developed eight performance indicator categories that support providing learners with multiple means of representation, expression, and engagement (see Table 3)(Burgstahler, 2007). 
Table 3

Performance Indicator Categories

\begin{tabular}{ll}
\hline Category & Definition \\
\hline Class climate & $\begin{array}{l}\text { Adopt practices that reflect high values } \\
\text { with respect to both diversity and } \\
\text { inclusiveness. }\end{array}$ \\
\hline Interaction & $\begin{array}{l}\text { Encourage regular and effective } \\
\text { interactions between students and the } \\
\text { instructor and ensure that communication } \\
\text { methods are accessible to all participants. }\end{array}$ \\
\hline Physical environments and products & $\begin{array}{l}\text { Ensure that facilities, activities, materials, } \\
\text { and equipment are physically accessible to } \\
\text { and usable by all students, and that } \\
\text { potential student characteristics are } \\
\text { addressed in safety considerations. }\end{array}$ \\
\hline Delivery methods & $\begin{array}{l}\text { Use multiple, accessible instructional } \\
\text { methods that are accessible to all learners. }\end{array}$ \\
\hline Information resources and technology & $\begin{array}{l}\text { Ensure that course materials, notes, and } \\
\text { other information resources are engaging, } \\
\text { flexible, and accessible for all students. }\end{array}$ \\
\hline Feedback & $\begin{array}{l}\text { Provide specific feedback on a regular } \\
\text { basis. }\end{array}$ \\
\hline Assessment & $\begin{array}{l}\text { Regularly assess student progress using } \\
\text { multiple accessible methods and tools, and } \\
\text { adjust instruction accordingly. }\end{array}$ \\
\hline Accommodation & $\begin{array}{l}\text { Plan for accommodations for students } \\
\text { whose needs are not met by the } \\
\text { instructional design. }\end{array}$ \\
\hline Burgstahler (2007)
\end{tabular}

Burgstahler (2007)

Around the same time period CAST developed UDL, scholars at the University of Guelph in Ontario, Canada, developed the seven principles of Universal Instructional Design (UID): (a) accessible and fair use, (b) flexibility in use, participation and presentation, (c) straightforward and consistent, (d) information is explicitly presented and readily perceived, (e) supportive learning environment, (f) minimize or eliminate unnecessary physical effort or requirements, (g) learning space accommodates both students and methods. These seven principles can be applied to the design of instruction, specific delivery strategies, course 
materials, and/or various learning environments including both traditional classrooms and online learning spaces (University of Guelph, 2001).

Only scholars and researchers who spend their time studying the linguistic transformations of the terminology, or are deeply invested in the educational profits that can be gained through the employment of Universal Design, recognize the distinction between these terms and the others in the mess of "alphabet soup". Most individuals in the realm of education merely lump Universal Design for Learning (UDL), Universal Design of/for Instruction (UDI), Universal Instructional Design (UID), and Universal Design in Education (UDE) all together in one disorganized and confounding category and use these terms indiscriminately without being intentional in their usage (McGuire, Scott, \& Shaw, 2006). This is often because the lines of distinction have become extremely blurred as many of the techniques and strategies used to accomplish the overarching principles are the same.

The following chapter will provide a review of literature concentrated around two common themes in Universal Design for Learning (UDL) exploration: the modern learner and UDL in the curriculum. The first section of the literature review includes materials that provide information related to the learner and the learner's perspectives of UDL. The remainder of Chapter 2 includes current texts and articles that discuss UDL as an instructional design method and a section on active learning and how it relates to UDL. Both of the divisions included in the review of literature present germane information about UDL that inform the case study research questions posed in these pages and establish the relevance of utilizing UDL in higher education. 


\section{The Modern Learner and UDL}

Who Are Our Students? The antiquated notion of the "typical" learner is facing imminent extinction and leaving many educators to ask, "who are our students?" Classroom demographics are changing from kindergarten through postsecondary education.

In 2004, The United States Department of Education's Office of Educational Technology published the National Education Technology Plan titled Toward A Golden Age in American Education: How the Internet, the Law, and Today's Students Are Revolutionizing Expectations to provide an update on the status of educational technology and share recommendations for future action. The report asserts that the educational landscape is clearly experiencing a major transformation driven by both changes in technology and an evolving population of learners.

According to the report, these young learners are often far ahead of their teachers in computer and Internet literacy. Children are growing up on the Internet and often know how to manipulate a computer before they are enrolled in school; therefore, when they arrive in the classrooms, teachers must utilize technology to challenge and engage their minds. The study found that while the development of instructional technology is thriving, the use of instructional technology in the classroom is stagnant. The National Education Technology Plan challenges educators and administrators to embrace digital technology and "creative new teaching models...that embrace technology" (2004, p. 22) as methods to achieve No Child Left Behind standards of accountability and to help all children learn using a tool with which they are familiar and already connected.

Additionally, the report illustrates that a portrait of today's learners would represent great diversity. "The nearly 50 million students in our elementary, middle and high schools today represent the largest and most diverse student body in our history. Thirty percent are minorities, 
meaning that our school population is more diverse than this country's adult population" (U.S. Department of Education, 2004, p.16). When approximately 250,000 of these high school students were surveyed by the United States Department of Education, 94 percent responded that they planned to continue their education after high school (2004).

In the new information driven global economy, students of all demographic backgrounds recognize the importance a college education. The evolving labor market leaves few career options available for individuals who lack a college degree. The already diverse populations on college and university campuses are sure to become increasingly more diverse when one looks at the additional statistics and future projections.

In September of 2008, The National Center for Education Statistics, the primary federal unit of the U.S. Department of Education responsible for collecting, analyzing, and reporting information related to education in the United States and around the world, published Projections of Education Statistics to 2017, a report and specialized analyses of enrollment trends from 2006 through the year 2017 (Hussar \& Bailey, 2008). The results presented are consistent with those proposed by other statisticians and researchers in the field. According to Hussar and Bailey, total enrollment in degree-granting institutions will increase between 2006 and 2017 with significant growth in the populations of 25-29 year-olds and minorities. Hussar and Bailey project that between 2006 and 2017, enrollment will increase "5 percent for students who are White, 26 percent for students who are Black, 39 percent for students who are Hispanic, 26 percent for students who are Asian or Pacific Islanders, 30 percent for students who are American Indian or Alaska Native, and 1 percent for students who are nonresident aliens" (2008, p. 10). Many of these new postsecondary learners will represent first generation college students and English 
may be their second language. These unique variables will need to be considered as faculty plan for future courses.

While institutions of higher education are preparing for more adult learners and minority students, they should also be acutely aware of the rapid growth in the number of students with disabilities who are enrolling in four-year colleges and universities. A study conducted by The American Council on Education in 2000, revealed that two out of every five freshman, or $40 \%$ of the freshman population, enrolled in a four-year postsecondary institution reported a disability. In only a little more than a decade, the number of freshman reporting a disability more than doubled from the $16 \%$ reporting a disability in 1988 (Henderson, 2001). Amendments to the Individuals with Disabilities Education Act (IDEA) have increased the focus on and improved transition services for students with disabilities in the K-12 education system, and postsecondary institutions should prepare for the enrollment numbers of students with disabilities to continue to increase (Scott, McGuire, \& Shaw, 2003).

The student bodies at most postsecondary institutions are complex populations composed of learners with various psychographic and demographic characteristics including culture, marital status, learning ability, communication skills, socioeconomic status, age, learning styles, gender, race, and religion just to name a few variables. Attempting to plan lessons that will engage and reach every learner in a classroom can be a real challenge for educators. Proponents of Universal Design for Learning (UDL) claim that effectively employing the principles of UDL will allow an instructor to connect with every student. While there are texts written from the instructor's perspective, little can be found from the learner's perspective. The following section is literature that discusses UDL from the student's perspective. 
Research Studies: Learner Perceptions. Chapter 6 Universal Design of Instruction: Reflections of Students in Universal Design in Higher Education: From Principles to Practice, edited by Sheryl Burgstahler, founder and director of the Disabilities, Opportunities, Internetworking, and Technology (DO-IT) Center at the University of Washington, and Rebecca Cory, research consultant for DO-IT at the University of Washington, presents student reflections about the use of UDI techniques in the classroom (2008). Students were asked to respond about specific strategies in eight indicator categories: (a) class climate, (b) interaction, (c) physical environments and products, (d) delivery methods, (e) information resources and technology, (f) feedback, (g) assessment, and (h) accommodation (2008). While students do not always agree on what strategies and techniques are most effective, "they make it clear that universal design strategies represent good teaching practice" (2008, p. 95). For example, one student focused heavily on the use of technology for content delivery (online review material, PowerPoint presentations, etc.), another discussed needing multiple modes of content delivery (lecture, small group discussion, hands-on activity), whereas a third student concentrated heavily on the importance of knowing what type of exam or assessment to expect or needing multiple sources of assessment.

Though UDI has a different set of established "principles" than does UDL (as stated above), many of the techniques to accomplish the goals remain the same: use of technology to make delivery more flexible, making the content relevant through authentic experiences, multiple methods for gaining knowledge (lecture, collaborative projects, and online-discussion boards, etc.), delivering instructions in multiple ways, and so forth. As Burgstahler and the researchers at DO-IT collect new student feedback, they update the online document, Equal Access: Universal Design of Instruction, to reflect the diverse perceptions held by the learners at 
the University of Washington (2008). Faculty, administrators, and others can access this checklist to discover innovative ways to build Universal Design into their courses.

In 2005, Appalachian State University professor Larry Kortering, technology facilities coordinator Terry McClannon, and project coordinator Patricia Braziel, conducted a research study at two high schools in North Carolina to examine student perceptions of Universal Design for Learning interventions in standard-diploma track biology and algebra classes. The study was designed to reveal students' perceptions of UDL interventions anchored by the three key principles of UDL - multiple methods for representation, multiple methods for expression, and multiple methods for engagement. A total of 320 students (100 algebra students and 220 biology students) participated in the study. The participants were a diverse group representing many cultures, races, socio-economic backgrounds, academic skills, and students with disabilities. Six algebra teachers and five biology teachers agreed to be trained and contribute to the research study. Student participants were exposed to as few as one, or as many as six, UDL interventions per course over the duration of one year (depending on their instructor and class setting) and then asked to complete a survey at the end of the class. The survey was comprised of both open-ended questions and closed-ended questions that provided a Likert scale of one to five to rank the participants' perceptions of a UDL intervention. A total of 709 responses were collected.

Overall, the results were very in favor of UDL invention. Both students with disabilities and those without disabilities almost unanimously were in favor of UDL interventions. An average of 90 percent of the students across both groups reported that they would like access to more UDL techniques in the classroom. Also, the majority of students were unable to identify any negatives to using UDL interventions and few had any recommendations for improvement. 
A small percentage of students stated they felt as though the interventions slowed the class down or made the assignments too tedious or repetitious.

Learner perceptions of UDL in the classroom is an area that has been virtually disregarded by researchers as they concentrate their attention on planning with UDL, implementation using UDL, UDL assessment techniques, course evaluation, student retention rates, and other departmental and institutional focus areas. The topic of students' perceptions of UDL techniques and strategies is an obvious gap in research that should be addressed.

\section{UDL in the Curriculum}

As the student population continues to grow more diverse and emphasis on learning standards continues to increase, educators face a difficult challenge in the classroom.

The definitive work on Universal Design for Learning (UDL), Teaching Every Student in the Digital Age: Universal Design for Learning, was written in 2002 by David Rose and Anne Meyer, co-founders of the Center for Applied Special Technology (CAST). Both Rose and Meyer are scholars with backgrounds in psychology and education. Rose attained his Bachelor of Arts degree in psychology from Harvard College, a Master of Arts degree in education from Reed College, and a doctorate in education from the Harvard Graduate School of Education. Meyer is a clinical psychologist who completed her undergraduate studies at Radcliffe College

and then received both her Master of Arts and doctoral degrees from Harvard Graduate School of Education.

Their UDL canon, Teaching Every Student in the Digital Age: Universal Design for Learning, is the result of 15 years of research on student learning. The textbook is divided into two distinct sections. Section one discusses education in the digital age, explains current brain research and why we need flexible instruction, and defines the concepts of UDL, while section 
two addresses the use of UDL in the classroom to set goals, support every learner, assess student progress, and make Universal Design a reality.

Both diversity in the classroom and expectations for high standards have risen and will continue to rise (Rose \& Meyer, 2002). "Cultural, educational, and legal changes have significantly altered the mix of students in regular education classrooms" (Rose \& Meyer, 2002, p. 5). Concurrently, emphasis on learning standards place greater responsibility on teachers and school districts to ensure that every student achieves. These changes pose an immense challenge for many educators. They face both greater diversity and increased accountability to meet the needs of a population that no longer fits into any mold.

Fortunately, research has shown that the old molds were wrong from their origin. At one time, scholars believed learners only had a single intelligence. Now, due to more recent revelations such as Gardner's Multiple Intelligence Theory and new brain research theories, we know that the vast majority of students have multifaceted learning capabilities (Rose \& Meyer, 2002). "Because of their inherent flexibility, digital technologies" like the World Wide Web, can be utilized to adjust to the various learning capabilities of learners so instructors can work with their students' strengths and areas of interests (Rose \& Meyer, 2002, p. 7).

For ages, teachers were taught that students' abilities were inherent and little could be done for a student if they did not grasp the material. Rose and Meyer present the philosophy that a student's abilities are not inherent but are in fact defined by the interaction between the learner's abilities and the tools they use. Traditional media, such as print, often limit learners to a one-size-fits all approach to learning that can create barriers for many learners. Digital media, on the other hand, provides flexibility and can be adjusted for every learner to provide alternative 
ways to reach the same end. The textbook provides an excellent example of how powerful digital media can be in the classroom.

Almost every American student has read Dr. Martin Luther King’s “I Have A Dream” speech. This speech is in many history books and is now published on many websites. If a class of sixth grade students were required to read a text copy of Dr. King's speech, some of the students would grasp the meaning and understand. However, if the same class of sixth grade students were encouraged to visit a web site that published a textual copy of the speech, a video of Dr. King presenting the speech, photographs of Dr. King, and additional links for more information, all of the students would then have a choice about how they might best learn and understand (Rose \& Meyer, 2002). Digital media, by its very nature, is flexible. It can be stored in various formats, transmitted in various ways, and used in a variety of educational contexts to meet a large number of diverse needs.

CAST researchers drew upon their knowledge of advances in digital media and neuroscience to develop Universal Design for Learning (UDL). While Rose and Meyer mention UDL briefly in prior chapters, they do not discuss UDL in depth until Chapter 4. "The central premise of UDL is that a curriculum should include alternatives to make it accessible and appropriate for individuals with different backgrounds, learning styles, abilities, and disabilities in widely varied learning contexts" (Rose \& Meyer, 2002, p. 70). The term "universal" does not suggest that there is a single method, or educational Band-Aid ${ }^{\mathrm{TM}}$, that will work for every student. Instead, the name reflects the fact that UDL evolved from an architectural movement known as Universal Design (Rose \& Meyer, 2002).

UDL expands upon universal design in two significant manners. First, UDL is an instructional design model that requires an integral flexibility in educational curricula. In 
addition, UDL takes universal design a step further by providing access to learning in addition to physical access within the classroom (Rose \& Meyer, 2002).

The UDL framework has three guiding principles: (a) provide multiple, flexible methods of presentation, (b) provide multiple, flexible methods of expression, and (c) provide multiple, flexible options for engagement. The three principles of UDL were established to provide learners with options and to minimize barriers (Rose \& Meyer, 2002).

Delivering information to students using various methods merely means giving them some options on how they can learn the material. For example, a professor delivers a 50-minute lecture using a 35-slide PowerPoint presentation. Some students will be capable of taking all the notes in class during the lecture and will miss neither content nor concept. Alternatively, other students will be so focused on note taking (directly from slides) that they will not hear a word the professor utters. Then again, the remainder of the class will be listening intently to the professor but will not record a word in their notebook. If this professor is using UDL techniques, she will most likely post the slides and any vital notes online for students to access at their discretion. She may have an online course discussion site established where students can meet to post questions or issues. She may have recorded the lecture as an audio and/or video file and may post these to the site. The professor may offer a digital copy of the course textbook. All of these methods would give students options for how they can access and learn the material.

To provide students with multiple, flexible means of expression, the professor would need to allow students to demonstrate their knowledge in various ways. Courses that have only two exams, a midterm and a final, often do not allow students the flexibility to express their understanding. The professor could plan hands-on activities, lab projects, cooperative group 
projects, quizzes, and other methods for assessment in addition to exams so that students have the opportunity to show their knowledge.

In order to learn, students must stay engaged. The professor should plan to implement a variety of engagement activities based upon the needs of her learners. Students need to remain motivated and challenged. If the method of engagement is the same every time, students will not continue to respond.

UDL is a blueprint for providing an individualized education whether in a large university lecture hall or in a small standards-based K-12 classroom environment. When utilized alone or as a supplement to another pedagogy, UDL enables instructors to incorporate flexibility into instruction to help every student learn (Rose \& Meyer, 2002).

Part two of Teaching Every Student in the Digital Age: Universal Design for Learning explains how instructors can use UDL to set goals, individualize instruction for the entire class through the use of UDL principles, and assess student learning in the classroom. Rose and Meyers suggest instructors should move away from tradition. They believe goals should be determined before one can decide on performance criteria or the activities to demonstrate knowledge. This idea asks educators to reframe the way they plan and design a course.

Though research supports the theory that clear, well-structured goals are fundamental for learning, many instructors lack the ability to develop lucid goals because they either do not have the correct tools (digital media) or they are still focused on using only the wrong tools (traditional media) to do the job (Rose \& Meyer, 2002). Once well-defined learning goals are established, the UDL framework can be completed with a variety of techniques to provide learners with options for engaging with materials, learning, and demonstrating their knowledge. 
Assessment of knowledge is an area in education seemingly always saturated with disagreement. However, Rose and Meyer argue that UDL assessment should be seamlessly embedded and flexible so that instructors will be able to align their assessment directly to their teaching goals and more accurately assess their learners (Rose \& Meyer, 2002). For example, a professor wanting to assess the ability of his students to generate a 90 -second environmental message to post as a YouTube video might permit a variety of options for the assignment including the use of still photography, video, animation, creative typography, script writing, music, or narration. He could then assess the students during each stage of the production process to be certain they were meeting the learning goals and adjust his teaching as necessary if the learners needed additional instruction.

Rose and Meyer know that UDL requires change; however, they feel strongly that UDL is the framework that will allow instructors to effectively respond to all the $21^{\text {st }}$ century challenges in education (2002). Teaching Every Student in the Digital Age: Universal Design for Learning was the only textbook on UDL until 2005.

In 2005, The Council for Exceptional Children published Universal Design for Learning: A Guide for Teachers and Education Professionals to serve as a handbook for educators teaching students with disabilities. While Rose and Meyer are frequently referenced, this book explores how UDL can support various approaches to instruction and how they relate to UDL. Chapter 3 discusses differentiated instruction, cooperative learning, thematic teaching, alternative instructive, community-based instruction, and activity-centered design in greater detail than did Rose and Meyer.

Activity Centered Design (ACD) is an approach that combines the learner (current knowledge and characteristics) with a flexible learning activity. "With the focus on high-stakes 
assessment, this approach may be particularly valuable for teachers working with diverse student populations to meet state standards of learning" (Council for Exceptional Children, 2005, p. 38). ACD places the learner in the center of the model, instead of the instructor, to teach students how to take ownership of their own learning and be participants in a community of learners. When combining UDL with an activity-centered approach, learners are given a variety of options for what they learn about (engagement/interest), how they learn about it (presentation/delivery of material), and how they demonstrate their knowledge (expression) (Council for Exceptional Children, 2005).

After four years had passed since the publication of their foundational textbook, Rose and Meyer came together once again to serve as the editors for A Practical Reader in Universal Design for Learning (2006). The book's title accurately portrays its contents and many of the contributing authors are known names in UDL research.

The first two chapters of the text share methods for applying UDL in the classroom. Chapter two presents a comparison study between traditional geography and social studies lesson plans and UDL designed lesson plans. Mrs. Jones has found that the UDL approach has produced a "hive of activity, a place where hard work, cooperation, confidence, and success are clearly evident” (Rose \& Meyer, 2006, p. 32). The third chapter, written by Grace Meo, CAST's Director of Professional Development \& Outreach Services, provides responses to frequently asked questions about UDL for educators and administrators who may be interested in learning more about this new paradigm in education. Chapters 4 through 6 offer a teacher's perspective of how UDL can be used in the classroom. Chapter 7 presents the argument that due to increasing diversity in the classroom, traditional methods of assessment are no longer valid or accurate. In chapter 8 , the authors discuss current legislation and how it has positively affected the learning 
environment for students with disabilities. The final chapters in the book revolve around literacy and importance of digital textbooks.

A Practical Reader in Universal Design for Learning did not present any new material and much of this may have been due to the fact that seven of the eleven chapters were reprinted with permission of the publisher.

Printed in May of 2008, Universal Design in Higher Education: From Principles to Practice, is the most recent publication regarding the application of UDL in higher education (Burgstahler \& Cory). "The content of this book emerged from decades of experience of educators, administrators, and researchers who share a common goal of making higher education more welcoming, accessible, usable, and inclusive for everyone" (Burgstahler, 2008, p. 17). The book is organized into four sections: (a) introduction, (b) Universal Design of Instruction in Higher Education, (c) Universal Design of Student Services, Physical Spaces, and Technological Environments in Higher Education, and (d) Institutionalization of Universal Design in Higher Education.

The first section, the introduction, provides a basic overview and history of Universal Design (UD). The author, Burgstahler, discusses the principles and applications of UD and explains the organization of the book. Chapter one provides an explanation of Burgstahler's new acronym UDHE, which stands for Universal Design in Higher Education.

In section two, various authors explore how UD relates to instruction as they share techniques and strategies, perspectives, and issues that can arise when employing UD teaching methods to curriculum and assessment. Here is where one can locate the lone UDL-dedicated chapter in Burgstahler and Cory's text. CAST's David Rose worked with four of his Harvard doctoral candidates, Wendy Harbour, Catherine Johnston, Samantha Daley, and Linda 
Abarbanell, to author Chapter 3 - an excerpt from Universal Design for Learning in Postsecondary Education: Reflections on Principles and Their Application.

Rose states that while the concept of UDL has become more familiar to educators, its application in postsecondary education lags far behind. This chapter provides an illustration of a course Rose instructs for the Harvard Graduate School of Education. The course, T-560: Meeting the Challenges of Individual Differences, was designed using the principles of UDL to meet the needs of a diverse population of learners who did not all know a lot about applying neuroscience to education. The basic goals of T-560 is to help learners understand the neuroscience behind learning, why there are learning differences, and then being able to use educational technologies and media to meet the needs of individual differences through universal design for learning (Rose et al., 2008).

First, methods of presentation must be considered. How is content being delivered to students? According to Rose, lectures and textbooks continue to be legitimate methods for instruction. They are rendered ineffective when they are the only methods for instruction. "While lectures and textbooks play an important role in instruction everywhere, both of them are ineffective for some students in all content areas and for all students in some content areas" (Rose et al., 2008, p. 48). These methods must be supplemented by alternative representations. For example, a sign language interpreter should be available if necessary. Lectures should be videotaped and posted on the course web site where they can be viewed at any time. Course notes and PowerPoint slides should be posted online for students who were unable to get everything during class (Rose et al., 2008). 
Next, an instructor must consider methods for keeping the class engaged. Discussion groups, review sessions, and course web sites are all methods for encouraging university students to interact with one another and the material.

Finally, student learning must be assessed through multiple means of expression. The assessment should be appropriate for the skill or knowledge the student is to demonstrate. For T560 , students are required to complete two projects for which they are graded. At midterm, students are required to select an atypical learner-type on which to conduct research and then they must submit a research project. The project can be a paper, something that includes images, video, etc. At the end of the semester, the students are required to have turned their research into a finished web site that can become part of an online learning network linked to other student sites (Rose et al., 2008).

Rose concludes that overall this course has been very successful and becomes more successful with each iteration. Students appreciate the autonomy and the choices they are given about how they learn, what they learn, and how they show what they have learned (Rose et al., 2008).

Section three in Universal Design in Higher Education: From Principles to Practice expands the application of UD to student service units like admissions, housing, and dining services. The chapters in this section discuss how to achieve positive desired outcomes such as full participation and all stakeholders feeling welcome. The majority of the chapters in this part of the book focus on the design of physical space and the other chapters concentrate on technological environments.

The final section of the text imparts strategies for assisting a campus to adopt UD into all its policies and procedures. "The result is an institution with instruction, services, physical 
spaces, and technology that is welcoming, accessible, and usable for everyone" (Burgstahler, 2008, p. 245). The final four chapters outline the stages necessary for systematic, institutional change to develop collaborations and promote Universally Designed colleges and universities.

\section{UDL Related to Scientific Teaching}

UDL is a framework that supports educational models where learners actively construct meaning (Rose \& Meyer, 2002). "Because it emphasizes developing flexible learning environments through multiple means, UDL creates a framework that other district initiatives can hang from" (Meo, 2005, p. 33). Fundamentally, UDL can effectively be used in conjunction with many other methods of instruction to reach a diverse population of learners. One science teaching strategy UDL can support is known as active learning. Active learning techniques are referenced and encouraged in UDL literature as these learning experiences provide a variety of information delivery and engagement for students.

According to Scientific Teaching: A Guide to Transforming Undergraduate Biology Education, a textbook written primarily by Jo Handelsman, Department Chairperson and Professor in the College of Agricultural and Life Sciences in the Department of Bacteriology at the University of Wisconsin in Madison and a renown proponent for the use of active learning in science education, effective teachers use a framework known as backward design which has three steps: (a) identify learning goals/objectives (what do I want my students to be able to do, know and/or understand?), (b) identify multiple methods of assessment (how will I know whether or now my students have met the goals/objectives?), and (c) plan learning experiences and activities (what techniques will engage a diverse group of learners in active learning?) (Handelsman, Lauffer, \& Pfund, 2006). Handelsman encourages teachers to ask themselves how they will encourage all students to be engaged learners and exactly what is meant by the term all 
students. She wants educators to really ponder how diversity is affecting their teaching and the learning that is taking place in their classroom. Handelsman asks educators to consider what might prohibit some students from learning to the best of their abilities and how this might be addressed through classroom strategies. Each of these questions, the notions of backward design, the idea of multiple methods of assessment, active learning, and the issue of diversity in the classroom directly relate to Universal Design for Learning (UDL). Rose and Meyer describe a similar, not identical, process for instructors when designing a course using a UDL framework in their textbook Teaching Every Student in the Digital Age: Universal Design for Learning (2006) (see discussion above).

Active learning is described as involving students in the classroom to enhance their understanding and retention and to make the classroom reflect the true nature of the course (Handelsman, Lauffer, \& Pfund, 2006). Assessment and active learning are believed to converge, as when the students become active, the instructor can discover what they know or need to know. Active classrooms can take many forms including, but not limited to the use of: group learning, clickers (audience response systems), group exams, one-minute questions at the beginning or end of class, strip sequences, concept mapping, brainstorming, decision making and various problemsolving activities (Handelsman, Lauffer, \& Pfund, 2006). Each of these techniques could easily be used as an option in the UDL framework.

Adequate research has not been conducted on the applications of UDL in higher education. A canvas of the literature that is available produced only one result concerning student perceptions of UDL and only a small number of sources that specifically discuss UDL as it applies to postsecondary education. UDL is a relatively modern paradigm of instruction that 
warrants further investigation to expand to the body of knowledge and literature currently possessed. 


\section{Chapter 3}

\section{Method}

The research questions for this study are: (a) how and to what extent Universal Design for Learning techniques are being implemented in the college classroom, and (b) what are the student perceptions of how Universal Design for Learning (UDL) techniques affect their learning.

Chapter 3 specifies the methods and procedures that were used to gather data about UDL being applied in the college classroom. This chapter will: (a) explain the research methodology for this study, (b) justify the units of analysis and sample selection, (c) describe the data sources and the procedures that will be used to collect data, (d) describe the procedures that will be used to analyze the data, and (e) discuss the limitations and delimitations of the study.

\section{Research Methodology}

Case study approach. Due to the context of the subject that was studied, the content of the research questions, and the nature of the responses sought, the case study research method was selected for this investigation. The case study method is a non-experimental descriptive manner of research that involves the careful examination of behaviors and the collection of records. Practitioners in the social-science disciplines and researchers who seek to examine practice-oriented fields such as education have used the case study method extensively. Traditionally, researchers have elected to use a case study strategy when the investigator seeks to focus on "how" and/or "why" questions that are related to a contemporary phenomenon existing within a real-life context where the investigator has little or no control over the events (Yin, 2003).

The case study explored how and to what extent Universal Design for Learning (UDL) techniques are being implemented in the college classroom, specifically through the use of 
Scientific Teaching, a teaching model used by the instructor. The researcher will not be the instructor of record, and will have no control or influence over course design, implementation, or evaluation. This case study of Universal Design for Learning (UDL) in the college classroom is descriptive in nature and required a qualitative method of data collection. The research methodology is summarized in Table 4 and is explained in subsequent sections.

Table 4

\begin{tabular}{|c|c|c|c|c|}
\hline $\begin{array}{l}\text { Research } \\
\text { Question }\end{array}$ & $\begin{array}{l}\text { Units of } \\
\text { Analysis/Participants }\end{array}$ & Data Source & $\begin{array}{l}\text { Collection } \\
\text { Procedure }\end{array}$ & $\begin{array}{l}\text { Analysis } \\
\text { Procedure }\end{array}$ \\
\hline \multirow{7}{*}{$\begin{array}{l}\text { How and to } \\
\text { what extent are } \\
\text { UDL } \\
\text { techniques } \\
\text { being } \\
\text { implemented in } \\
\text { the college } \\
\text { classroom? }\end{array}$} & Instructor & Field notes & Direct observation & \multirow{11}{*}{$\begin{array}{l}\text { Content } \\
\text { analysis using } \\
\text { Krippendorff's } \\
\text { (2004) six } \\
\text { components as } \\
\text { described in } \\
\text { Table 5. }\end{array}$} \\
\hline & Instructor & $\begin{array}{l}\text { Interview } \\
\text { notes }\end{array}$ & Interview & \\
\hline & $\begin{array}{l}\text { BIOL } 593 \text { students } \\
\text { (5) }\end{array}$ & $\begin{array}{l}\text { Interview } \\
\text { notes }\end{array}$ & Interviews & \\
\hline & BIOL 593 & $\begin{array}{l}\text { Course } \\
\text { materials }\end{array}$ & $\begin{array}{l}\text { Direct observation/ } \\
\text { Interview }\end{array}$ & \\
\hline & BIOL 115 & $\begin{array}{l}\text { Course } \\
\text { materials }\end{array}$ & $\begin{array}{l}\text { Instructor's archived } \\
\text { data }\end{array}$ & \\
\hline & $\begin{array}{l}\text { BIOL } 115 \text { students } \\
\text { (33) }\end{array}$ & $\begin{array}{l}\text { E-mail } \\
\text { responses }\end{array}$ & E-mail survey & \\
\hline & $\begin{array}{l}\text { BIOL } 115 \text { students } \\
\text { (33) }\end{array}$ & $\begin{array}{l}\text { Interview } \\
\text { notes }\end{array}$ & Interviews & \\
\hline \multirow{4}{*}{$\begin{array}{l}\text { What are } \\
\text { student } \\
\text { perceptions of } \\
\text { how UDL } \\
\text { techniques } \\
\text { affect their } \\
\text { learning? }\end{array}$} & Instructor & $\begin{array}{l}\text { Interview } \\
\text { notes }\end{array}$ & Interview & \\
\hline & $\begin{array}{l}\text { BIOL } 593 \text { students } \\
\text { (5) }\end{array}$ & $\begin{array}{l}\text { Interview } \\
\text { notes }\end{array}$ & Interviews & \\
\hline & $\begin{array}{l}\text { BIOL } 115 \text { students } \\
\text { (7) }\end{array}$ & $\begin{array}{l}\text { Interview } \\
\text { notes }\end{array}$ & Interviews & \\
\hline & $\begin{array}{l}\text { BIOL } 115 \text { students } \\
\text { (5) }\end{array}$ & $\begin{array}{l}\text { E-mail } \\
\text { responses }\end{array}$ & E-mail survey & \\
\hline
\end{tabular}

\section{Units of Analysis and Participant Selection}

Units of analysis. The instructor's biology courses, BIOL 115 Principles of Biology and BIOL 593 Special Topics in Teaching Pedagogy: Scholarly Teaching for Future College Faculty, offered by the department of biology at an institution of higher education in West Virginia, served as the units of analysis for this case study. BIOL 593 is an upper division course designed 
for a small number of graduate students, and BIOL 115 is a course for an average of 220 first year biology majors and pre-med students per semester. While the instructor identifies her pedagogy as Scientific Teaching, preliminary investigations by the researcher revealed that Universal Design for Learning principles, through various techniques and strategies, had been embedded in her instruction and in her assessment of student learning.

The instructor earned her Ph.D. in neuroscience from the University of Arizona at Tucson, and then served as a postdoctoral researcher at Brandeis University in Massachusetts. Before coming to West Virginia to teach biology, the instructor taught for the Introductory Biology Program at the Louisiana State University for seven years. In 2004, she participated in the National Academies Summer Institute on Undergraduate Education, the national standard for biology education, and was introduced to Scientific Teaching. In her current position, she has worked to develop curricula and find better ways to teach post-secondary science. Every summer, the instructor organizes a four-day professional development seminar, the West Virginia Summer Institute on Undergraduate Science Education, which focuses on teaching instructors how to use Scientific Teaching. The entire workshop is modeled after her experience at the National Academies Summer Institute on Undergraduate Education.

Course description of BIOL 115. BIOL 115, Principles of Biology, is a 4-credit introductory laboratory science course designed to present students with the basic principles of modern biology. BIOL 115 is the first course in a sequence of four courses that are required of biology majors. BIOL 115 must also be taken by students in various other medical and sciencerelated majors. BIOL 115 fulfills one of the basic math and scientific inquiry general education curriculum objectives. See Appendix A for the syllabus. 
Course description of BIOL 593. BIOL 593 is a 3-credit special topics graduate course titled "Scholarly Teaching for Future College Faculty". BIOL 593 is specifically designed to introduce students to both the theories and practices of Scientific Teaching, a pedagogical model used in undergraduate science classrooms and laboratories that approaches teaching and learning with the same experimental processes used in science (Handelsman, et. al, 2007). Students are asked to learn about and discuss the theories related to Scientific Teaching and then model various teaching strategies and techniques in the classroom to acquire practical experience. See Appendix B for the syllabus.

Participant selection. While this study was conducted during the Spring 2009 semester, the potential number of participants for the study included the instructor, 5 students enrolled in BIOL 593, and 220 students who had already completed BIOL 115 during the fall 2008 semester. Students were selected from the previous semester because they had recently completed her course and would be able to easily remember details and also to compare and contrast their learning experience in the instructor's course with other courses at the institution. Actual participants in this study included the instructor, 33 students from BIOL 115, and the 5 graduate students enrolled in BIOL 593.

\section{Data Source Description and Collection Procedures}

Course materials. Course syllabi and supplementary materials, such as handouts, PowerPoint slides, course notes, a textbook, and online materials, were collected to provide information on how the courses were organized and how Universal Design for Learning (UDL) was integrated into the course structure.

Instructor interviews. Semi-structured data collection was used to gather information from the instructor and a select group of student participants. While an initial set of structured 
questions was used to guide and begin the interview process, emergent questions arose during the interview. These supplementary questions were used to provide additional detail and depth in the data. Field notes were kept for responses, behaviors, and other vital information to inform the study. The structured questions used during the initial interviews with the instructor are in Appendix C and the questions used to guide the BIOL 593 student interviews are in Appendix D. Interviews with the instructor ranged in length from 30 minutes to an hour. There were four scheduled appointments during the semester and multiple occasions where unplanned meetings occurred. Electronic mail messages were also exchanged as additional questions emerged.

Interviews were conducted with the instructor throughout the semester to learn as much as is possible about how (and to what extent) Universal Design for Learning (UDL) was implemented in BIOL 593 and BIOL 115, and what her reactions and perceptions were to the use of UDL using Scientific Teaching. During the interview process, the instructor was asked to respond to a variety of open-ended questions that were designed to disclose factual content first, then to reveal perceptions regarding the factual statements. Throughout the interviews, the investigator often asked the instructor to provide examples or elaborate upon data provided. To ensure the validity of the data gathered, initial interview questions were designed to revolve around the established principles used in prior UDL research. As discussed in the literature review, Rose and Meyer (2002) have identified three basic principles upon which UDL depends. Instruction utilizing UDL must be designed with (a) multiple methods of information presentation, (b) multiple methods for students to demonstrate their acquisition of skills and knowledge, and (c) multiple methods of engaging student motivation and interaction with the curriculum. Many of the early interview questions were structured around these predetermined principles so that the responses would provide descriptive information that specifically addressed 
how and to what extend UDL was being implemented in her biology courses. In addition, the interview questions were designed to generate responses that addressed why the instructor utilized the strategies and methods she used and how the instructor perceived the use of these (UDL) strategies in her classroom.

The first set of questions was designed to provide demographic data about the students in the courses she teaches. The instructor was asked to describe the demographic characteristics of her class populations, if she knew of any students who had self identified as having disabilities and had asked for accommodations, if she was aware of students for whom English was a second language, and what majors were enrolled in her courses.

The next set of questions addressed the UDL principles. To address multiple means of representation, the instructor was asked how she presented information to her students, how she shared learning objectives/expectations with her students, and what the role of instructional technologies were in her classroom. She was then asked to how her students were assessed to address multiple means of expression. To address multiple means of engagement, the instructor was asked how she communicated with her students directly, how she motivated students, how she provided feedback to her students, and if she selected readings that were available online.

The five open-ended questions provided the instructor with the opportunity to reply about any of the UDL principles, perceptions, or present original information for further research. First, she was asked to share a typical lecture. She was then asked to describe her teaching. The instructor was asked what techniques she believed were the most effective in helping her students learn and what have been some of the definitive outcomes of using these techniques. Finally, she was asked what she perceived as the students' reaction to her courses. 
Student interviews. Near the end of the spring 2009 semester, guided interviews were conducted with students enrolled in BIOL 593 (see Appendix D). Interviews were conducted with students on April 21, April 28, May 1, May 4, and May 7, 2009. The interview questions were constructed to address both research questions (a) how and to what extent Universal Design for Learning (UDL) techniques are being implemented in the college classroom and (b) what are student perceptions of how Universal Design for Learning techniques affect their learning. Interview times with the students ranged in length from 20 minutes to an hour. While only one set of structured interview questions was used, additional data was gathered from each of the students throughout the course of the semester during discussions that occurred both before and after class. Electronic mail messages were also exchanged with a few of the students in the course to collect data.

Demographic data for this group was gathered during the interview with the instructor and during direct observations of the class. During class discussions of diversity, much of this information was shared by the students.

Interview questions were written to address the three basic principles of Universal Design for Learning (UDL): (a) multiple methods of information presentation, (b) multiple methods for students to demonstrate their acquisition of skills and knowledge, and (c) multiple methods of engaging student motivation and interaction with the curriculum (Rose \& Meyer, 2002). To address multiple means of representation, students were asked how the instructor presented information to the class. They were asked to describe a typical lecture, what instructional technologies were used during lecture, and if the instructor's expectations were consistent with the learning objectives stated in the course syllabus. To address the principle multiple means of expression, students were asked in what ways they were expected to demonstrate their 
understanding of the material, or what their grades were based upon. Finally, to address multiple means of engagement, students were asked to describe their level of interest in the course and to tell if they enjoyed attending. They were asked how the instructor kept them motivated. They were also asked how they received feedback on their assignments.

Two open-ended questions provided students with the freedom to reply about any of the UDL principles, perceptions, or present novel information. Students were asked to share what they liked most about the course and what they would change about the course. Another set of open-ended questions collected information about students' perceptions of the course in comparison to other courses. First, students were asked how they would describe the course in comparison to other courses they had taken or were currently taking at the institution providing both similarities and differences. Second, students were asked if they felt they learned less, the same, or more in BIOL 593 than they had in other courses at the same institution and to explain their answer.

Students were also asked about their grades in the course. The students were asked what grade they received at midterm and also what grade they anticipated receiving at the end of the semester. The rationale for inclusion of these questions was threefold. First, the collection of data at two points allows one to identify student growth or decline from midterm to final grade reports. While this small piece of data regarding only one student might not have value, trends can be identified as a group of responses is analyzed. Second, many research studies have been done that indicate a direct correlation between academic performance and attitude about a subject area or course (Depaolo \& Mclaren, 2006; Liddell \& Davidson, 2004). Grades might serve as a predictor of learner perceptions, behaviors, and attitudes. Third, grades can help identify outliers in data. If a student responds to the questions with responses that are extremely 
different from their peers, and reports that he/she is failing the course, the data may be skewed due to excessive absences or having not ever attended the course.

During the interview process, students were asked to respond to a variety of open-ended questions that were designed to disclose factual content about the course, then to reveal their perceptions. Throughout the interviews, students were often asked to provide examples or elaborate upon data provided. After the data was gathered, the notes were transcribed to retain all the details.

Direct observation. Experiential data was collected through non-intrusive direct observation of the instructor leading her BIOL 593 lectures. The instructor and students were observed in the classroom environment so that behaviors, actions, and reactions could be recorded in field notes as they occurred. The instructor and students were aware of the investigator's presence, but the students were informed that only the instructor's teaching methods were being observed.

BIOL 593 met twice per week, at 2:00 p.m. on Tuesdays and Thursdays, during the Spring 2009 semester. To gather information, the investigator observed eleven class sessions. Observations began on February 3, 2009, when IRB approval was granted to begin research. Classroom observations were conducted on the following dates: February 3, February 10, February 12, March 5, March 12, March 24, March 31, April 7, April 14, April 21, \& April 28.

E-mail survey. The electronic mail (e-mail) survey approach was chosen as a method of inquiry for a number of reasons. See Appendix E for the complete e-mail and survey questions sent to students in BIOL 115. First, the open-ended responses being solicited were of the nature that e-mail can effectively and efficiently encourage and collect. According to a 2001 study conducted by Kim Sheehan, Assistant Professor of the School of Journalism and Communication 
at the University of Oregon, e-mail surveys often allow individuals to provide more thorough, candid responses than other methods of survey research. Recipients can provide as much information as they wish with no space constraints.

Due to the number of students included in the study, lack of access and/or direct contact time with the students, an e-mail survey approach allowed the maximum amount of data to be collected both cost and time effectively (University of Maryland Survey Research Center, 2000). Recipients returned the e-mail survey with a click of their mouse-button. Therefore, the turnaround rate was faster with email response than with surface mail and less time was lost waiting for results. E-mail survey research also permits the investigator to track how many email messages were undeliverable, when an e-mail message was opened, and other such data that can improve accuracy for analysis. The purpose of the e-mail was to quickly collect structured interview data, posing the same set of interview questions, using an e-mail survey approach.

The survey was e-mailed to 220 individual students who had been enrolled in BIOL 115 during the fall 2008 semester in February 2009, March 2009, and April 2009. Replies were stored digitally in an online folder until August 2009 when the responses were converted to a single word document for analysis.

To ensure consistency and validity of the data gathered, the BIOL 115 survey questionnaire was designed to collect the same information as the initial BIOL 593 interview questions and additionally to identify a random population of students willing to participate beyond the initial survey. The e-mail survey was organized as follows: (a) initial closed-ended, forced choice questions to gather demographic information, (b) open-ended demographic/psychographic questions, and (c) open-ended questions revolving around student perceptions of UDL. To ensure that all student participants answered the same set of questions, 
the survey designed for the BIOL 115 students was comprised of questions that were past tense versions of the structured interview questions posed to the students who were enrolled in BIOL 593.

The initial sets of questions were included to collect demographic data about the students in BIOL 115. Respondents were asked to provide information about their gender, year in college, and age. They were then asked to identify if they were a student with a disability, if English was a second language, and/or if they were an Honors student. These questions were all structured as closed answer responses. Finally, respondents were asked to describe their race/cultural background and provide their major.

The next six questions were written to revolve around the three basic principles of Universal Design for Learning (UDL): (a) multiple methods of information presentation, (b) multiple methods for students to demonstrate their acquisition of skills and knowledge, and (c) multiple methods of engaging student motivation and interaction with the curriculum (Rose \& Meyer, 2002). To address multiple means of representation, respondents were asked how the instructor presented information to the class, what instructional technologies were used during lecture, and if the instructor's expectations were consistent with the learning objectives stated in the course syllabus. Respondents were asked in what ways they were expected to demonstrate their understanding of the material, or what their grades were based upon, to address the principle multiple means of expression. Finally, to address multiple means of engagement, respondents were asked to describe their level of interest in the course and to tell if they enjoyed attending. They were asked how the instructor kept them motivated. They were also asked how they received feedback on their assignments. 
Two open-ended questions followed. Students were asked to share what they liked most about BIOL 115 and what they would change about BIOL 115. The last two open-ended questions were asked to collect information about respondents' perceptions of the course in comparison to others. First, respondents were asked how they would describe BIOL 115 in comparison to other courses they had taken or were currently taking at the institution providing both similarities and differences. Then, respondents were asked if they felt they learned less, the same, or more in BIOL 115 than they had in other courses at the same institution and to explain their answer.

Additionally, two questions were asked about respondents' grades in the course. The respondents were asked what grade they received at midterm and also what grade they had received at the conclusion of the course. The rationale for inclusion of these questions was previously explained. The final question asked students if they would be willing to participate in an interview.

\section{Data Analysis Procedures}

After the collection of field notes, e-mail correspondence, student responses, and course materials was complete, a content analysis of the data was conducted. Content analysis was selected as the analytical approach as it is a descriptive method that seeks to define "what" is present, or not present, without a need to explain "why". Content analysis was used to examine student responses, interview responses, and course materials to identify meaningful patterns, themes, and concepts. Deviations from emergent patterns were also noted as these may provide information for further research. Each response and data source was carefully examined for UDL language and terminology. During the process of analysis, it was anticipated that relationships 
and various themes might arise. The data was analyzed from an inductive perspective as the investigation focused on a specific case in hopes that the results will lead to generalizable data.

Content analysis was completed on all of the data collected using Klaus Krippendorff's (2004) six components, or stages, of data analysis (see Table 5). The first four stages comprise what Krippendorff (2004) refers to as "data making - creating computable data from raw or unedited texts" (p. 83). After a researcher has data, only then should deductions be made about the observed phenomena, and only inferences that are supported by the data collected. The final step is to provide a detailed narrative explanation of the data that is consistent with the traditions and conventions established within the discipline of the researcher. The six phases of analysis are not always linear in nature. "A content analysis may include iterative loops - the repetition of particular processes until a certain quality is achieved" (Krippendorff, 2004, p. 85). The repetition enables the researcher to support one's interpretations by including quotations, construct parallelisms, and engage in triangulation of data sources. This support adds to the credibility of the study.

Table 5

Krippendorff's (2004) Components of Content Analysis

\begin{tabular}{ll}
\hline Component & Definition \\
\hline Unitizing & $\begin{array}{l}\text { Systematic distinguishing of text segments that are of interest for } \\
\text { analysis }\end{array}$ \\
\hline Sampling & $\begin{array}{l}\text { Selecting portions of text to use - text can be read at levels: words, } \\
\text { sentences, paragraphs, chapters, whole publications, etc. }\end{array}$ \\
\hline Recording/Coding & $\begin{array}{l}\text { Bridges the gap between units of analysis and researcher's } \\
\text { interpretation of them. }\end{array}$ \\
\hline Reducing data & $\begin{array}{l}\text { Creates manageable representations of data that other individuals } \\
\text { reading the research can understand. }\end{array}$ \\
\hline $\begin{array}{l}\text { Abductively } \\
\text { inferring }\end{array}$ & $\begin{array}{l}\text { Stepping from strict data to unobserved phenomena that is inferred } \\
\text { and supported by the evidence shown in the text. }\end{array}$ \\
\hline Narrating & Explaining the findings and their practical significance. \\
\hline
\end{tabular}


These six phases enabled all of the data to be unitized, sampled, coded, reduced, interpreted, and explained through narration to answer the research questions. Each of the phases is part of the whole content analysis process. As stated earlier, content analysis is not linear in nature. The first four stages, the "data making" phases, frequently require many iterative readings over the same materials to be positive every criterion has been coded for and each reading may include new samples and reduction of data. A researcher may make many loops through these phases before the process of analysis is exhaustive. Each of the six phases, or components of analysis, are now described.

Unitizing. As defined in Table 5, unitizing is the systematic distinguishing of text segments that are of interest for analysis. For this study, data was sorted into units based upon information sources. The units were identified as: (a) 11 units of field notes from each day of classroom observations, (b) five units of student interview notes, (c) four units of instructor interview notes, (d) a textbook unit, (e) two units from course syllabi, (f) one unit of BIOL 593 course materials, and (g) 33 units of BIOL 115 student survey responses with additional interview material where applicable. Each unit of analysis was analyzed independently of the other sources.

Sampling. The process of sampling consists of selecting text portions at various levels: words, sentences, paragraphs, chapters, or whole publications. For this study, the units of analysis were used in their entirety. For example, the entire textbook, Scientific Teaching, was analyzed, not a single chapter. Terms and phrases were read and considered for meaning in context, not removed and merely counted for frequency.

Recording/coding. Coding is the phase used to create a clear and valid connection between the units of analysis and researcher's interpretation of data. For this study, priori coding 
was used in terms of established principles and criteria for Universal Design for Learning (UDL) (Rose \& Meyer, 2002). When developing the coding instrument, these pre-established principles and criteria were identified to categorize all the data. Using pre-established categories for coding increased the validity of data interpretation as the coding categories were identified from the UDL literature.

The coding used to categorize data was selected to address the research questions (a) how and to what extent are Universal Design for Learning techniques being implemented in the college classroom, and (b) what are the student perceptions of how Universal Design for Learning techniques affect their learning, based upon the three primary principles of UDL as established by the Center for Applied Special Technology (CAST) and the eight performance indicator categories that are related to UDL (see Table 3). The principles of UDL are: (a) multiple means of representation, (b) multiple means of expression, and (c) multiple means of engagement. The UDL-related performance indicator categories are (a) class climate, (b) interaction, (c) physical environments and products, (d) delivery methods, (e) information resources and technology, (f) feedback, (g) assessment, and (h) accommodation.

The first UDL principle, multiple means of representation, includes all the ways in which an instructor provides for diverse learners through a variety of options for acquiring information, skills, and knowledge. Principle one is aligned with delivery methods and information resources and technology as these are defined by information delivery. The second UDL principle, multiple means of expression, provides learners with options for the act of demonstrating their knowledge and understanding and corresponds with assessment. Assessment is defined as the regular determination of student progress using a variety of methods and tools. This is directly related to the demonstration of knowledge, as Universal Design for Learning (UDL) requires 
multiple formative assessments of a learner, such as cooperative group performances and individual displays of achievement, to assess a learner's demonstration of knowledge. The third UDL principle, multiple means of engagement, consists of the methods educators use to develop learner's interests, create appropriate challenges, and provide motivation for learners. Class climate, interaction, physical environment, feedback, and accommodation are all aligned with multiple means of engagement, because all of these relate to how an instructor develops relationships and motivates learners in the classroom.

Texts were read in repeated cycles using key word in context searches to identify key terms and phrases like engaging, multiple options, variety, diversity, learning styles, etc., that fit within each of the categories so they could be appropriately coded. As terms were located, they were recorded in separate documents for each unit of analysis. For example, as Scientific Teaching was analyzed, each term or phrase was recorded with the page number and principle and performance indicator category.

Reducing data. Data reduction creates manageable representations of data that readers of the research can understand. For this study, data reduction was accomplished through a series of 3 steps.

First, each independent unit of analysis had been sampled and coded so that data could be recorded into a table for that individual unit of analysis. After this was complete, data reduction could begin.

To address the first research question, how and to what extent are Universal Design for Learning techniques being implemented in the college classroom, all units of analysis were sources of data (see Table 6). The first step of data reduction was to transfer all of the content from each of the individual units of analysis tables into one large table. 
Step two was to analyze this large document for patterns and themes as they relate to UDL in the classroom. Once recognized, these repetitive patterns reduced the data to the significant results that are reported in Table 7.

The last step, step 3, was to take the results in Table 7 and once again reduce the data for a summary product that would report the significant findings for research question one.

Table 6

Data Sources

\begin{tabular}{lll}
\hline Instructor & Course & Research Question Addressed \\
\hline Field notes & & RQ 1 \\
$\begin{array}{l}\text { Interview notes } \\
\text { Course materials }\end{array}$ & RIOL 593 and 115 & RQ 1 and RQ 2 \\
& & \\
Students & BIOL 593 and BIOL 115 & RQ 1 and RQ 2 \\
Interview Notes & BIOL 593 & RQ 1 \\
$\begin{array}{l}\text { Field notes } \\
\text { E-mail responses }\end{array}$ & BIOL 115 & RQ 1 and RQ 2 \\
\hline
\end{tabular}

The same process was followed for the second research question: What are the student perceptions of how Universal Design for Learning techniques affect their learning? For this question, the data from individual sources/units of analysis (interview notes, field notes, and email responses) (see Table 6) was analyzed and then placed into a large document organized by course. This document was analyzed for patterns and themes as they relate to student perceptions of UDL. These repetitive patterns were used to reduce the data to the significant results that are reported in Table 16. Additionally, results that were unique in some manner were also reported as these could lead to further insight.

The reduction of data also included analyzing data for frequency and contextual direction of a reference. Contextual direction analysis refers to whether data references were favorable, unfavorable, or neutral with regard to technique or perception. Frequency analysis was done not 
to merely count how many times a phrase or word was repeated, but instead to identify categories of techniques or perceptions.

Only after a researcher has data, should deductions be made about the observed phenomena, and then only inferences that are supported by the data collected. The final step is to provide a detailed narrative.

Abductively inferring. Abductively inferring is accomplished when one moves away from the actual data to unobserved phenomena that is inferred by the data and can be supported by evidence in the text. At this stage, the researcher interprets the data. The interpretation of data can be read in Chapter 5 .

Narrating. Narrating gives the researcher the forum to explain the data and the practical significance of the findings. For this case study, narration is used in Chapter 5 to provide a holistic portrayal of the instructor's classroom and illustrate areas of both strengths and weaknesses in the extent of UDL technique use.

Content analysis example. For instance, between the dates of February 3 and April 30, 2009, more than 15 hours of direct observation was conducted during the instructor's BIOL 593 course. Data was collected in the form of observational field notes that included descriptions of discussions, activities, specific techniques, behaviors and reactions, instructor comments, student comments, and observer comments of important items to remember at a later date.

The field notes were identified as a unit of analysis as they were an independent information source that provided data that could be categorized and analyzed. After each observation session, field notes were transcribed into another notebook to maintain an accurate record of the interactions and activities. These notes were maintained as single unit so they could be analyzed together. 
As a unit, the field notes were a sample of text to be analyzed. This means they were read, reviewed, and reread (through multiple cycles) for key terminology, phrases, and ideas in context that fit within the predetermined categories for coding.

The notes were analyzed and coded for how and to what extent Universal Design for Learning (UDL) techniques were being implemented. To address this research question, the material was coded for the three basic principles of UDL and then the eight indicator categories. The first principle of UDL, multiple means of representation, includes all the ways in which an instructor provides for diverse learners through a variety of options for acquiring information, skills, and knowledge. These notes were highlighted and marked with a 1 . The second UDL principle, multiple means of expression, includes providing learners with options for the act of demonstrating their knowledge and understanding. These notes were highlighted and marked with a 2. The third UDL principle, multiple means of engagement, consists of the methods educators use to develop learner's interests, create appropriate challenges, and provide motivation for learners. These notes were highlighted and marked with a 3 .

After the principles were identified, the indicator categories were coded. The eight performance indicator categories are related to UDL (see Table 3). Delivery methods and information resources and technology are aligned with multiple means of representation as they are both defined by information delivery. Delivery methods were coded with a "DM" and information resources and technology items were marked with an "IT". Assessment corresponds with multiple means of expression, as the definition of assessment is to regularly assess student progress using a variety of methods for demonstration of knowledge. Assessment was coded with an "AS". Class climate, interaction, physical environment, feedback, and accommodation are all aligned with multiple means of engagement because each of these relate directly to how 
an instructor develops relationships and motivates learners in the classroom. Class climate was denoted using a "CC", interaction was an "IN", the physical environment was a "PE", feedback was an "FB", and accommodation was coded "AC". Additionally, the field notes were also read and coded for any demographic information about the students in the course.

To begin the data reduction process, all of the coded information was then transferred into a table so that the researcher, and later readers, could quickly identify what techniques/methods were being used and what principles they met (see Table 7 in Chapter 4).

While these phases are described in a linear fashion, the "data making" stages of content analysis are not linear. For this unit of analysis, both unitizing and sampling were completed the first time. However, before all the content was fully analyzed, the researcher made multiple passes between coding and reducing data.

Only once these four phases were complete, and all the data was revealed, could the next two phases begin. Chapter 5 documents the results of the abductively inferring and narrating stages of content analysis.

\section{Research question one: How and to what extent are UDL techniques being}

implemented in the college classroom. To answer research question one, each data source (see Table 6) was examined in relationship to the basic principles of UDL and the indicator categories. Priori coding was used for the analysis as the categories for the data were established and agreed upon by UDL researchers prior to the study. Categories for data coding included: demographic variables, each of the three fundamental principles, and the eight indicator categories that are often used for Universal Design in the higher education classroom.

Discussions with the instructor, student responses, and observations of BIOL 593 offered an understanding of the implementation and assessment of UDL techniques in the college 
classroom. Interviews, student responses, and observations revealed information regarding how UDL is practiced through the three foremost principles - multiple methods of representation, expression, and engagement - and the eight subsequent performance indicator categories. Data gathered described the UDL methods and strategies that have been used and the results of using these techniques.

Communication with the instructor, student responses, and course materials presented information regarding course results and evaluation. Data was accumulated concerning student success rates and how her teaching has been modified.

Interviews with the course instructor led to the confirmation of the preexisting categories for data coding. She was asked to share her views of Scientific Teaching (and indirectly UDL techniques), discuss perceptions of events and behaviors, discuss any consistencies and inconsistencies, and compare the techniques used in BIOL 115 and 593, in addition to a list of other predetermined and emergent questions that arose over the course of the semester. A content analysis of her responses was conducted to identify significant patterns and themes related to her perceptions of using Universal Design for Learning (UDL).

\section{Research question two: What are student perceptions of how UDL techniques}

affects their learning? Demographic information was collected from students to generate a detailed description of the course population for BIOL 115 and BIOL 593. Additionally, the demographic data revealed relationships, patterns, and themes as the information was analyzed. Content analysis, as previously described, was conducted on the open-ended survey and interview responses to identify student attitudes and perceptions of UDL techniques, consistencies and inconsistencies, and comparisons between BIOL 115 and BIOL 593. See Table 4 for a summary of the data collection and analysis procedures used for this study. 


\section{Limitations and Delimitations}

Limitations. As the case study method is exploratory, rather than explanatory, no controlled conditions existed to allow absolute conclusions about cause-effect relationships. Phenomena and related behaviors are described, not explained; however, hypothesis and correlation possibilities indicate a need for further research of Universal Design for Learning in the college classroom.

Because case studies often rely on the descriptive data provided by individuals, instead of experimental data, some researchers feel there is greater room for error and for important information to be overlooked (Yin, 2003). In an effort to gather thorough and valid descriptive data, in-depth interviews were conducted and open-ended survey questions were used. Both the interview questions and the survey questionnaire were constructed in a manner to eliminate as much bias as possible. Triangulation, using multiple data sources, was done to both strengthen and validate the interpretation of the data, and reduce any potential bias that might exist.

Only adult students, those who are 18 and older, were asked to participate in this research study. Students enrolled in BIOL 115 who are under the age of 18 were excluded from the survey data.

Delimitations. Often stated in social science research, delimitations draw clear boundaries around a study to indicate what the study does and does not include (Punch, 2005). Because case studies typically involve a single group of individuals, they often are not deemed generalizable to a larger population. While biology courses were used as the units of analysis from which to gather data, the information collected does not focus on course-specific subject matter. Instead, the case study will allow future researchers to learn about to the integration of Universal Design for Learning techniques through basic stages of course development, during 
implementation, and evaluation, specific methodology used, and contextual conditions in an effort to add to the current base of knowledge. The information collected is applicable for other colleges and universities to use across their curricula. In this manner, the data gathered from this case study can be readily transferred to many other subject areas and is therefore generalizable to larger populations. Additionally, this study revolved around real-life current events to further increase its credibility. 


\section{Chapter 4}

\section{Results}

During the spring semester of the 2009 school year, data was gathered; classroom observations were completed, interviews were conducted, and materials were collected. Chapter 4 presents the analyzed data through a series of tables and narrative discussions that explain each of the tables.

This chapter is organized by research question and addresses each research question by the units of analysis that were identified during the content analysis. A final section summarizes the results for each research question. The research questions identified for this study were: (a) how and to what extent are Universal Design for Learning (UDL) techniques being implemented in the college classroom, and (b) what are the student perceptions of how UDL techniques affect their learning. The units of analysis (Krippendorff, 2004) identified were: (a) direct classroom observation field notes, (b) student interview notes, (c) Instructor's interview notes, (d) textbook, (e) BIOL 593 syllabus, (f) BIOL 593 course materials, (g) BIOL 115 student survey responses and interviews, and (h) BIOL 115 syllabi.

\section{Results}

\section{Research question: How and to what extent are UDL techniques being implemented in the college classroom?}

Analysis table description. Table 7 addresses research question (a) how and to what extent are UDL techniques are being implemented in the college classroom. Table 7 provides a visual representation of all the UDL techniques being implemented and shows into which categories they are classified. This table represents the first set of reduced data, which provides 
an overview of the wide range of UDL techniques used in the classroom. Table 15, provided in the Summary of this Chapter, presents the second set of data reduced from Table 7.

Table 7 is separated into three columns. Column one is separated into the three primary principles of UDL as established by the Center for Applied Special Technology (CAST). The first UDL principle, multiple means of representation, encompasses all the ways in which an instructor provides for diverse learners through a variety of options for acquiring information, skills, and knowledge. The second UDL principle, multiple means of expression, includes providing learners with options for the act of demonstrating their knowledge and understanding. The final UDL principle, multiple means of engagement, consists of the methods educators use to develop learners' interests, create appropriate challenges, and provide motivation for learners. The second column is divided into the eight performance indicator categories that are related to UDL (see Table 3). Delivery methods and information resources and technology are aligned with multiple means of representation as they are both defined by information delivery. Assessment corresponds with multiple means of expression, as the definition of assessment is to regularly assess student progress using a variety of methods for demonstration of knowledge. Class climate, interaction, physical environment, feedback, and accommodation are all aligned with multiple means of engagement because each of these relate directly to how an instructor develops relationships and motivates learners in the classroom.

The third column lists all the various techniques and practices that were identified during the examination of the units of analysis. Though the instructor practices Scientific Teaching, and had never heard of UDL prior to this study, her teaching practices met each of the principles for UDL. 
Table 7

How and to what extent are UDL techniques being implemented in the college classroom?

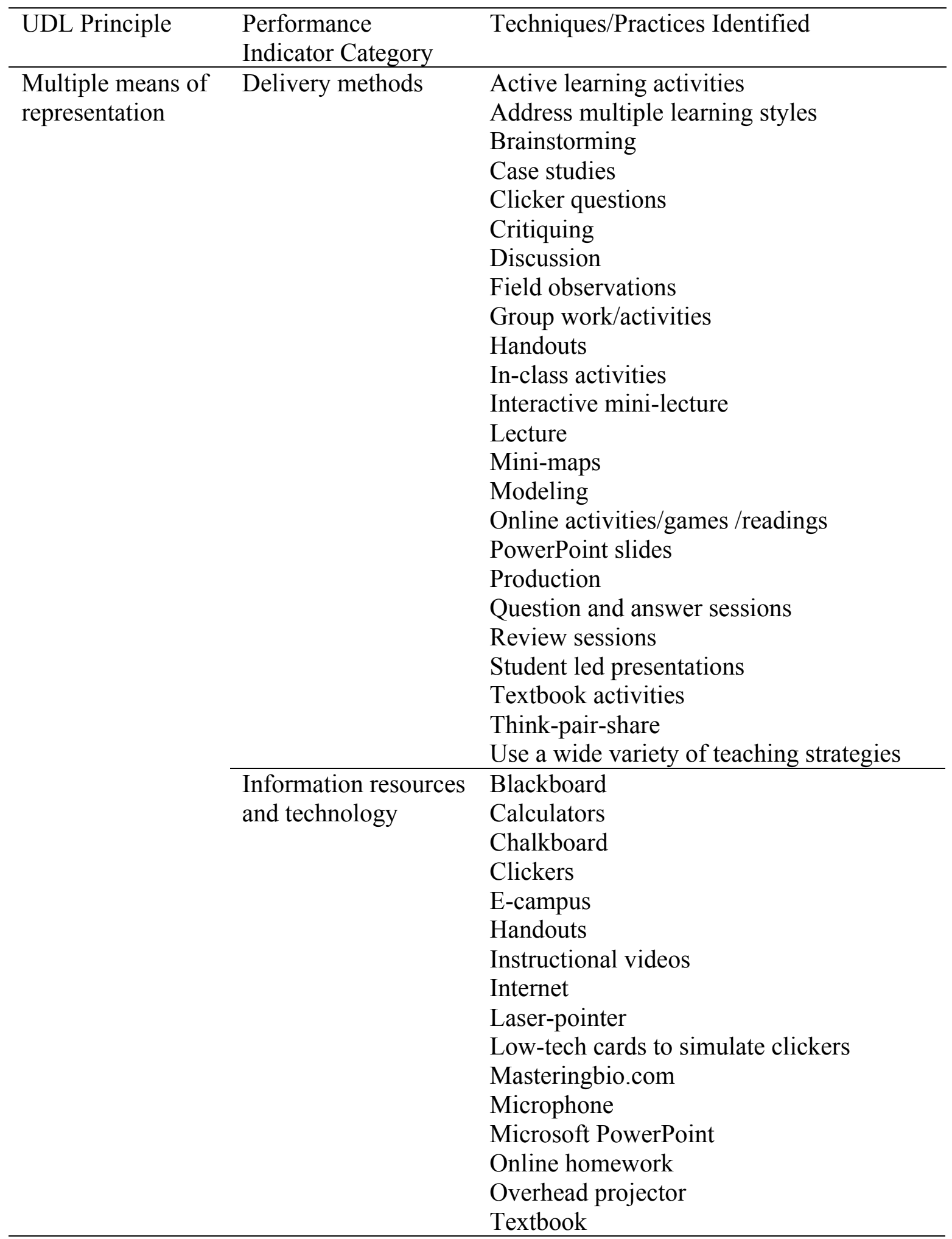




\begin{tabular}{|c|c|c|}
\hline & & $\begin{array}{l}\text { Whiteboard } \\
\text { YouTube }\end{array}$ \\
\hline $\begin{array}{l}\text { Multiple means of } \\
\text { expression }\end{array}$ & Assessment & $\begin{array}{l}\text { Always on multiple tasks } \\
\text { Attendance } \\
\text { Based on learning objectives } \\
\text { Clicker questions } \\
\text { Create activities to fit learning } \\
\text { styles/preferences } \\
\text { Discussion and class participation } \\
\text { E-campus assignments } \\
\text { Exams } \\
\text { Exams include multiple question formats } \\
\text { Extra credit questions } \\
\text { Group work } \\
\text { Homework } \\
\text { Individual work } \\
\text { Lab grades } \\
\text { Online activities/games } \\
\text { Paper on classroom observation } \\
\text { Participation } \\
\text { Peer critiques } \\
\text { Philosophy of teaching statements } \\
\text { Quizzes (in-class and online) } \\
\text { Reading assessment techniques } \\
\text { Reading assignments } \\
\text { Syllabus } \\
\text { Take home exams } \\
\text { Teaching presentations in class } \\
\text { Wide variety of exercises and assessment } \\
\text { strategies } \\
\text { Writing assignments }\end{array}$ \\
\hline $\begin{array}{l}\text { Multiple means of } \\
\text { engagement }\end{array}$ & Class climate & $\begin{array}{l}\text { Awareness of diversity } \\
\text { Call students by name } \\
\text { Class was fun } \\
\text { Create a safe environment for a diverse } \\
\text { population } \\
\text { Diversity celebrated } \\
\text { Engagement important } \\
\text { Everyone was friendly } \\
\text { Friendly, relaxed mood } \\
\text { Gave students choices about what } \\
\text { interested them for discussion } \\
\text { Inclusive of all } \\
\text { Laid back } \\
\text { Open class environment } \\
\text { Student-centered }\end{array}$ \\
\hline
\end{tabular}




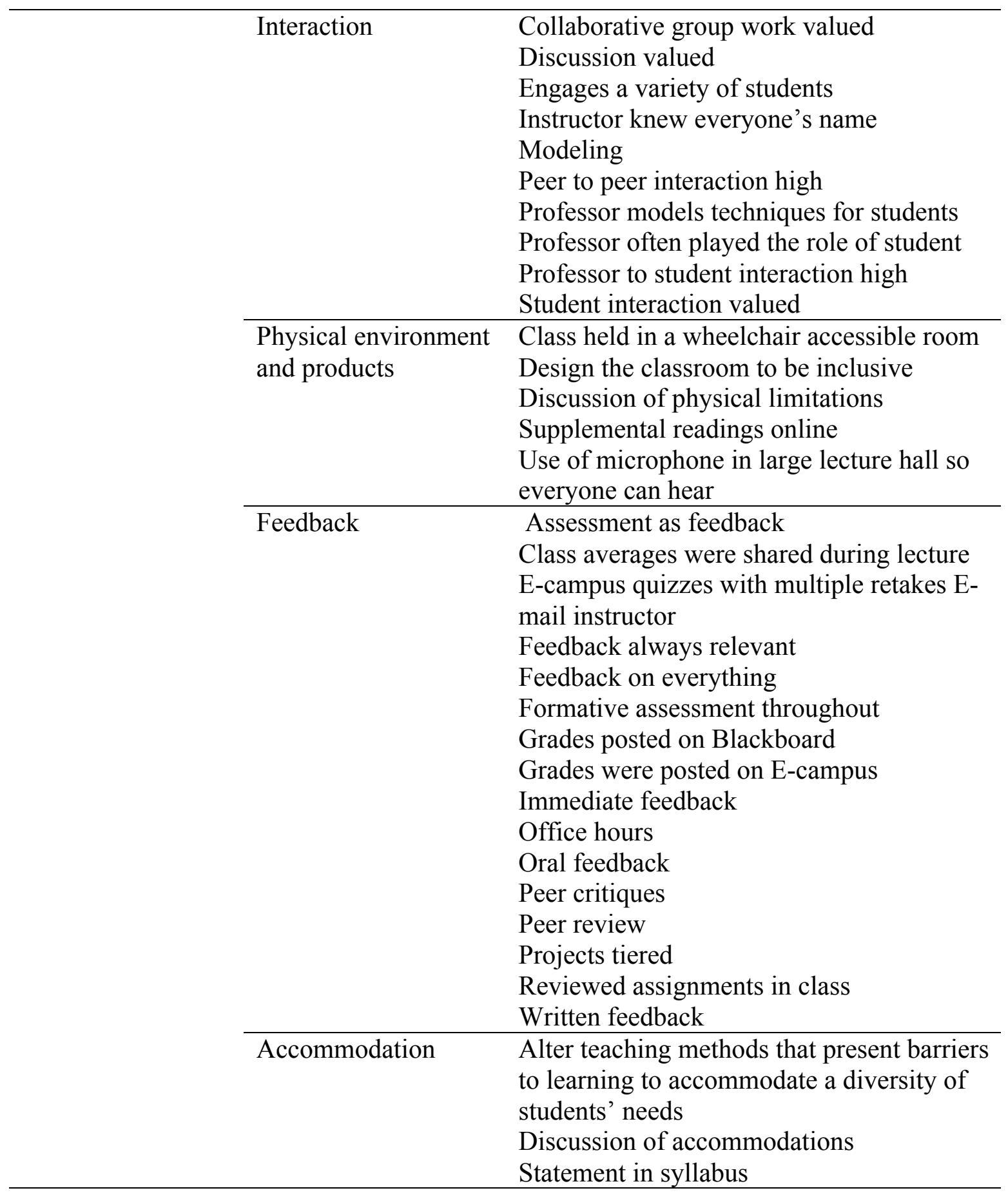

Direct observations. Between the dates of February 3 and April 30, 2009, more than 15 hours of direct observation was conducted during 11 class sessions of the instructor's BIOL 593 Scholarly Teaching for Future College Faculty. BIOL 593 is a graduate course that revolves around the pedagogy and practice of Scientific Teaching. Scientific Teaching is a pedagogical 
model that is used in undergraduate science laboratories and classrooms that approaches learning and teaching with the same experimental processes that are used in science (Handelsman, et. al, 2007). Students are asked to learn about and discuss the theories related to Scientific Teaching and then model various teaching strategies and techniques in the classroom to acquire practical experience. According to her syllabus, the instructor structured the course to model each of the teaching methods about which the students learning. Each class session is designed to provide new knowledge, discussion, and hands-on practice with techniques. See Appendix B for the syllabus.

The fall 2009 class was comprised of five female graduate students who appeared to be from similar Caucasian European ethnic ancestry. During diversity discussions, students shared information about their heritage and one of the students revealed her partial Native American heritage. Four of the students were between the ages of 23 and 25 and one was a nontraditional student. Two students were doing graduate work in biology, two in chemistry, and one in women's studies.

During each of the observation sessions, field notes were collected. These notes were rewritten and then coded for how/what Universal Design for Learning (UDL) techniques were being implemented (as described in detail in Chapter 3).

Multiple means of representation. On two occasions, the instructor told her students that she used a variety of delivery methods to provide them with a "toolbox" of learning and teaching options. During every class session, students were brainstorming with one another, interacting to develop ideas, and sharing their discoveries. Even during the class sessions where the instructor presented new information to students via lecture, the lectures were interactive and students were engaged through questions and various activities. As one exercise, students read case studies, 
discussed the studies, the diagnoses, and ways they could use case studies to teach about a multitude of subject areas. During another exercise, students completed an online unconscious bias survey and played a supplemental video game to determine what prejudices they held. After the students completed the activities, they brought their results to class for discussion and to talk about ways to recognize and eliminate bias in the classroom. In addition to their classroom learning experience, the instructor asked the students to glean information by conducting field observations of another instructor. The students were required to attend a class taught by a professor in their discipline so they could critique the instructional techniques without being a part of the course.

As these students were current instructors or intended to be future instructors, their professor also wanted them to model the techniques and be able to employ each option in their own classroom. Their instructor would often assign a brief out of class reading, either from the course textbook, or from an online source, and then have the class practice through in-class activities. Students were responsible for leading these in-class activities. Throughout the course of the semester, each student in the class was given multiple opportunities to practice classroom instruction. A few instructional techniques were commonly used by both the instructor and the students to share information: think-pair-share, mini-maps, brainstorming, and discussion. Through the course of the semester, the instructor shared multiple examples with her students of how these techniques are used to encourage cooperative learning in a college classroom. Thinkpair-share is an instructional technique where students are allowed time to think by themselves for a given period of time to solve a problem or create a theory, then asked to discuss the problem with a partner or in a very small group, and then finally asked to share with the whole class. Mini-maps are similar to concept maps that allow students to visually organize information 
to show relationships between ideas. To construct a mini-map, instructors provide students with a list of terms or concepts. Students then work in teams to develop a logical structure for the terms or concepts. While they are working, the instructor typically interacts with each team to find out if they are able to logically articulate their argument. When finished, a team or two will share their map and explanation with the whole class (Handelsman, 2007).

As learners enrolled in the course, students were asked to access information in a multitude of manners using a variety of information resources and technology. Students were required to read from an array of sources including the course textbook, online research papers and other primary source literature, materials that could be downloaded as portable document format (PDF) files or PowerPoint slides from E-campus, and various other handouts that were distributed in class. A few assignments required students to complete online activities that were available either on E-campus or the World Wide Web. The instructor also put her lecture notes, via PowerPoint slides, and handouts on E-campus for students to access if they needed them for later reference.

The instructor talked often about the use of a classroom response system, or Clickers, to ask questions and gather student reactions during lectures. To use a Clicker system, each student uses a remote-like device to answer questions that appear in a PowerPoint presentation designed by the instructor. The lecturer can immediately show the class the results in the form of a chart or graph. Additionally, a lecturer can save the data for later use and evaluation. Near the end of the semester, the class used the Clicker system during a couple class sessions to experience how the classroom response system could be utilized to engage the students and facilitate class discussion, collect immediate feedback and address any confusion students have about the material before moving onto a new concept, encourage peer interaction, and perform formative 
assessment as data is collected throughout the semester. The instructor also shared that she uses her Clicker system to take attendance in large lecture sections where taking attendance can be a challenge.

During most class sessions, colored index cards were used as a low-tech Clicker system with PowerPoint slides. As a topic was being discussed, the instructor/presenter of information would inject a PowerPoint slide with a question and a series of possible responses. Each response had a color assigned with the name of the color spelled out beside the possible answer. Students would hold up the index card of the color they believed to be the correct response.

Multiple means of expression. Students were presented with multiple methods for demonstrating their knowledge. They were expected to come prepared for discussion and ready to participate in peer-led activities. The instructor required several individual projects and an equal number of cooperative group activities. Individually, students were required to plan and create a syllabus, write a philosophy of teaching statement, compose a paper on their classroom observation experience, and generate multiple teaching presentations that were delivered to their peers and the instructor in the class. Additionally, after each student-led lecture, the class (including the professor as a participant) would complete peer critique forms to provide the student presenter with feedback about her presentation. According to the instructor, these forms also were a way the student completing the critique could gage how well she understood the concepts being discussed in class. The student completing the peer critique form needed to have comprehended the material being covered to provide detailed feedback for the presenter, and therefore, demonstrate her knowledge.

One particular exercise done in BIOL 593 to demonstrate an understanding of Bloom's Taxonomy was a dissection of BIOL 115 Principles of Biology exams. Students were asked to 
read each question of the exam and determine what level of cognitive skill was being utilized. The learners were asked to rank each knowledge or comprehension question as a LOCS, or lower order cognitive skill. Application questions were marked as applications. Questions that required synthesis of knowledge, analysis, or evaluation were ranked as HOCS, or higher order cognitive skills. This activity took the class the entire hour and fifteen minute time period and then an additional fifteen minutes for discussion. The instructor worked beside the students to analyze the exams. After they finished the classifications, students admitted they were quite surprised to learn that on a multiple-choice exam there were so many HOCS. They had expected to find the opposite. During the discussion, the instructor explained that the questions on the exam must align with the questions asked in class and reflect the levels of thinking instructors want our students to be capable of doing outside the classroom. She pointed out that even though the exam used a scantron sheet to collect final answers, the majority of the questions asked were designed to force students beyond lower order cognitive skills. The questions on the exam were similar to those in class, but never the same as those used in class or in the textbook, as she desires to test comprehension not the ability to memorize.

Multiple means of engagement. The instructor's class climate was an open, safe environment where her students were invited to ask questions and propose new topics for discussion or debate. After the first couple of class sessions, the students (and often the instructor) brought food to place at the center of the table to share with everyone during class. As students shared what they brought, they would sometimes discuss the weekly assignment even before the instructor arrived to begin the class. Though the class typically went over the allotted time, students did not mind. They continued to ask questions and keep the discussion alive until the instructor dismissed class. 
The instructor always called her students by name and asked that they call her by her first name. During one discussion, she explained the value of addressing students by their name, even in a large lecture section. She explained that she has her students write their names on folders that they hold up when they have a question or wish to respond. In this fashion, she can learn their names and eventually will not need the cue cards.

While the population in the class was far from dissimilar, diversity was celebrated and discussed in great length. Three class sessions were devoted to discussion of diversity in the classroom and various activities were completed in addition to teaching presentations. The instructor asked the learners if they should treat all their students the same and the class seemed to think that was a wise idea. This was before they discussed diversity. The instructor explained that celebrating diversity means recognizing student differences and observing these differences equally; therefore, treating each student as an individual.

Everyone participated in class discussions even when controversial or sensitive subjects were discussed. Students were given the opportunity to ask questions and encouraged to introduce topics of their own interests for discussion.

As stated previously, both individual and group work was completed throughout the semester. The majority of the in-class activities revolved around interpersonal dynamics and cooperative exercises. Students were virtually always interacting with one another during exercises and presentations. Unless delivering a lecture, the instructor frequently participated as if she herself were one of the learners.

During one mini-lecture, the instructor broached the subject of accessible and usable products. Students were advised to always write out the words for all names of colors in addition 
to the use of the actual color on PowerPoint slides as students who are colorblind can read the name of the color but may not be able to "see" the true color.

The physical space used for the course in the Life Sciences Building was an accessible room, and while there were no students with any visible disabilities enrolled in the course, the subject of students with disabilities arose on a couple of occasions without being the focus of any one class period. When student questions arose, the instructor encouraged her students to create inclusive classroom environments that included all diverse learners.

The instructor gave immediate feedback to her students after every project they completed. After in class teaching presentations, learners received critiques from both the instructor and their peers in the form of rubric sheets that provided them a review of their lecture, positive feedback, and areas of weakness that they should strengthen before their next exercise.

Additionally, almost every project in the course was done in tiered steps to allow students to gather feedback before submitting their final work. Often, students were encouraged to bring drafts of their work into class to receive peer and instructor feedback before submitting their final product.

The instructor has an accommodation policy statement in her syllabus that provides students with disabilities the number for the Office of Disability Services and instructs them to inform her of the necessary accommodations during the first week of class, if possible.

BIOL 593 student interviews. Guided interviews were conducted with students enrolled in the instructor's BIOL 593 course to address both research questions (a) how and to what extent Universal Design for Learning (UDL) techniques are being implemented in the college classroom and (b) what are student perceptions of how Universal Design for Learning techniques affect their learning. Table 8 provides the research question, the interview question structured to 
address the research area, and the specific principle upon which the interview question

concentrates.

Table 8

BIOL 593 Student Interview Questions

\begin{tabular}{|c|c|c|}
\hline Research Question & Interview Question & Principle/Category \\
\hline \multirow[t]{6}{*}{$\begin{array}{l}\text { How and to what extent are } \\
\text { UDL techniques being } \\
\text { implemented in the college } \\
\text { classroom? }\end{array}$} & $\begin{array}{l}\text { Throughout this course, } \\
\text { how did the instructor } \\
\text { present information to the } \\
\text { class? }\end{array}$ & $\begin{array}{l}\text { Multiple means of } \\
\text { representation }\end{array}$ \\
\hline & $\begin{array}{l}\text { What instructional } \\
\text { technologies were used } \\
\text { during lecture? }\end{array}$ & $\begin{array}{l}\text { Multiple means of } \\
\text { representation }\end{array}$ \\
\hline & $\begin{array}{l}\text { Describe your level of } \\
\text { interest in this course - did } \\
\text { you enjoy the course? How } \\
\text { did the instructor keep you } \\
\text { motivated? }\end{array}$ & $\begin{array}{l}\text { Multiple means of } \\
\text { engagement }\end{array}$ \\
\hline & $\begin{array}{l}\text { How did you receive } \\
\text { feedback on your } \\
\text { assignments? }\end{array}$ & $\begin{array}{l}\text { Multiple means of } \\
\text { engagement }\end{array}$ \\
\hline & $\begin{array}{l}\text { In what ways were you } \\
\text { expected to demonstrate } \\
\text { your understanding of the } \\
\text { material? (In other words, } \\
\text { what was your grade based } \\
\text { upon?) }\end{array}$ & $\begin{array}{l}\text { Multiple means of } \\
\text { expression }\end{array}$ \\
\hline & $\begin{array}{l}\text { Were the instructor's } \\
\text { expectations consistent with } \\
\text { the learning objectives } \\
\text { stated in the course } \\
\text { syllabus? }\end{array}$ & $\begin{array}{l}\text { Multiple means of } \\
\text { representation }\end{array}$ \\
\hline \multirow[t]{3}{*}{$\begin{array}{l}\text { What are student } \\
\text { perceptions of how UDL } \\
\text { techniques affect their } \\
\text { learning? }\end{array}$} & $\begin{array}{l}\text { What did you like most } \\
\text { about the course? }\end{array}$ & $\begin{array}{l}\text { Multiple means of } \\
\text { representation/multiple } \\
\text { means of expression/ } \\
\text { multiple means of } \\
\text { engagement/perceptions }\end{array}$ \\
\hline & $\begin{array}{l}\text { What would you change } \\
\text { about the course? }\end{array}$ & $\begin{array}{l}\text { Multiple means of } \\
\text { representation/multiple } \\
\text { means of expression/ } \\
\text { multiple means of } \\
\text { engagement/perceptions }\end{array}$ \\
\hline & How would you describe & Perceptions \\
\hline
\end{tabular}




this course in comparison to
other courses you have
taken or are currently taking
at this institution? How are
they similar? How are they
different?
Do you feel you learned Perceptions
less/the same/or more in
this course than in other
courses at this institution?
Why or why not? Please
explain.

Note. Students were also asked questions about their midterm grade and what final grade they expected to receive for the course. The rationale for the inclusion of these questions is explained in the narrative discussion.

The first six interview questions were designed to revolve around the three basic principles of UDL (a) multiple methods of information presentation, (b) multiple methods for students to demonstrate their acquisition of skills and knowledge, and (c) multiple methods of engaging student motivation and interaction with the curriculum (Rose \& Meyer, 2002). The next two questions allowed students freedom to respond in a multitude of manners that might present information about any facet of UDL, student perceptions, or open doors to entirely unexplored realms. The final two questions were asked to gather information about learner perceptions of the course. Additionally, students were asked about their grades in the course. Students were asked what grade they received at midterm and also what grade they anticipated receiving at the conclusion of the course. The rationale for inclusion of these questions was threefold. First, the collection of data at two points allows one to identify student growth or decline from midterm to final grade reports. While this small piece of data regarding only one student might not have value, trends can be identified as the larger group is analyzed. Next, many research studies have been done that indicate a direct correlation between academic performance and attitude about a subject area or course. Grades might serve as a predictor of 
learner perceptions, behaviors, and attitudes. Finally, grades could help us identify outliers in data. If a student responds to the interview questions with responses that are extremely different from their peers, and reports that he/she is failing the course, the data may be skewed due to excessive absences or having not ever attended the course. In this case, all of the students had earned an A at the midterm and expected to receive an A for the course.

These questions were used to guide the interview process. As students responded, additional questions were asked for depth and clarification of responses when necessary. Students were interviewed individually so that no two students in the course would hear one another's responses. This section only focuses on the responses to the questions that answer the research question (a) how and to what extent Universal Design for Learning (UDL) techniques are being implemented in the college classroom. The others will be discussed in the next section of this chapter.

During the interviews, when students were asked to describe a typical lecture, all of the students responded that class was far more of an interactive discussion than a typical lecture. A couple students also stated "modeling was used a lot". According to two students, when the instructor needed to present information, delivery was done through a variety of media. Learners identified PowerPoint slides used to lead her mini-lectures, the assortment of handouts provided in class, online readings and textbook readings, and her use of student led presentations to allow students to model the theories they were reading about each week for the other students in the class. They also noted the instructor's use of E-campus and the Internet in addition to the textbook to provide information and materials.

When asked what technologies were used during lecture, students listed many of the various technologies that were used in class from calculators to colored note cards that served as 
pseudo-clickers to the projector and whiteboard used for PowerPoint presentations. Students also noted many of the instructional technologies they had used outside of class such as the online articles, E-campus, the unconscious bias surveys and the online computer video game simulation program. According to a student, the unconscious bias surveys were set up as computer simulations that required the individual to watch a sequence of images and use their keypad to select characters that were attributed to positive or negative as the images were being shown. Based upon the keystrokes selected, the computer program could determine if the individual had a preference toward one side or the other. The video game was a similar concept except students were required to shoot "enemies" and save "civilians". After a player finished, the game would show how many individuals were targeted of a certain racial profile, etc.

The third question of the interview was structured as a two-part inquiry. Students were first asked to describe their level of interest in the course, and then to discuss how the instructor kept them motivated. All five of the students stated that they enjoyed attending the course. Three of the five cited the atmosphere as a reason for high interest. One described the atmosphere as open, another laid back, and a third appreciated the friendly unrushed manner in which the course was presented. One of the students liked everything about the course. One of the students mentioned that at first she had concern because the course appeared tailored for students in hard science disciplines, but the material covered and the instructor's feedback kept her motivated. In fact, three of the five students referred to feedback as a source of motivation in the course. One of the students stated that the instructor cared so much about education that her passion made all her students want to do well, "she has a level of commitment that you want to return." This student, and two others, mentioned that everything they were learning in the course was applicable and had immediate relevance in their field, and this was very motivational. One 
student noted that she could select material that was of interest to her to create reading assessment technique demonstrations and teaching presentations. Another student stated that the variety built into the course helped to motivate her. She liked having different types of projects to complete. The same student was also pleased to have built a network of peers with whom she could call upon. Teamwork was motivation for another learner who found that working with her peers and getting to know her classmates made going to class fun.

When asked how they received feedback on assignments, three students responded that peer review was a helpful method of getting "constructive criticism" on assignments. These same students mentioned feedback as a source of motivation. One student felt that the written comments she received through the peer review process were "amazing" and she could tell if the activity she led went well. Three of the students were pleased that the instructor provided critiques on every teaching activity done in class. These students cited that the immediate instructor feedback was important to them. Students also cited that they could met with the instructor in person, exchange e-mails with her, or check the E-campus grade book for updated records. One student mentioned slight discomfort with having no grades written on returned work. She stated that she had a hard time adjusting to the way the course was graded because she was used to a structured, rigid grading rubric. However, she also added that she knew if there had been any issues with her work, the instructor would have provided her with feedback on how she could improve.

When asked how they were expected to demonstrate their understanding of the material, the majority of the students began listing the various assignments and in-class activities they had been asked to complete. One of the students commented that there was a variety of ways students could demonstrate their understanding of the material from classroom demonstrations to out of 
class writing assignments. Three of the five students noted that they were constantly "using everything from the beginning" of the course to execute tasks and they were always "doing something".

The whole group agreed that the instructor's expectations were consistent with the learning objectives stated in the course syllabus. Two students stated that she maintained high expectation and one added that she wanted her learners "to be able to understand, demonstrate, and create, not just memorize." Another student said that every learning objective was achieved and those skills were refined as the semester progressed.

Instructor interviews. Guided interviews were also conducted with the instructor of the course to gain insight into how and to what extent Universal Design for Learning (UDL) techniques are being implemented in the college classroom. The instructor earned her Ph.D. in neuroscience in 1995 and then served as a post-doctoral researcher at a University in Massachusetts. Before coming to her current position, the instructor taught for an introductory biology program for another institution of higher education for seven years. In 2004, she participated in the National Academies Summer Institute on Undergraduate Education, the national standard for biology education, and was introduced to Scientific Teaching. The instructor now serves as an assistant professor in the department of biology for an institution in West Virginia where she has worked to develop curricula and find better ways to teach postsecondary science. Every summer, she organizes a four-day professional development seminar that focuses on teaching instructors how to use Scientific Teaching. The entire workshop is modeled after her experience at the National Academies Summer Institute on Undergraduate Education. 
Table 9 provides a list of the interview questions that were specifically structured to address the various principles and indicator categories of UDL, the principle, and the category upon which the question concentrates.

Table 9

Instructor Interview Questions

\begin{tabular}{|c|c|c|}
\hline Interview Question & Principle & Indicator Category \\
\hline $\begin{array}{l}\text { What formats do you use to } \\
\text { present information to your } \\
\text { students? }\end{array}$ & $\begin{array}{l}\text { Multiple means of } \\
\text { representation }\end{array}$ & Delivery methods \\
\hline $\begin{array}{l}\text { How do you share learning } \\
\text { objectives/expectations with } \\
\text { the students? }\end{array}$ & $\begin{array}{l}\text { Multiple means of } \\
\text { representation }\end{array}$ & Delivery methods \\
\hline Describe a typical lecture. & $\begin{array}{l}\text { Multiple means of } \\
\text { representation }\end{array}$ & $\begin{array}{l}\text { Delivery methods and Information } \\
\text { resources and technology }\end{array}$ \\
\hline $\begin{array}{l}\text { Do you select readings that are } \\
\text { available online? }\end{array}$ & $\begin{array}{l}\text { Multiple means of } \\
\text { representation }\end{array}$ & $\begin{array}{l}\text { Information resources and } \\
\text { technology }\end{array}$ \\
\hline $\begin{array}{l}\text { What is the role of instructional } \\
\text { technology in our classroom? }\end{array}$ & $\begin{array}{l}\text { Multiple means of } \\
\text { representation }\end{array}$ & $\begin{array}{l}\text { Information resources and } \\
\text { technology }\end{array}$ \\
\hline $\begin{array}{l}\text { How do your provide feedback } \\
\text { to your students }\end{array}$ & $\begin{array}{l}\text { Multiple means of } \\
\text { engagement }\end{array}$ & Feedback \\
\hline $\begin{array}{l}\text { How do you motivate your } \\
\text { students? }\end{array}$ & $\begin{array}{l}\text { Multiple means of } \\
\text { engagement }\end{array}$ & $\begin{array}{l}\text { Class climate, interaction, physical } \\
\text { environment, feedback and/or } \\
\text { accommodation }\end{array}$ \\
\hline $\begin{array}{l}\text { How are students assessed in } \\
\text { your course(s)? }\end{array}$ & $\begin{array}{l}\text { Multiple means of } \\
\text { expression }\end{array}$ & Assessment \\
\hline $\begin{array}{l}\text { How would you describe your } \\
\text { teaching? }\end{array}$ & All are applicable & All are applicable \\
\hline $\begin{array}{l}\text { What techniques do you feel } \\
\text { are the most effective in } \\
\text { helping your students to learn } \\
\text { the material? }\end{array}$ & All are applicable & All are applicable \\
\hline
\end{tabular}

Note. Additional questions at the beginning of the interview to gather demographic information and at the end of the interview to gather perceptual data. This information is discussed in the narrative.

In addition to the questions listed in Table 9, questions were asked to gather demographic data and perceptual information. During the stream of dialogue, BIOL 593 and BIOL 115 were often both discussed as the instructor uses many of the same teaching methods in both courses. 
When asked the initial set of questions, she described the demographic characteristics of her class population in BIOL 593E as homogenous for the most part with four traditional students, all white, all female, with only one nontraditional student. No one in the course had identified herself as having a disability, nor did any of the women speak English as a second language. Also, four of the five students were science majors - two chemistry, two biology - and only one student was a humanities major from women's studies. BIOL 115, however, was a far more diverse population with demographic characteristics that she described as "everywhere." She knew there were students in BIOL 115 with disabilities and for whom English was a second language. Also, many majors were represented because BIOL 115 fulfills a general education curriculum requirement.

The instructor shares learning objectives/expectations with students in her syllabi and each time she introduces a new topic, she places learning objectives into the PowerPoint presentations for each mini-lecture that are both discussed in class and then posted on e-Campus. The PowerPoint presentations from each class are posted for students to reference and use for study. The instructor said she wants to make sure students have access to the course information. While the textbooks for her courses are not yet available online, the supplemental readings she selects for her courses are available online. The instructor said she views instructional technology as a valuable tool and uses PowerPoint presentations and Clicker technology in many of her lectures.

When asked to describe a typical lecture, the instructor stated that she works more in the realm of the mini-lecture with a lot of group work and discussion interspersed. She stated that she feels very strongly that instructors need to model a topic, and demonstrate the subject, not merely talk about the material for an hour. 
The instructor said she uses modeling the material as a method of motivation for her students. "If they experience it, they will buy in - shared experiences provide motivation for them," she said. She explained her belief that students who are able to actively participate in their own learning are more likely to take ownership of their learning and be motivated to want to learn. Using active learning, she gets students involved in different ways depending on the course. She said having students in BIOL 593 produce teaching materials and participate in peer critiques is one way to help them experience the material. In BIOL 593, she plans a lot of time in the course for student-led presentations so learners can practice the theories they are reading about and discussing. In BIOL 115, she does a lot of group activities where students may be simulating a lab experiment through discussion or talking through a case study.

When asked how she would describe her teaching, the instructor states that she uses Scientific Teaching as her overall format, as she is a basic researcher who believes in constructivism and backwards design (discussed in detail in the Scientific Teaching textbook section of this chapter). She also feels strongly about the use of effective assessment, learning objectives, the role of diversity in the classroom, knowing how instruction affects diversity, and being able to use a variety of approaches that will reach everyone. The instructor said she even keeps diversity in mind during the creation of course materials and will attempt to break traditional ethnic and gender stereotypes when providing examples for students in PowerPoint presentations and other resources by using nontraditional illustrations. She provided the example of simply presenting a female doctor as the lead instead of a male because often men dominate the science, technology, engineering, and mathematical fields. The instructor believes showing a woman in the position of doctor, instead of nurse or assistant, will give young women the message that they can be just as successful as men in science and math related fields. 
To assess students, the instructor said she has students demonstrate their comprehension in a multitude of ways depending on the course, learning objectives, and the learners. In BIOL 593, graduate level learners were asked to produce course materials, write papers, deliver presentations, and actively engage in ongoing formative evaluation of themselves and others. In BIOL 115, on the other hand, a large lecture course comprised of undergraduate learners, students are asked to complete online quizzes, various written homework assignments, lab activities and reports, participate in group activities during lecture, answer in-class questions with Clickers, and take exams.

The instructor stated that she believes in continual and ongoing assessment. During BIOL 593, she said she consciously provided direct feedback in every class. She used a rubric every time the students presented to be sure the students were given oral feedback directly after they finished and then written feedback later so they could reflect on their strengths and weaknesses. The instructor also said she posts all grades on Blackboard so students are not left wondering where they stand in a course.

When asked to share what techniques she feels are the most effective in helping her students learn the material, the instructor did not hesitate to answer. She said that active learning and formative assessment are her most effective techniques "as they go together and almost cannot be separated from one another. You have to go back and forth. Students need to read a little, practice the skills you want them to be able to do, note what they still need to learn, practice more," she explained. She provided the following example. "You can't teach a student to play the piano by telling them how to play it, they have to practice. Practice is important, but the feedback that you get from the practice is one of the most important aspects. You need to hear yourself hit the kilunkers. If you practice the piano with earplugs, you wouldn't hear when 
you made mistakes, so you wouldn't change what you were doing or ever get any better," she said. The instructor said that learners need to be engaged with the material if they are going to learn it and active learning strategies help students to "practice" the skills they need to learn. She said she then encourages learning by providing continual feedback for the students so they can continue improving their skills and knowledge through additional practice activities.

Due to use of these techniques, the instructor said she has observed an increase in class attendance, higher levels of student engagement, fewer students drop her courses, and higher overall averages in her courses. Since she began using Scientific Teaching strategies in 2004, the instructor has been gathering data to show that the majority of students in biology courses using active learning techniques have a higher success rate than those in courses using traditional lecture. She said that in BIOL 115 "one can observe a change over the course of a semester as light bulbs go on for students and they begin to start understanding the bigger picture" instead of merely memorizing facts to pass an exam.

Though the fall 2009 section of BIOL 593 was the first time this course was offered, and enrollment was much lower than what the instructor had initially planned, she perceived student reactions to the course to be very enthusiastic. Students appeared to have "buy in from day one" and they all really wanted to be a part of the course. In fact, about midway through the semester, the instructor said she realized having fifteen students in this type of course would have been too much. The instructor explained that BIOL 593 was designed to offer learners substantial time for presentations and to allow ample time for feedback. If there were fifteen students, as originally anticipated, the course would not have had the same rhythm.

When asked if she had ever heard of Universal Design for Learning (UDL), the instructor said that she had not, but hoped that when all the research was concluded and the results were 
compiled, that the final conclusions would be shared with her so she would then know a little about UDL and the research study that had been conducted.

Scientific Teaching (2007) textbook. The textbook used in the instructor's BIOL 593 course, Scientific Teaching, written by Jo Handlesman, Sarah Miller, and Christine Pfund, (2007) founders of The Wisconsin Program for Scientific Teaching, provides much insight about the philosophies of Scientific Teaching and how they relate to those of Universal Design for Learning (UDL). As one studies the two teaching pedagogies, vast similarities and overlapping concepts are revealed. Both UDL and Scientific Teaching are learner-centered pedagogies that focus on teaching students how to learn so they can continue to build, transfer, and form associations beyond a solitary course. Additionally, both UDL and Scientific Teaching promote active learning as a primary method for engaging learners in the classroom.

Scientific Teaching is defined as a pedagogical approach that is employed in undergraduate science classrooms to approach teaching and learning through active learning strategies that engage students in the processes of science utilizing instruction and assessment methods that have been systematically examined and proven to reach diverse students (Handelsman, et al., 2004). Universal Design for Learning (UDL) also positions itself as an approach to learning that uses instruction and assessment to reach a diverse group of learners. UDL is a research-based framework for designing curricula to enable all students to learn. UDL provides a flexible blueprint for generating learning goals, teaching techniques, materials, and assessment strategies that will accommodate vast learner diversity (Rose \& Meyer, 2002).

"The traditional college curriculum, designed around information and factual knowledge, provides insufficient education...In short, practicing real science in the college classroom benefits everyone," state the authors of Scientific Teaching (2007, pp. 2-3). The writers discuss 
the typical classroom lecture dominated by the pontification of facts and share evidence that reflects retention from traditional lecture-only teaching is poor. The authors suggest that while instructors are aware alternatives to lecture exist, the majority of educators are not sure how to design a course or implement the design in the classroom. While the focus of the text is clearly on the science classroom, a parallel can easily be drawn between their statement and that of UDL researchers who find that the curriculum is flawed by design and is most often any educators greatest impediment. As one studies the philosophies of Scientific Teaching, many such parallels present themselves. Table 10 documents the Scientific Teaching textbook references that specifically used language synonymous with that of the UDL principles.

Table 10

Scientific Teaching Textbook

\begin{tabular}{|c|c|c|}
\hline $\begin{array}{l}\text { UDL Principle } \\
\text { Multiple means of } \\
\text { representation }\end{array}$ & Performance Indicator Category & Textbook Reference \\
\hline \multirow[t]{2}{*}{$\begin{array}{l}\text { Multiple means of } \\
\text { representation }\end{array}$} & Delivery methods & $\begin{array}{l}\text { Variety of active learning } \\
\text { methods to engage students } \\
\text { Lectures should include a } \\
\text { mixture of visual } \\
\text { representations of data, images } \\
\text { and/or pictures, and include } \\
\text { opportunities for students to } \\
\text { manipulate information } \\
\text { through concept maps or group } \\
\text { discussion/problem solving to } \\
\text { address multiple learning styles } \\
\text { Variety of teaching methods to } \\
\text { address a diversity of students }\end{array}$ \\
\hline & $\begin{array}{l}\text { Information resources and } \\
\text { technology }\end{array}$ & $\begin{array}{l}\text { Proponent of the clicker system } \\
\text { Use resources that already } \\
\text { exist; Internet sources are } \\
\text { freely available }\end{array}$ \\
\hline $\begin{array}{l}\text { Multiple means of } \\
\text { expression }\end{array}$ & Assessment & $\begin{array}{l}\text { Encourages instructors to } \\
\text { create reading assessments that } \\
\text { give students the freedom to } \\
\text { create activities that fit their } \\
\text { individual learning styles and } \\
\text { preferences so they can learn }\end{array}$ \\
\hline
\end{tabular}




\begin{tabular}{|c|c|c|}
\hline & & $\begin{array}{l}\text { and understand the material } \\
\text { In addition to in-class exams, } \\
\text { instructor gives some take } \\
\text { home exams and students have } \\
\text { a week to complete them } \\
\text { Instructor integrates a variety } \\
\text { of exercises and assessment } \\
\text { tools into class and homework } \\
\text { Exams include multiple } \\
\text { question formats }\end{array}$ \\
\hline \multirow[t]{5}{*}{$\begin{array}{l}\text { Multiple means of } \\
\text { engagement }\end{array}$} & Class climate & $\begin{array}{l}\text { Effective classrooms foster } \\
\text { curiosity by engaging the } \\
\text { diversity of students' minds } \\
\text { through instructional design } \\
\text { and classroom environment } \\
\text { Chapter } 4 \text { discussions on } \\
\text { diverse and inclusive } \\
\text { classrooms } \\
\text { Create a safe environment for a } \\
\text { diverse population }\end{array}$ \\
\hline & Interaction & $\begin{array}{l}\text { High value on collaborative } \\
\text { group work } \\
\text { Use students' names in the } \\
\text { classroom to make it personal }\end{array}$ \\
\hline & $\begin{array}{l}\text { Physical environment and } \\
\text { products }\end{array}$ & $\begin{array}{l}\text { Design the classroom to be } \\
\text { inclusive - integrate mobile } \\
\text { chairs and tables that can } \\
\text { accommodate flexible } \\
\text { arrangements } \\
\text { Class held in a wheelchair } \\
\text { accessible room } \\
\text { Instructor in a large lecture hall } \\
\text { ensures everyone can hear by } \\
\text { using a microphone }\end{array}$ \\
\hline & Feedback & $\begin{array}{l}\text { Teachers uses feedback from } \\
\text { assessment to revise instruction } \\
\text { Assessment is feedback that is } \\
\text { used provide regular and } \\
\text { ongoing feedback to students }\end{array}$ \\
\hline & Accommodation & $\begin{array}{l}\text { Instructors need to alter } \\
\text { teaching methods that present } \\
\text { barriers to students' learning } \\
\text { and accommodate a diversity } \\
\text { of students' needs. }\end{array}$ \\
\hline
\end{tabular}

Handelsman, et al. (2007) 


\section{Multiple means of representation. The authors of Scientific Teaching recognize that} most classrooms are comprised of diverse student populations who come to class with a lot of “prior knowledge (which may or may not be accurate); they also bring their past experiences, culture, gender, race, ethnicity, beliefs, sexual orientation, physical condition, and psychological status" (Handelsman, et al., 2007, p. 5). Due to their differences, many of these students will have unique learning needs. Handelsman and her team of writers devote a section to the discussion of learning styles and they stress that instructors must understand how students best learn. In subsequent chapters, they continue this discussion and suggest that instructors address multiple learning styles by incorporating visual representations of data into their lectures and providing opportunities for students to cognitively and/or physically manipulate information. The authors also encourage teachers to use a variety of teaching methods to be sure they are engaging a diversity of students. Active learning, "the process in which students are actively engaged in learning" (Handelsman, et al., 2007 p. 19) is an approach that includes a variety of methods for engaging students with the material. Active learning includes inquiry-based learning, cooperative learning groups, think-pair-share activities, student-led review sessions, games used as assignments or for review, student debates, case study review, concept mapping, mini-maps, etc. According to the authors, active learning is far from a new concept in education, but is often forgotten or unused in the realm of higher education. The authors argue active learning methods reach audiences with diverse learning needs to help them learn difficult material and therefore should be used in the college classroom.

The authors of Scientific Teaching are also proponents of employing technology in the classroom. When used properly, the authors indicate that electronic audience response systems, more commonly referred to as "clicker" systems, can serve as a valuable informational tool and 
educational resource in the classroom. Instructors can use this technology to take attendance and measure student understanding, and students are able to gage their own level of knowledge and conceptual understanding. Clickers provide both the instructor and the student immediate, realtime feedback that can generate discussion and questions to ensure students are getting the material. Throughout the text, the writers mention the use of multimedia in the classroom and they encourage instructors to use instructional resources that are freely available on the Internet as there are vast digital libraries of peer-reviewed educational materials that can be easily adapted.

Multiple means of expression. The authors of Scientific Teaching promote the use of multiple methods for the demonstration of knowledge and assessment in various places throughout their text. Practitioners of Scientific Teaching are encouraged to generate reading assignments that allow students the freedom to design activities that fit with their learning styles and individual preferences. This assures that students are more likely to actually do the reading assignments and understand what they reading. Instructors, of course, guide this process to ensure that students are working toward a common goal and within specific boundaries (due dates, formats, etc.). Often, students do part of their assignment individually and are then expected to participate during class in-group activities where they must demonstrate their knowledge to their peers. This also persuades students to complete the reading because they do not want to let the members of their group down by not completing a task. "Moreover, students' investment increases when they are given a chance to make decisions about their own learning" (Handelsman, et al., 2007, p. 50).

Instructors are also encouraged to "integrate a variety of active learning exercises" (Handelsman, et al., 2007, p. 79) into both the classroom and homework on a regular basis. 
Throughout the text, the authors provide extensive descriptions of techniques instructors can use to incorporate active learning approaches into their classroom.

In addition to flexibility with assignments that support learner differences and learning styles, Scientific Teaching supports the ideology that exams should be created to align with assignments so as to truly test student knowledge and therefore should include multiple formats. Instructors are also encouraged to consider giving students take-home or group exams in addition to their in-class exams and allowing students more time to complete these exams.

Multiple means of engagement. Scientific Teaching offers instructors various suggestions for methods to maximize learners' interest in the classroom, offer suitable challenges, and increase student motivation.

The classroom environment is mentioned in numerous places throughout the textbook as the authors stress that the most effective and engaging classrooms are those that foster student curiosity though "instructional design and classroom environment" (Handelsman, et al., 2007, p. 13). Chapter 4 devotes large sections of text to the discussion of how significant both diversity and inclusiveness are in the classroom. Instructors are encouraged to create learning environments where interaction and collaboration allow students to feel as though they are active contributors and where all students, including women and underrepresented populations, feel safe.

As stated, practitioners of Scientific Teaching place high value on collaboration and interaction in the classroom. The terms interactive, interaction, collaborative, and collaboration are repeated frequently by the authors to describe group work and active learning exercises used to engage learners with the material. The authors support the belief that instructors need to make personal contact with students during class by using students' names and taking the time to ask 
them for opinions. By taking time to establish rapport with a class, students will know they are thought of as individuals, not merely identification numbers on paper, and will set higher aspirations for themselves.

Another significant point made by the authors of Scientific Teaching is that the classroom's physical environment should be designed to be inclusive. "The best classrooms integrate mobile chairs and tables that accommodate flexible arrangements and facilitate discussions" (Handelsman, et al., 2007, p. 44). The physical location should be wheelchairaccessible to assure an inclusive classroom environment and instructors in large lecture halls should use a microphone to ensure that all students can hear when something is spoken.

In the same way that the physical environment, human interaction, and classroom climate can be used to engage students, Scientific Teaching uses feedback to promote participation and encourage students to learn how to assess their own learning. Instructors are encouraged to provide regular and ongoing feedback to learners through both formative assessments conducted during activities and summative assessments conducted at the completion of activities. The authors stress that when assessment is aligned properly with active learning and feedback, assessment is an engagement tool far more powerful than grades as it provides feedback for both the student and instructor that can literally be used to guide student learning and diagnose any potential problems. Handelsman and her team of writers argue that to be effective, instructors should use the feedback they gather from assessments to revise their instruction.

Finally, the authors also address the need for accommodation and the need "to change teaching methods that present barriers to some students' learning, or fail to accommodate different students' needs" (Handelsman, et al., 2007, p. 17). The writers call attention to the fact that if instructors desire to help all students learn, they have to consider the diverse differences 
among their students - physiological, cultural, cognitive, social, age, experiences, even unconscious differences - that affect how learners behave, how they are motivated, how they learn, and even how well they learn.

The authors of Scientific Teaching are the foremost advocates for an idea they have identified as "EnGaugement," which is defined as "an activity that simultaneously engages students in learning and gauges their understanding" (Handelsman, et al., 2007, p. 20). These active learning techniques are promoted to motivate students in the classroom while also allowing both the instructor and learner to gather feedback about student comprehension of the material. The activities are designed to provide students with relevant learning experiences that allow them to use the material they have read or learned about to test understanding and comprehension.

Scientific Teaching also promotes the concept of backward design, proposed by Grant Wiggins and Jay McTighe (1998) in their original work, Understanding by Design. To introduce their book, Wiggins and McTighe pose two questions: (a) how do we create a curriculum design that allows more students to really understand what they are asked to learn, and (b) what can we do to have an impact on all students with varied learning styles and interests. Backward design is the one of their primary solutions. Backward design includes three primary steps: “(a) identify desired results (learning goals), (b) determine evidence for learning (learning outcomes and assessment), and (c) plan learning experiences and instruction (activities)" (Handelsman, et al., 2007, p. 14). The structure is called backward design because for most educators the process is in reverse order of how they are accustomed to designing their lesson plans. Too often, instructors plan activities based primarily around their teaching instead of around successful student learning. "They spend most of their time thinking, first, about what they will do, what materials 
they will use, and what they will ask students to do rather than first considering what the learner will need in order to accomplish the learning goals," (Wiggins \& McTighe, 2005, p. 15). The structure of backward design requires educators to reorganize and rethink old teaching practices to establish a learning experience where the goals, assessment, activities, and even instructional materials are all in alignment so as to successfully engage a diversity of learners.

BIOL 593 syllabus. The BIOL 593 course syllabus was analyzed to identify how the principles of Universal Design for Learning (UDL) were applied to the design of the overall course structure. The BIOL 593 course syllabus can be examined in Appendix B.

Multiple means of representation. BIOL 593 was designed to provide students with opportunities to gain hands-on experience and "model the teaching practices about which" they were learning. In the learning outcomes section of the syllabus, one can identify each of the principles and several of the indicator categories. The learning outcomes address delivery methods in the skills section: "By the end of this course, we will be able to choose teaching methods based on evidence". According to the instructor, the phrase "based on evidence" that is included at the end of this outcome, is related to data gathered by experts and herself, not students in the course. The students in the course were focused on the selection of teaching methods; therefore, this practice aligns with Rose and Meyer's belief that instructors should employ multiple UDL strategies to meet the learning styles and needs of an entire diversity of learners in a classroom (2002).

In the learning outcomes skills section, the indicator category information resources and technology is also addressed: "By the end of this course, we will be able to use instructional resources, technology, and literature in the development of new materials." Materials and resources are mentioned again in the products section: "By the end of this course, we will have 
created a toolbox of ideas, materials, and resources for teaching." These practices are in alignment with multiple means of representation as Rose and Meyer are advocates for providing differentiated instruction so learners have multiple formats from which to learn (2002).

Multiple means of expression. There was no learning outcome clearly dedicated to this principle. Students in BIOL 593 were provided with multiple assignments to complete over the duration of the course that were varied in the nature of the task. According to the syllabus, learners were expected to attend class and participate as part of their course grade. Additionally, they would be assessed based upon their in class teaching presentations, their teachable units (lesson plans), a syllabus, class critique, teaching philosophy statement, and their peer-reviews of assignments. Providing students with several types of assignments throughout a semester to give learners the opportunity to demonstrate and practice what they know is consistent with UDL practices (Rose \& Meyer, 2002).

Multiple means of engagement. The principle multiple means of engagement is addressed by the syllabus in four of the five performance indicator categories. In the learning outcomes skills section, the indicator category class climate is addressed: "By the end of this course, we will be able to create an inclusive classroom." One of the goals of UDL is to provide instructional materials and strategies that enhance the learning experience of all students in the classroom, to create a truly inclusive learning environment (Rose \& Meyer, 2002). The disability statement inviting students to meet with the instructor to arrange accommodations opens the door for discussion. The class civility statement, "respect for individual differences and alternative viewpoints will be maintained at all times," also supports an inclusive class climate. According to Rose and Meyer, environments that offer multiple means of engagement through class 
climate, interaction, feedback, etc., will help the learners to connect with curriculum in meaningful ways so they can learn and will be motivated to want to learn (2002).

To address the performance indicator category interaction, one must visit multiple sections of the syllabus. In the learning outcomes section, the term peer-review is used twice. Viewing the course schedule, one immediately notes that the term peer-review appears 14 times throughout the schedule. The term peer-review appears once again in the learning assessment/evaluation segment. In total, the word peer-review emerges 17 times in the five-page syllabus. There is a great deal of emphasis placed on peer-review and peer interaction in the course. Peer learning, cooperative learning, group discussions, and other peer-based learning strategies are commonly used UDL interaction techniques (Rose \& Meyer, 2002).

Feedback too is emphasized in the syllabus with almost an entire page devoted to the description of "giving and receiving constructive feedback". The term feedback is used 12 times in the syllabus. Another theme that is important to mention is project scaffolding. The term draft appears in the course schedule three times. Students were given the opportunity to submit draft work before submitting their final product. Both the focus on feedback and use of scaffolding are consistent with Rose and Meyers UDL visions of providing ongoing, relevant feedback to students and allowing learners to become proficient with a single step of an assignment before they are expected to complete the entire task.

The performance indicator category accommodation is addressed in the instructor's syllabus via a disability statement. The statement gives students the information they need to contact the Office of Disability Services to make necessary arrangements and also invites them to contact the instructor. 
BIOL 593E course materials. Course materials from BIOL 593 were analyzed to see if the principles of Universal Design for Learning (UDL) were evident in the resources being used for the course. One can identify each of the principles.

Multiple means of representation. The performance indicator category delivery methods was addressed by the document, "Guidelines for Developing a Teaching Statement/Philosophy," modified from University of Wisconsin, Madison Wisconsin Program for Scientific Learning. The handout was provided to the students to guide the drafts of their teaching philosophy statements. The document was broken into eight sections: (a) definition of teaching and learning, (b) view of the learner, (c) view of the teacher, (d) goals and expectations of the student-teacher relationship, (e) teaching methods, (f) learning assessment, (g) professional development, and (h) organization of the statement. In the teaching methods discussion boxes, writers are encouraged to discuss or "clearly demonstrate evidence of the ability to use a wide variety of teaching strategies," which is consistent with UDL's multiple methods of representation (Rose \& Meyer, 2002).

Multiple means of expression. The assessment indicator category was also addressed by the Guidelines for Developing a Teaching Statement/Philosophy handout. As previously stated, the document was broken into eight sections: (a) definition of teaching and learning, (b) view of the learner, (c) view of the teacher, (d) goals and expectations of the student-teacher relationship, (e) teaching methods, (f) learning assessment, (g) professional development, and (h) organization of the statement. In the learning assessment sections, the writer is encouraged to show evidence of the ability to employ a variety of assessment strategies. This is consistent with Rose and Meyers (2002) UDL and aligns with multiple methods of expression. 
Multiple means of engagement. The teachable unit rubrics addressed the principle multiple means of engagement in two of the performance indicator categories. First, interaction was addressed as students were asked to determine if the activity "engaged a variety of students". This facet of the rubric dealt directly with engagement and also a diversity of learners in the classroom, both of which relate specifically to UDL (Rose \& Meyer, 2002). Additionally, students are asked to determine if the activity provided feedback to both the instructor and the student about student learning. This too is consistent with the UDL ideology that students need immediate and consistent feedback so they can become self-regulated learners who are able to correct their errors and learn from mistakes (Rose \& Meyer, 2002).

BIOL 115 student responses. As of August 2009, 33 respondents from the 220 e-mail surveys sent were received for a response rate of $15 \%$. Due to the nature of the study and the data being collected, the low response rate was of no consequence, as the researcher was using the survey to collect structured interview data and a random population of students willing to participate beyond the initial survey if necessary.

The questions were constructed to address both research questions (a) how and to what extent Universal Design for Learning (UDL) techniques are being implemented in the college classroom and (b) what are student perceptions of how Universal Design for Learning techniques affect their learning.

The first set of questions was included to collect demographic data about the students. Students were first asked to provide information about their gender, year in college, and age. They were then asked to identify if they were a student with a disability, if English was a second language, and/or if they were an Honors student. These questions were all structured for closed 
responses. Finally, students were asked to describe their race/cultural background and provide their major.

The next six questions were written to revolve around the three basic principles of Universal Design for Learning (UDL) (a) multiple methods of information presentation, (b) multiple methods for students to demonstrate their acquisition of skills and knowledge, and (c) multiple methods of engaging student motivation and interaction with the curriculum (Rose \& Meyer, 2002). The two questions immediately following were designed to provide students freedom to respond in a multitude of approaches that might present data about any of the UDL principles, student perceptions, or present uncultivated information for further research. The last two questions were asked to collect information about student perceptions of the course.

In addition to the questions discussed above, two questions were asked about students' grades in the course. The respondents were asked what grade they received at midterm and also what grade they had received at the conclusion of the course. As shared in the discussion of the structured interview questions, the rationale for inclusion of these questions was threefold. First, the collection of data at two points allows one to identify student growth or decline from midterm to final grade reports. While this small piece of data regarding only one student might not have value, trends can be identified as the larger group is analyzed. Next, many research studies have been done that indicate a direct correlation between academic performance and attitude about a subject area or course. Grades might serve as a predictor of learner perceptions, behaviors, and attitudes. Finally, grades could help us identify outliers in data. If a student responds to the questions with responses that are extremely different from their peers, and reports that he/she is failing the course, the data may be skewed due to excessive absences or 
having not ever attended the course. The final question asked students if they would be willing to participate in an interview.

Table 11 provides the research question, the question structured to address the research area, and the specific principle upon which the interview question concentrates.

Table 11

BIOL 115 E-mail Survey Questions

\begin{tabular}{|c|c|c|}
\hline Research Question & Interview Question & Principle/Category \\
\hline \multirow{6}{*}{$\begin{array}{l}\text { How and to what extent are } \\
\text { UDL techniques being } \\
\text { implemented in the college } \\
\text { classroom? }\end{array}$} & $\begin{array}{l}\text { In BIOL } 115, \text { how did the } \\
\text { instructor present } \\
\text { information to the class? }\end{array}$ & Multiple means of representation \\
\hline & $\begin{array}{l}\text { What instructional } \\
\text { technologies were used } \\
\text { during BIOL } 115 \text { lectures? }\end{array}$ & Multiple means of representation \\
\hline & $\begin{array}{l}\text { Describe your level of } \\
\text { interest in BIOL } 115-\text { did } \\
\text { you enjoy attending the } \\
\text { course? How did the } \\
\text { instructor keep you } \\
\text { motivated? }\end{array}$ & Multiple means of engagement \\
\hline & $\begin{array}{l}\text { How did you receive } \\
\text { feedback on your } \\
\text { assignments? }\end{array}$ & Multiple means of engagement \\
\hline & $\begin{array}{l}\text { In what ways were you } \\
\text { expected to demonstrate } \\
\text { your understanding of the } \\
\text { material? (In other words, } \\
\text { what was your grade based } \\
\text { upon?) }\end{array}$ & Multiple means of expression \\
\hline & $\begin{array}{l}\text { Were the instructor's } \\
\text { expectations consistent with } \\
\text { the learning objectives } \\
\text { stated in the course } \\
\text { syllabus? }\end{array}$ & Multiple means of representation \\
\hline \multirow[t]{2}{*}{$\begin{array}{l}\text { What are students' perceptions } \\
\text { of how UDL techniques affect } \\
\text { their learning? }\end{array}$} & $\begin{array}{l}\text { What did you like most } \\
\text { about BIOL } 115 ?\end{array}$ & $\begin{array}{l}\text { Multiple means of representation } \\
\text { /multiple means of engagement/ } \\
\text { multiple means of expression/ } \\
\text { perceptions }\end{array}$ \\
\hline & $\begin{array}{l}\text { What would you change } \\
\text { about BIOL } 115 ?\end{array}$ & $\begin{array}{l}\text { Multiple means of representation } \\
\text { /multiple means of engagement/ }\end{array}$ \\
\hline
\end{tabular}




\begin{tabular}{ll}
\hline & $\begin{array}{l}\text { multiple means of expression/ } \\
\text { perceptions }\end{array}$ \\
\hline How would you describe & Perceptions \\
BIOL 115 in comparison to & \\
other courses you have & \\
taken or are currently taking & \\
at the institution? How are & \\
they similar? How are they & \\
different? & \\
\hline Do you feel you learned & Perceptions \\
less/the same/or more in & \\
BIOL 115 than in other & \\
courses at the institution? & \\
Why or why not? Please & \\
explain. & \\
\hline
\end{tabular}

Note. Students were also asked for demographic information and questions about their midterm grade and what final grade they expected to receive for the course. The rationale for the inclusion of these questions is explained in the narrative.

The student population who responded to the e-mail survey was diverse. As one can see in Table 12, almost twice as many females responded as males and the majority of the respondents were freshmen between 18 and 22 years of age. The number of freshmen responses was anticipated. BIOL 115 is an introductory course designed to present the principles of biology for students who intend to enroll in the four-course, integrated sequence of courses that are required of many majors at the university. The number of female respondents versus male respondents may have been due to the slightly higher proportion of females enrolled in the course, but this is impossible to determine. Seven of the students who responded were upperclassmen and one respondent claimed the status 'other' for year in college. Only a single student identified him/herself as a non-traditional student between the ages of 45-60. However, 4 or $12 \%$ of the respondents stated that they were students with a disability, the same number identified themselves as individuals for whom English was a second language, and 10 or 30\% stated that they were Honors students. Additionally, $18 \%$ of the respondents classified themselves as belonging to underrepresented populations (Asian, Hispanic, Native American, or 
African American). Considering that the institution's total percent of students of color is currently at only 9\%, according to the institution's Program Coordinator for Minority Recruitment, this number was impressive for a single classroom (see Table 13). Moreover, one might note that seven of the respondents did not provide an answer in response to the question of race/ethnicity. Therefore, the percentage of underrepresented populations may have been higher. Also, the students who responded came from a range of majors and colleges.

Table 12

BIOL 115 Student Demographic Data

\begin{tabular}{|c|c|c|c|c|}
\hline \multicolumn{5}{|l|}{ Variable } \\
\hline Gender & 12 male & 21 female & & \\
\hline Year & $23 \mathrm{fr}$. & $1 \mathrm{jr}$ & $1 \mathrm{sr}$. & 1 other \\
\hline Age & $30 / 18-22$ yrs. old & $\begin{array}{l}1 / 45-60 \text { yrs. } \\
\text { old }\end{array}$ & & \\
\hline Disability & 27 false & 4 true & & \\
\hline ESL & 27 false & 4 true & & \\
\hline Honors & 21 no & 10 yes & & \\
\hline Race & $\begin{array}{l}\text { Caucasian/White } \\
\text { Asian } \\
\text { Middle Eastern } \\
\text { Hispanic } \\
\text { Native American } \\
\text { Black/African Am } \\
\text { No response }\end{array}$ & rican & $\begin{array}{l}19 \\
3 \\
1 \\
1 \\
1 \\
1 \\
7 \\
\end{array}$ & \\
\hline Majors & $\begin{array}{l}\text { Animal and nutriti } \\
\text { Animal and veterir } \\
\text { Athletic training } \\
\text { Biology/pre } \\
\text { Chemical engineer } \\
\text { Chemistry } \\
\text { Computer enginee } \\
\text { Forensics/pre }\end{array}$ & $\begin{array}{l}\text { nal science } \\
\text { ary science } \\
\text { ng } \\
\text { ng }\end{array}$ & $\begin{array}{l}1 \\
1 \\
1 \\
7 \\
1 \\
5 \\
1 \\
3\end{array}$ & \\
\hline
\end{tabular}




\begin{tabular}{ll}
\hline Forensic chemistry & 1 \\
Medical technologies & 1 \\
Pharmacy/pre & 6 \\
Psychology & 2 \\
Undecided & 1 \\
No response & 2 \\
\hline
\end{tabular}

Table 13

Underrepresented Populations in 2009 at the Institution of Higher Education

\begin{tabular}{lll}
\hline Population & Number of students on campus & Percentage \\
\hline African American & 900 & 3 \\
\hline Latino & 650 & 2 \\
\hline Asian American & 500 & 2 \\
\hline Pacific Islander American & 30 & 1 \\
\hline Native American & 75 & 1 \\
\hline $\begin{array}{l}\text { Students who identify with two } \\
\text { or more races }\end{array}$ & 500 & 2 \\
\hline Total students of color & 2500 & 9 \\
\hline
\end{tabular}

Note. Data provided by the Undergraduate Student Recruitment Office at the postsecondary institution in West Virginia where the case study occurred.

While 33 responses were received, two of the respondents did not provide complete demographic information and therefore were not included in all the numbers. However, the respondents did provide reactions to many of the open answered questions and one was willing to be interviewed at a later date to provide additional information.

Multiple means of representation. In response to the question regarding how the instructor presented information to the class, the majority of respondents submitted multiple answers or lists. One student responded specifically that the instructor used a variety of different methods to deliver information with in-class lectures being her primary format. Another young woman wrote about the group activities done during class and she discussed that often the lectures and activities were used to present and support information that was important to know but did not come from the textbook. Three students identified active learning by name. The following were identified as delivery methods used by the instructor: PowerPoint presentations 
(listed by 21 students), lecture (listed by 10 students), discussion (listed by six students), group activities (listed by five students), active learning activities (listed by three students), in-class activities (listed by two students), and clicker questions (listed by two students).

Clickers were the most frequently repeated response to the question asking students to identify what instructional technologies where used in their BIOL 115 lectures. The next most often identified was Microsoft PowerPoint, followed by the microphone and online homework. Once more, the majority of respondents provided multiple answers to this query. The following were identified as information resources and technology used in the instructor's classroom: 21 students listed Clickers, 14 students listed Microsoft PowerPoint, six students listed online homework, three students listed Masteringbio.com, three students listed an overhead projector, and instructional videos, a laser pointer, and YouTube were each listed by one student.

With regard to adherence to stated learning objectives, twenty-four of the respondents said yes, they felt the instructor's expectations were consistent with the learning objectives stated in the course syllabus. One responded stated, "Yes, the instructor made the learning objectives clear before almost every chapter." Three respondents said no, they did not feel the instructor's expectations were consistent with the learning objectives stated in the course syllabus, and three of the students provided responses to the questions that were not relevant to the inquiry. One of the three responded with the answer - not applicable. Another said he did not understand the question. As for the final four respondents, one said she was "close," one replied "slightly," and the other two did not respond at all.

Multiple means of expression. When asked in what ways were you expected to demonstrate your understanding of the material, respondents' reactions varied radically. Some of the students continued to provide lists. Three of the students stated that their grade was primary 
based upon exams. A handful of students wrote that being able to think logically and make "big picture" connections, not just memorizing facts for an exam, was an area they felt they were assessed on during BIOL 115. The following were identified by BIOL 115 students as means of expression/assessment methods used by the instructor: exams (listed by 30 students), in-class and online quizzes (listed by 17 students), homework (listed by 13 students), clicker questions (listed by 12 students), lab grades (listed by six students), attendance (listed by five students), group work (listed by five students), participation (listed by four students), E-campus assignments (listed by three students), and extra-credit questions (listed by one student).

Multiple means of engagement. According to the respondents, the instructor had multiple methods for keeping the class engaged. Six of the respondents described the class climate as fun. Students stated that they enjoyed the high level of interaction they had with their peers and with the instructor. Three others described the class environment having a friendly, relaxed mood. A few of the respondents wrote several sentences about how they valued that the instructor interacted constantly with the class.

Of the 33 students who responded, 24 , or $72 \%$ responded that they enjoyed attending the course. Respondents stated that they enjoyed the way information was presented, class interaction and group activities made class fun, and they found that class was never boring. "I enjoyed the class very much - missed very few classes - the professor had us interacting with her so much, the class was never boring," said a respondent. Another said, "Though I did not have a large interest in biology, I enjoyed the class activities and group work. I become interested in the class and enjoyed that I could apply what I learned to other subjects." Students said that they were motivated by her teaching strategies, her enthusiasm, and because she forced them to develop a sense of logic over pure memorization. "It was my favorite class of the 
semester. She taught us to actually understand the information, not just memorize it. She kept me motivated by making me think about things logically and in depth instead of just showing us the information. She made the learning actually fun," said one of the respondents. One student specifically stated that "the course was engaging" and this kept her motivated to learn.

Nine respondents, or $27 \%$ of the respondents, stated that they did not enjoy attending the course. Two of the respondents stated that were not motivated because they did not enjoy the material. One stated disinterest because biology has nothing to do with forensic science. Two other respondents stated that they were not motivated in the course because, "the instructor forced the students to learn how to teach themselves". One respondent stated a preference for a traditional lecture to increase motivation. The remaining respondents expressed that they did not enjoy attending and that they were not motivated, but provided no rationale for their response.

The final question specifically targeted at the principle of engagement, asked respondents to share how they received feedback on their assignments. Again, the majority of the students responded with multiple answers or lists. A few provided a single answer. Two respondents stated that they did not receive any feedback. The following were identified by respondents as feedback methods used by the instructor: 14 students listed grades being posted on E-campus, 10 students listed visits during office, five students listed class averages being shared during lecture, four students listed E-campus homework quizzes, two students listed e-mailing the instructor, and one student listed reviewing assignments in class. One of the respondents wrote that they liked the homework quizzes on E-campus because students could retake them and continue to retake them until they figured out the correct answers. The student felt this allowed student to figure things out for themselves and improve. Another student also commented on the fact that 
the E-campus quiz scores were posted immediately upon completion so students could determine how they had done.

BIOL 115 syllabus. The BIOL 115 course syllabus was analyzed to identify how the principles of Universal Design for Learning (UDL) were applied to the design of the overall course structure. The BIOL 115 course syllabus can be examined in Appendix A.

Multiple means of representation. BIOL 115 was created to be an introductory course designed to present the principles of biology for students who intend to enroll in the four-course, integrated sequence of courses that are required of many majors at the university. In the syllabus, one can identify each of the principles and several of the indicator categories. In the course methods section of the syllabus, delivery methods are addressed. The instructor writes that minilectures, active learning, and group work will be her main delivery methods. This practice aligns with Rose and Meyer's (2002) belief that instructors should employ multiple techniques to meet the learning styles and needs of an entire diversity of learners in a classroom.

Also mentioned in the course methods section is the use of Clicker technology. The personal response system is described in a little more detail in the required material section. The BIOL 115 syllabus provides students with a list of the information resources and technology that will be used in the course. As one reads the syllabus, E-campus and online homework are mentioned in addition to the course textbook and $3 \times 5$ note cards. This practice is in alignment with multiple means of representation. Rose and Meyer (2002) are advocates for providing differentiated instruction so learners have multiple formats from which to learn.

Multiple means of expression. According to the BIOL 115 syllabus, students were expected to attend and participate in class. Attendance was assessed as part of the in class, nonexam grade that was $15 \%$ of a student's final grade. Additionally, students were given five 
exams that were a total of $62 \%$ of the final grade, and a lab grade that was $23 \%$ of the final grade. According to the syllabus, the non-exam grade was comprised of quizzes, homework, clicker questions, group exercises, and/or individual exercises. Providing students with several types of assignments throughout a semester to give learners the opportunity to demonstrate and practice what they know is consistent with UDL practices (Rose \& Meyer, 2002).

Multiple means of engagement. The principle multiple means of engagement is addressed by the syllabus in four of the five performance indicator categories. The disability statement inviting students to meet with the instructor to arrange accommodations addresses class climate as this encourages students to talk with the professor if they have special needs. The class civility statement, "respect for individual differences and alternative viewpoints will be maintained at all times," also is in alignment with class climate and encouraging inclusive practices (Rose \& Meyer, 2002).

The performance indicator category interaction is addressed in the syllabus by the stress on group work and group in-class activities. As previously stated, peer learning, cooperative learning, group discussions, and other peer-based learning strategies are commonly used UDL interaction techniques (Rose \& Meyer, 2002).

Formative assessment, mentioned by the instructor in the course method section of the syllabus, addresses the performance indicator category feedback. The instructor practices Scientific Teaching, which views formative assessment as a form of feedback used to help students correct their mistakes and help instructors adapt teaching methods to meet learner needs (Handelsman, et al., 2007). The Scientific Teaching view of formative assessment is consistent with how formative assessment is used by practitioners of UDL (Rose \& Meyer, 2002). 
The performance indicator category accommodation is addressed in the instructor's syllabus through the inclusion of a disability statement. The statement gives students the information they need to contact the Office of Disability Services to make necessary arrangements and also invites them to contact the instructor.

Changes over time. Using syllabi from BIOL 115 and BIOL 1202, a similar level biology for science majors course taught by the instructor at Louisiana State University, one is able to identify a few modifications in instructions between 2007 and 2009. Because no syllabi were provided prior to 2004, when the instructor began using Scientific Teaching, creating a complete timeline of specific course modifications is impossible.

The primary area of change occurred in the instructor's grading policy and in how students were assessed in the course. Students in BIOL 1202 earned their final course grade based on exam scores and homework. Exam scores accounted for $84 \%$ of the total course grade and the remaining 16\% was homework scores. Students enrolled in BIOL 115 earned their final course grade based on exam scores, lab work, and non-exam work. Exam scores accounted for $62 \%$ of the total course grade, and the remaining $38 \%$ included lab activities and non-exam work. The grading policy in the BIOL 115 syllabus provides more detailed information and does not use all capital letters that appear to be appear to be yelling at the audience, therefore, it seems less harsh. In the BIOL 1202 syllabus, the instructor states that she does not negotiate grades. She says this in bold and in all capital letters at the end of a very brief sentence regarding grades. The BIOL 115 syllabus provides a bit more detail regarding lecture and lab and does not include a nonegotiation sentiment.

Another difference noted was in the attendance policy. Students in the BIOL 1202 course were permitted to drop six participation assignments due to University-approved absences. In 
BIOL 115, students were allowed 10 dropped participation assignments due to Universityapproved absences and the syllabus states that these drops will not affect the student's grade in the course.

The BIOL 115 syllabus has a small clip art graphic in the top right hand corner of the first page that depicts a student playing with some lab equipment and exclaiming "whoa" with a block type that states "way cool science stuff". While a minor detail, this small element adds a bit of levity to the document that is obviously not present in the others.

BIOL 115 course materials. The instructor provided a generous amount of material from both BIOL 115 and BIOL 1202 for review, however, all the documents were generated after she had adopted Scientific Teaching in 2004 and so the creation of a timeline of specific course modifications is impossible. Additionally, without seeing these materials in use, there is no way of knowing if any or all the principles of UDL were met by their use. For the record, the instructor used a variety of movie files, PowerPoint files, and various assignments that included online simulations. She also provided sample of some of her online quizzes, and make up exams.

\section{Research question: What are students' perceptions of how UDL techniques affect their learning?}

Analysis table description. Table 14 addresses the research question (b) what are student perceptions of how UDL techniques affect their learning. Table 14 provides a visual representation of the student perceptions related to UDL techniques. This table represents the first set of reduced data, which provides an overview of the wide range of student perceptions. Table 16, provided in the Summary of this Chapter, presents the second set of data reduced from Table 14. Column one, of Table 14, is separated into the questions that were asked of BIOL 593 and BIOL 115 students. Column two shows the category of the question. The third column 
indicates which group of student responses can be read in column four. The responses that are italicized in column four are those that directly relate to the principles of UDL or fall into the performance indicator categories.

Table 14

What are students' perceptions of how UDL techniques affect their learning?

\begin{tabular}{|c|c|c|c|}
\hline $\begin{array}{l}\text { Question Asked } \\
\text { to Students }\end{array}$ & Category & Course & Student Responses \\
\hline \multirow[t]{2}{*}{$\begin{array}{l}\text { What did you } \\
\text { like most about } \\
\text { the course? }\end{array}$} & $\begin{array}{l}\text { Multiple means of } \\
\text { representation/multiple } \\
\text { means of expression/ } \\
\text { multiple means of } \\
\text { engagement/perceptions }\end{array}$ & $\begin{array}{l}\text { BIOL } \\
593\end{array}$ & $\begin{array}{l}\text { Amount of feedback given } \\
\text { Class atmosphere } \\
\text { Discussion } \\
\text { Learning active learning methods } \\
\text { to engage students } \\
\text { Learning the language of } \\
\text { education } \\
\text { Modeling the methods } \\
\text { Practicing teaching } \\
\text { Relevance of information learned } \\
\text { Student-centered nature of course }\end{array}$ \\
\hline & & $\begin{array}{l}\text { BIOL } \\
115\end{array}$ & $\begin{array}{l}\text { Active Learning } \\
\text { All of it } \\
\text { Biology itself } \\
\text { Class was fun \& interesting } \\
\text { Clicker questions } \\
\text { Could miss } 10 \text { classes w/o penalty } \\
\text { Detailed review guide for exams } \\
\text { The instructor } \\
\text { The Instructor's available during } \\
\text { office hours } \\
\text { The instructor challenged us to } \\
\text { think } \\
\text { The instructor's enthusiasm } \\
\text { The instructor's willingness to } \\
\text { stay after class to answer } \\
\text { questions } \\
\text { E-campus assignments } \\
\text { Evolution } \\
\text { Extra credit for participation } \\
\text { Flexible times for taking exams } \\
\text { Genetics/DNA } \\
\text { Grade I received } \\
\text { Group activities }\end{array}$ \\
\hline
\end{tabular}




\begin{tabular}{|c|c|c|c|}
\hline \multirow{3}{*}{$\begin{array}{l}\text { What would you } \\
\text { change about the } \\
\text { course? }\end{array}$} & \multirow{3}{*}{$\begin{array}{l}\text { Multiple means of } \\
\text { representation/multiple } \\
\text { means of expression/ } \\
\text { multiple means of } \\
\text { engagement/perceptions }\end{array}$} & & $\begin{array}{l}\text { How information was presented } \\
\text { Interactivity } \\
\text { Labs } \\
\text { Learned a lot } \\
\text { Leaving the class } \\
\text { Meeting new people/friends } \\
\text { Music before class } \\
\text { Nothing } \\
\text { Online exams } \\
\text { Review for exams } \\
\text { Teaching methods } \\
\text { Topics themselves } \\
\text { Understanding versus } \\
\text { memorization } \\
\text { Unlimited opportunities on online } \\
\text { quizzes }\end{array}$ \\
\hline & & $\begin{array}{l}\text { BIOL } \\
593\end{array}$ & $\begin{array}{l}\text { Define course terminology earlier } \\
\text { in the semester } \\
\text { Nothing } \\
\text { Publicize the course more } \\
\text { Solid/defined grades on every } \\
\text { project }\end{array}$ \\
\hline & & $\begin{array}{l}\text { BIOL } \\
115\end{array}$ & $\begin{array}{l}\text { A little more lecture } \\
\text { Different instructor } \\
\text { Do not cover so much in one } \\
\text { semester } \\
\text { Everything } \\
\text { Exams on paper instead of online } \\
\text { Have the students talk less } \\
\text { Labs } \\
\text { Less group work } \\
\text { Make the class smaller } \\
\text { More detailed syllabus } \\
\text { More focus on the textbook } \\
\text { More Masteringbio assignments } \\
\text { More material to study } \\
\text { No Clickers } \\
\text { Nothing } \\
\text { Offer lecture at night } \\
\text { Offer traditional lecture } \\
\text { Professor should not assume } \\
\text { we've had biology before } \\
\text { Post slides before class } \\
\text { Tests were too hard } \\
\text { The order in which material is } \\
\text { covered }\end{array}$ \\
\hline
\end{tabular}




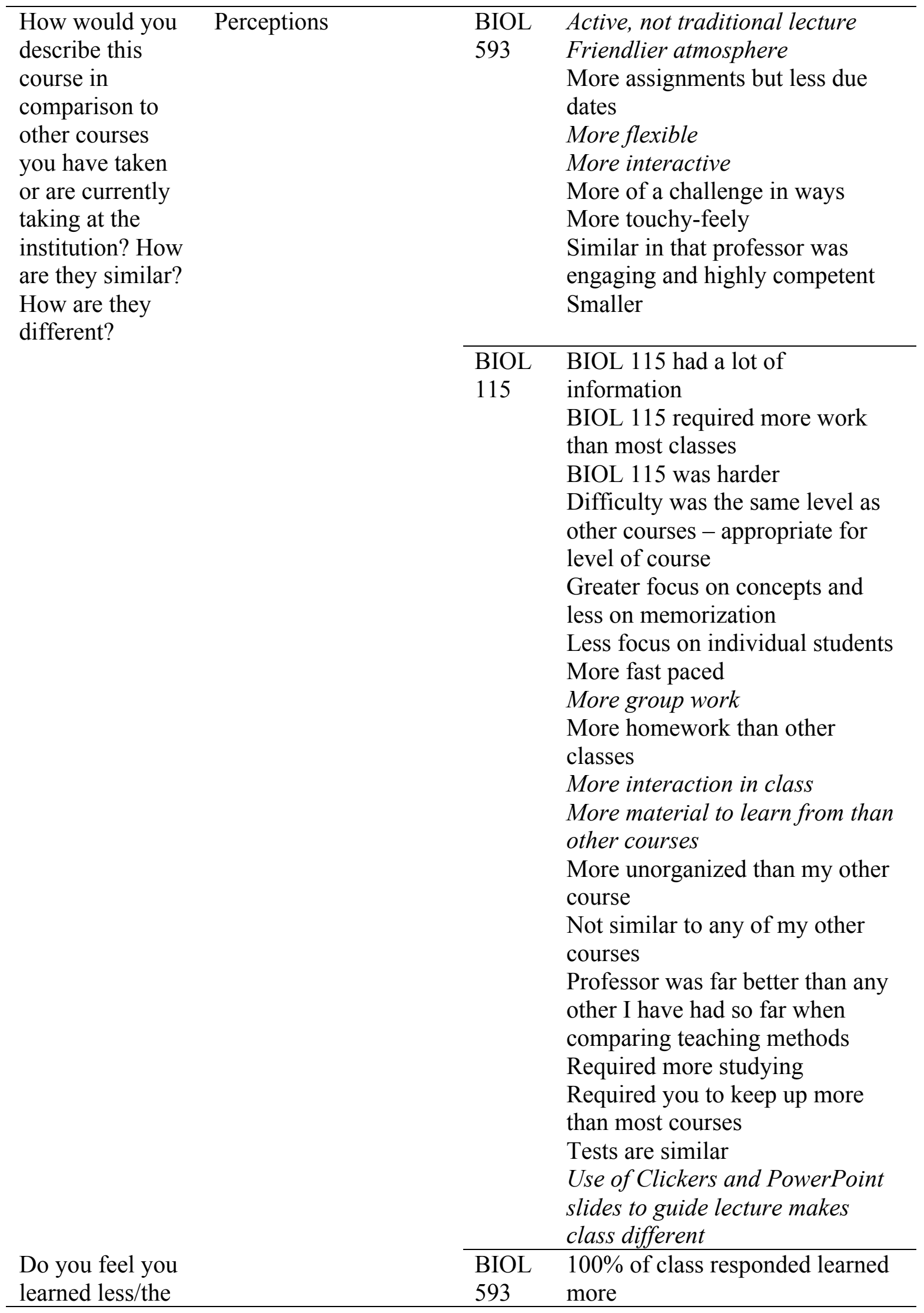




\begin{tabular}{|c|c|c|}
\hline $\begin{array}{l}\text { same/or more in } \\
\text { this course than } \\
\text { in other courses } \\
\text { at this } \\
\text { institution? Why } \\
\text { or why not? } \\
\text { Please explain. }\end{array}$ & $\begin{array}{l}\text { BIOL } \\
115\end{array}$ & $\begin{array}{l}\text { Class was fun } \\
\text { Could immediately use the } \\
\text { concepts learned in class } \\
\text { High level of activity } \\
\text { Most I've ever learned in any } \\
\text { course at this institution } \\
\text { Nature of the course } \\
\text { Variety of materials and } \\
\text { discussions } \\
17 \text { responded learned MORE } \\
\text { Concepts not memorization } \\
\text { First biology course ever taken } \\
\text { Hands-on activities } \\
\text { Higher exam grades } \\
\text { Highly motivated } \\
\text { Learned how to think logically } \\
\text { Learned study skills and how to } \\
\text { learn } \\
\text { Leniency with assignments and } \\
\text { absences helped } \\
\text { Material covered in depth } \\
\text { PowerPoint slides } \\
\text { Teaching methods } \\
7 \text { responded learned LESS } \\
\text { Could not hear the instructor } \\
\text { Could not understand the teacher } \\
\text { Did not like teaching style } \\
\text { Did not like the instructor } \\
\text { Lecture } \\
\text { No relevance in my life } \\
\text { Too many PowerPoint slides with } \\
\text { only picture } \\
\text { Too many questions asked during } \\
\text { lecture } \\
6 \text { responded SAME } \\
\text { Had AP in high school and this } \\
\text { was not that different } \\
\text { Way less in labs, but more in the } \\
\text { class } \\
3 \text { did not answer the question }\end{array}$ \\
\hline
\end{tabular}

Note: Students were also asked about their midterm grade and what final grade they expected to receive for the course. The rationale for the inclusion of these questions is explained in the narrative discussion. 
BIOL 593 student interviews. Guided interviews were conducted with students enrolled in the instructor's Biology 593 course to address both research questions (a) how and to what extent Universal Design for Learning (UDL) techniques are being implemented in the college classroom and (b) what are student perceptions of how Universal Design for Learning techniques affect their learning. This section only focuses on the responses to the questions that answer the research question (b) what are student perceptions of how Universal Design for Learning techniques affect their learning. The others were discussed in the first section of this chapter.

Table 14 provides the interview question structured to address the research question, the category for each question, the group of students answering the question, and the students' responses for the set of questions.

Students were asked to identify what they most liked about BIOL 593 and what they would change about the course. These questions were asked to gather information from students regarding their perceptions of how UDL techniques affects their learning, gain insight about any of the facets of UDL, or discover what other phenomena might be exposed.

When asked what they liked most about the course, two of the students focused some of their response on the student-centered approach the instructor used with the class. One of these students stated that the discussion based nature of the course, the personal relevance of the material learned, and the amount of feedback provided were all facets of the course that she really liked. Another student declared that she has had several education courses where she has learned how not to lecture, but "the instructor practices what she preaches - she models" and this encouraged her to become more involved in this course than any other. Two of the students were very pleased they had the opportunity to practice teaching. For one, it was the first time they had been in front of a classroom. For another, she expressed that she enjoyed gaining experience with 
new active learning methods that she could employ to engage her students. One of the young women stated that she enjoyed being able to model all the techniques after reading about them. A student also mentioned that she liked learning the language of the education world so she will be well prepared for job interviews.

When asked how they would modify BIOL 593, defining course terminology earlier in the semester was a response provided by two students. Two students said they would have appreciated more defined, solid grades. One student offered that this course should be more widely publicized. She said that while this is a criticism with positive intent, she still feels that more students should be made aware of the course. One student said there was nothing she would change about the course.

Next, students were asked to compare BIOL 593 with other courses they have taken at the institution to establish if they identified with any of the UDL techniques used and what perceptions they held about these methods.

When asked how they would describe BIOL 593E in comparison to other courses at the institution, four of the five students focused their responses on lecture style differences. Students described BIOL 593 as a challenge, interactive, active, touchy-feely, and flexible versus other courses that are "more chalk talk" where professors are "rigid" and "all lecture". One student explained that most courses are set up in a fashion where students attend lectures, take notes, study, and then take tests to see what they know from the material. "This course was different because it was all active," she explained. Another student noted that the instructor "actually used the textbook and PowerPoint and e-Campus" all as different resources in the same course. One student mentioned that it was the smallest class she has taken and another stated that the course 
had a much friendlier atmosphere. One of the women stated that while she had more assignments, there were less dates, and she enjoyed the work she was doing.

All five of the students stated that they learned more in this class than in other courses at the institution when asked if they felt they had learned less/the same/or more in this course than in other courses at the institution. Three of the students stated that they learned more, and will retain the information more readily, because the information was relevant to them and they were able to immediately integrate what they were learning in class into their daily lives. One student stated that she learned more due to the nature of the course. Another student believes she learned more in this class than any other she has ever taken because of the variety of assignments, high level of activity, and the classroom discussions. The final student in the group found that she learned more because she took pleasure from the work. She said that even though there was constantly work to do for the course, she found that she really enjoyed all the experiences and had fun.

BIOL 115 student responses. Survey data and interview notes were collected to address both research questions (a) how and to what extent Universal Design for Learning (UDL) techniques are being implemented in the college classroom and (b) what are student perceptions of how Universal Design for Learning techniques affect their learning. Table 11 provides the research question, the question structured to address the research area, and the specific principle upon which the survey/interview question concentrates.

This section focuses only on the responses to the questions that answer the research question (b) what are student perceptions of how Universal Design for Learning techniques affect their learning. The others were discussed in the first section of this chapter. 
Respondents were asked to react to what they liked about BIOL 115, what they would change about BIOL 115, how they would compare BIOL 115 with other courses they have taken at the institution, and how much the felt they learned in BIOL 115 in comparison to other courses at the institution. These questions were posed to establish if respondents identified with any of the UDL techniques used and what perceptions, if any, were held about these methods.

When asked what they liked most about BIOL 115, the respondents had a variety of answers ranging from "all of it" to "nothing". Many students again presented multiple responses. Four students said the clicker questions were a favorite component of the course. This was the most frequent response. Three students specifically stated that the instructor's method of teaching was what they liked most about BIOL 115. One student commented that they wished the same teaching method used in BIOL 115 would carry into BIOL 117. One wrote, "I really enjoyed the group activities and having a group in lecture. The random people I met in my group turned out to be some of the people I study with the most now." Another student wrote, "A lot the teacher was interested and put a lot of time into the class to figure out what methods would work, gave extra credit for participation, gave unlimited opportunities for online quizzes, didn't penalize for having to miss a class - could miss 10 - was available for office hours, was willing to answer questions, and that she put out a detailed review guide for the tests." Three students wrote about group activities as their favorite part of BIOL 115. Two students focused on the music before class and how this helped to set "the right atmosphere" for class discussion and two others wrote about how they made new friends in BIOL 115. Two students specifically stated that what they liked most was the new active learning style. Other students focused on the instructor's availability, her enthusiasm, willingness to stay after class to answer questions, and various teaching methods she used during the class. One student said that he loved the level of 
interactivity in BIOL 115 . Twenty, or approximately $61 \%$, of the 33 responses provided for this answer relate to a strategy of UDL.

When asked what they would change about BIOL 115, eight students provided no response and many responses were repeated. Five students said they would change nothing about BIOL 115. Three respondents stated a desire for traditional lecture. Three students also had concerns about the exams in BIOL 115. Two students would prefer paper exams instead of online exams and a third student felt that the exams were too challenging. A couple of the respondents mentioned that the size of the class was an issue and two students stated that they would have liked PowerPoint slide material posted before class so they could prepare before class. The student who commented that there was too much group work stated, "it felt too much like high school, but the class was mostly freshmen, so this may have contributed, and I am sure the groups worked for them." Another respondent said that BIOL 115 needed a transition period where students could become comfortable with speaking during class, as most of the students were not accustomed to being asked to participate; they were only accustomed to listening. One student wrote that the instructor should not assume students have any background in biology. One student expressed that while pleased with the course, a little more lecture on certain subjects might have been beneficial at times. One student stated a hatred for the use of Clickers and said that the whole process of signing them out and putting them back took too much time away from class lecture. Ten, or approximately $48 \%$, of the 21 responses provided for this answer relate to a strategy of UDL.

When asked to describe BIOL 115 in comparison to other courses they have taken at the institution, there was some disagreement among student responses. Four respondents replied that BIOL 115 was similar to their other courses and at about the same difficulty level, four 
respondents stated that BIOL 115 took more time to study and was more work in comparison to other courses, and three students did not feel that BIOL 115 was like any of their other courses. Of the respondents who stated that BIOL 115 was difficult, one added that while more time was needed to study, the student also felt more was learned. Another stated that the curriculum suits the level of the course. The other two respondents were critical of the amount of information included on the exams and how the course was instructed. A student stated, "BIOL 115 was harder for me because of the way it was taught however, I have some courses this semester that are harder." The four who stated the course was similar added no details. Only one of the respondents who stated that BIOL 115 was unlike other courses provided a detailed explanation. The student stated that while a large lecture class was necessary for the course, "BIOL 115 was very different in that I have never had a huge lecture where the teacher actually got the people to participate and where it was fun to learn. Usually that rapport only happens in a small group setting." Two students focused on the greater level of interaction in BIOL 115 than in their other courses. Other respondents stated that BIOL 115 was different because it incorporated more group activities, use of Clickers and PowerPoint slides to guide lecture, and the instructor used different teaching methods.

Of the respondents, 17 (51.5\%) stated that they felt they learned more in BIOL 115 than in other courses at the institution, $7(21.2 \%)$ of the respondents stated they learned less, 6 $(18.1 \%)$ of the respondents stated they learned the same amount, and $3(.09 \%)$ did not respond. Of the students who responded that they learned more, a few declared this was due to the fact they were more likely to attend class to earn points for clicker questions and therefore ended up learning more in the process. A handful of respondents acknowledged a belief that the manner in which the material was presented helped them to learn the concepts for later application instead 
of merely memorizing facts for reproduction. One student stated, "The instructor took great pains to present the material in a way that made you question the concepts with a variety of teaching methods. The PowerPoint slides were also a big bonus - a good many teachers don't bother. Also, the ability to have a little leniency (able to delete 10 points for absences or missed work) but still demonstrate the concepts through group work or online quizzes, etc., was very helpful." Another student answered more because preparing for BIOL 115 taught the student how to study and how to do work for other classes. One student said he learned more because of the hands-on activities done in class and another said she learned more because she was highly motivated in BIOL 115.

Six of the seven students who responded that they learned less in BIOL 115 provided a rationale for their answer. One felt that too many questions were asked in class and therefore not enough time was spend covering material. Another felt that the teaching style used was not appropriate for the class and would have preferred a traditional lecture. Additionally, this student stated that the course was not relevant in life. Two students expressed their dislike for the instructor and their belief that she could not teach even if she did know the material. One respondent stated that she could not hear the instructor nor could she understand what she was saying. The final respondent said he felt he learned less because there were too many PowerPoint slides that only contained pictures without enough information.

Only two of the individuals who responded to having learned the same amount in BIOL 115 provided an explanation. One respondent shared that the biology labs were disorganized and needed more direction including goals and stated learning objectives. This respondent stated that if the lab experience were better, the answer would have been learned more. The other 
respondent stated that due to a high school AP course, BIOL 115 was not significantly differently enough to qualify for having learned more.

As previously mentioned, the respondents were asked to share their grades received at midterm and at the end of the semester. One trend was immediately evident. With the exception of three individuals who failed the course, and a few students who earned steady A's or B's throughout the semester, all of the students' scores improved from midterm to the final grade. No one who responded dropped from midterm to the final grade. Two of the three students who failed the course earned an $\mathrm{F}$ at both midterm and for the final grade. The third student did not report a midterm grade, only a final grade for the course.

When asked if willing to participate in an interview if additional information was needed, $23(70 \%)$ of the respondents said yes, 7 (21\%) said no, and 3 (9\%) replied maybe. Additional data was collected from a few of the respondents, but not all of the students were contacted a second time.

\section{Summary of Results}

\section{Research question: How and to what extent are UDL techniques being implemented in the college classroom?}

The three principles of design were met in the instructor's classroom (see Table 15). Though her pedagogy was Scientific Teaching, she met all of the criteria for the implementation of UDL except for knowledge of UDL's existence. Table 15 provides a summarization of the specific UDL techniques used in the classroom that met the standards established by the Center for Applied Special Technology (CAST). Table 15 represents a final data reduction to answer the first research question: How and to what extent is UDL being implemented in the college classroom? Columns one and two present the UDL principles and performance indicator 
categories. Column three presents a summary of the specific UDL techniques used in the instructor's classroom.

Table 15

Summary of Instructor's Implementation of UDL Techniques in the College Classroom

\begin{tabular}{|c|c|c|}
\hline UDL Principle & $\begin{array}{l}\text { Performance } \\
\text { Indicator Category }\end{array}$ & Specific Technique \\
\hline \multirow[t]{2}{*}{$\begin{array}{l}\text { Multiple means of } \\
\text { representation }\end{array}$} & Delivery methods & $\begin{array}{l}\text { - } \text { Addresses multiple learning styles } \\
\text { - } \quad \text { Delivers information in multiple } \\
\text { formats } \\
\text { - Expectations were consistent with } \\
\text { learning objectives stated in syllabus } \\
\text { - Presents material in consistent } \\
\text { method } \\
\text { - Uses a variety of teaching methods } \\
\text { - Use of visuals to enhance interest }\end{array}$ \\
\hline & $\begin{array}{l}\text { Information } \\
\text { resources and } \\
\text { technology }\end{array}$ & $\begin{array}{l}\text { Provides electronic equivalents of } \\
\text { class resources } \\
\text { - Required reading assignments (other } \\
\text { than textbook) available online } \\
\text { - Use of instructional technology } \\
\text { - Use of web page to provide course } \\
\text { materials }\end{array}$ \\
\hline $\begin{array}{l}\text { Multiple means of } \\
\text { expression }\end{array}$ & Assessment & 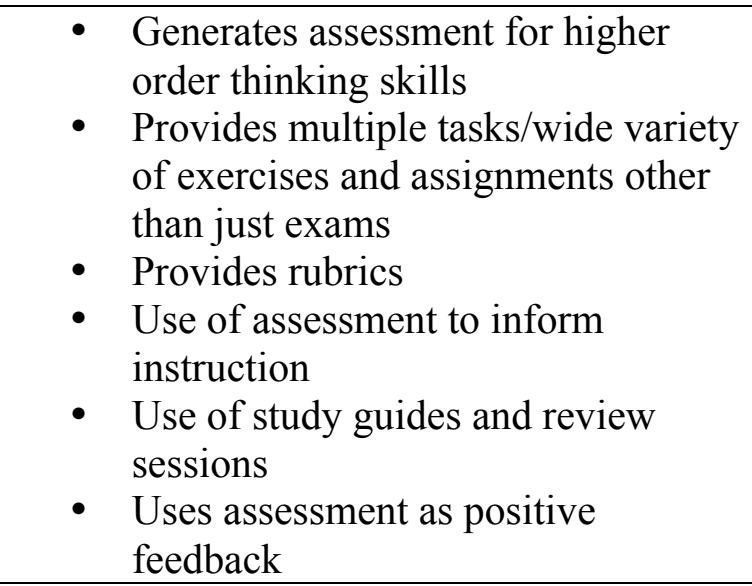 \\
\hline \multirow[t]{2}{*}{$\begin{array}{l}\text { Multiple means of } \\
\text { engagement }\end{array}$} & Class climate & $\begin{array}{l}\text { Approachable and available to } \\
\text { students } \\
\text { - Identifying students and their } \\
\text { interests } \\
\text { - Creates a class climate in which } \\
\text { diversity is respected }\end{array}$ \\
\hline & Interaction & $\begin{array}{l}\text { Expresses enthusiasm for topics } \\
\text { covered in course }\end{array}$ \\
\hline
\end{tabular}




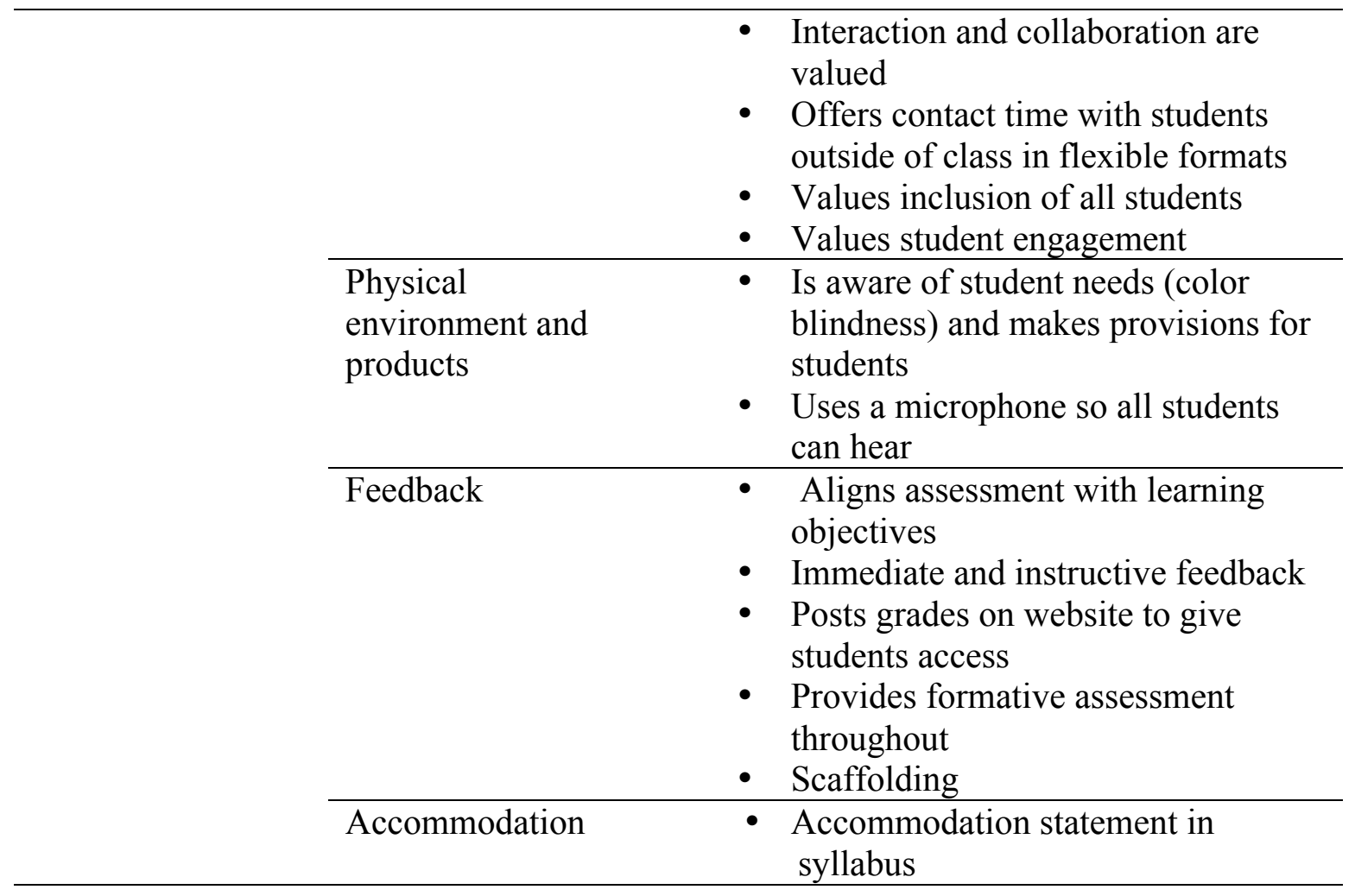

Multiple means of representation. In the category of delivery methods, active learning, group work and activities, discussion, clicker questions, case studies, field observations, and modeling, are categorized under 'uses a variety of teaching methods'. The use of lecture, graphics, and video, for example, can all be classified as 'delivers information in multiple formats'. An area stressed by virtually all pedagogies is consistency in delivery of message. According to students, and recorded during observation, material was delivered through the use of PowerPoint slides with lecture and discussion for reinforcement. The instructor then published the slides online to provide the students with electronic access to the materials at any time.

In addition to the PowerPoint slides, the instructor provided electronic equivalents of all class resources and made required reading assignments (other than the textbook) available online. The instructor used a variety of instructional technologies in the classroom including 
Clickers, YouTube and other various Internet sites, and videos, and she used E-campus and Blackboard to provide electronic access to materials and grades.

Multiple means of expression. The instructor believes in using assessment as positive feedback to provide students with corrective information so they can improve and fix their mistakes. She provides learners with a variety of tasks from writing assignments to practical projects that require higher order thinking skills in addition to exams. The instructor provides students with rubrics to guide their work. She posts online study guides and holds review sessions before exams.

Multiple means of engagement. The instructor is viewed as both approachable and available by her students. She is seen as being able to identify with her students and their interests. Additionally, diversity is a high priority in her classroom as is evidenced by the instructor's comments, course materials, and student comments.

Student's indicated that they felt the instructor was enthusiastic about the subject matter. The course was interactive, and collaboration, inclusion, and engagement were valued. Students stated the instructor was available outside of class and in a variety of formats including face-toface office meetings, and via e-mail, and telephone.

To address the physical environment and products, students reported that the instructor used a microphone when lecturing. Also, in her PowerPoint designs, the instructor included the spelled out names of colors with the use of color (when relevant) so students who may have colorblindness would not be at a disadvantage.

The instructor used scaffolding to tier projects so students could receive feedback and improve their work before final submission. Formative assessment was used throughout the 
course to provide students with immediate and instructive feedback so they could continually improve and learn from mistakes.

In this case study, the UDL framework complemented the Scientific Teaching pedagogy well. The two approaches blended seamlessly together due to their vast number of similarities including a constructivist approach to how students best learn and learner-centered philosophies. The instructor used scaffolding, focused on student diversity, determined goals before designing activities, and believed in the need for multiple tasks, multiple teaching approaches, and engagement.

\section{Research question: What are the student perceptions of how UDL techniques affect their} learning?

The majority of students liked the variety provided through the use of UDL techniques and $57.9 \%$ of the students responded that they learned more in their classes (BIOL 115 and BIOL 593) than in other classes in which they were enrolled at the same institution. Overall, students reported a higher frequency of positive experiences with and perceptions of UDL techniques than negative experiences or perceptions. Table 16 summarizes student perceptions of UDL techniques and how they affect their learning. Columns one presents the question posed to the student. Columns two and three present the UDL principles and performance indicator categories. Column four presents a summary of student responses. 
Table 16

Summary of student perceptions of UDL techniques and how they affect their learning

\begin{tabular}{|c|c|c|c|}
\hline $\begin{array}{l}\text { Questions Asked to } \\
\text { Students }\end{array}$ & UDL Principle & $\begin{array}{l}\text { Performance } \\
\text { Indicator Category }\end{array}$ & Responses \\
\hline \multirow[t]{6}{*}{$\begin{array}{l}\text { What did you like } \\
\text { most about the } \\
\text { course? }\end{array}$} & $\begin{array}{l}\text { Multiple means of } \\
\text { representation }\end{array}$ & Delivery methods & $\begin{array}{ll}\text { - } & \text { Active Learning } \\
\text { strategies } \\
\text { - } \quad \text { Variety of formats } \\
\text { used }\end{array}$ \\
\hline & & $\begin{array}{l}\text { Information resources } \\
\text { and technology }\end{array}$ & $\begin{array}{ll}- & \text { E-campus } \\
& \text { homework } \\
\text { - } & \text { Online quizzes }\end{array}$ \\
\hline & $\begin{array}{l}\text { Multiple means of } \\
\text { expression }\end{array}$ & Assessment & $\begin{array}{ll}\text { - } & \text { Amount of } \\
& \text { feedback } \\
\text { - } & \text { Detailed review } \\
\text { - } & \text { Flexible exam } \\
& \text { times } \\
\text { - } & \text { Leniency } \\
\text { - } & \text { Relevance of } \\
& \text { information } \\
\end{array}$ \\
\hline & $\begin{array}{l}\text { Multiple means of } \\
\text { engagement }\end{array}$ & Class climate & $\begin{array}{ll}\text { - } & \text { Class atmosphere } \\
\text { - } & \text { Instructor's } \\
\text { - } & \text { Inthusiasm } \\
\text { - Interactivity }\end{array}$ \\
\hline & & Interaction & $\begin{array}{ll}\text { - } & \text { Instructor } \\
\text { availability } \\
\text { - } & \text { Student-centered } \\
\text { nature of the } \\
\text { course }\end{array}$ \\
\hline & Perception & & $\begin{array}{l}\text { - Challenged to } \\
\text { think - } \\
\text { understanding } \\
\text { versus } \\
\text { memorization }\end{array}$ \\
\hline \multirow[t]{2}{*}{$\begin{array}{l}\text { What would you } \\
\text { change about the } \\
\text { course? }\end{array}$} & $\begin{array}{l}\text { Multiple means of } \\
\text { representation }\end{array}$ & Delivery methods & $\begin{array}{ll}\text { - } & \text { More focus on the } \\
\text { textbook } \\
\text { - } & \text { More traditional } \\
\text { lecture } \\
\text { - } & \text { Post PowerPoint } \\
\text { slides before class } \\
\text { - } & \text { Provide a more } \\
\text { detailed syllabus }\end{array}$ \\
\hline & & $\begin{array}{l}\text { Information resources } \\
\text { and technology }\end{array}$ & $\begin{array}{ll}\text { - } & \text { Exams on paper } \\
\text { instead of online } \\
\text { - } \quad \text { More study }\end{array}$ \\
\hline
\end{tabular}




Multiple means of Assessment
expression

Multiple means of Interaction
engagement

materials

- Defined grades on every project

- More online assignments

- Make the class smaller

- Less group work

- Less student led discussion

\section{Perceptions}

- Nothing

$\begin{array}{ll}\text { How would you } & \text { Positive } \\ \text { describe this course in } & \text { Perceptions } \\ \text { comparison to other } \\ \text { courses you have } \\ \text { taken or are currently } \\ \text { taking at this } \\ \text { institution? How are } \\ \text { they similar? How are } \\ \text { they different? }\end{array}$

- Instructor should not assume prior knowledge

- More flexibility with times course is offered for nontraditional students

- Greater focus on concepts and less on memorization

- More flexible

- More interactive

- More instructional materials provided

- Challenging and engaging

- Use of Clickers and other technology

- More social atmosphere

- Required more studying

- More work than most courses

- Harder than most courses

Neutral perceptions

- Not similar to any other course

Do you feel you Perceptions: More $22 / 38$ students or learned less/the $57.9 \%$

course than in other course at this institution? Why or
- Active learning

- Course was fun

- Highly motivated

- Instructional technology

- Interactivity 
why not? Please

explain.

- Relevant material

- Variety of materials and discussion

\begin{tabular}{l} 
Perceptions: Same \\
$6 / 38$ students or \\
$15.8 \%$ \\
\\
\hline Perceptions: Less \\
$7 / 38$ students or \\
$18.4 \%$
\end{tabular}

- More in class/less in lab

- Not that different from AP

- Could not hear the instructor

- Could not understand the instructor

- Desired additional delivery formats

- Did not see relevance

- Displeased with teaching methods

Note: Three students did not respond to the last question, so the percentages do not total $100 \%$.

Likes. Students indicated that they liked UDL techniques that fit in to each of the UDL principle areas. In terms of multiple means of representation, many students remarked that they liked active learning strategies like Clickers, group work, discussion, and the modeling used by the instructor. Students were pleased with the online homework and posting of grades.

To address multiple means of expression, students liked the leniency of being able to drop their ten lowest homework grades and being able to retake online quizzes until they succeeded. Students liked having review sessions and study guides available, as well as receiving a lot of feedback.

Students liked the class atmosphere, the instructor's enthusiasm for the course and availability, the student-centered nature of the course, and the level of course interaction. These factors were the primary means of engagement according to the students. 
Some students also remarked that they were pleased that the information being presented was relevant and that they were challenged to think. They enjoyed learning to understand the material versus merely memorizing notes for an exam.

Dislikes. Students indicated changes related to each of the UDL principle areas. In terms of multiple means of representation, a student requested a more detailed syllabus be prepared for the course instead of relying on e-mail updates to provide homework information. A couple of students requested the PowerPoint slides be posted prior to class. Addressing multiple means of expression, a few students wanted more study materials and paper exams instead of online exams. A couple of students asked for defined grades on every projects and more online assignments. A couple of students addressed the principle multiple means of engagement by stating their desire for less interaction. One student suggested making the class smaller.

One student suggested that there should be more flexibility in when courses are offered to accommodate non-traditional students' schedules. Another student suggested that the instructor should not assume prior knowledge. Finally, a handful of students responded that they would change nothing about the course.

Comparisons. The majority of students compared the courses from this instructor favorably against other courses in which they were currently enrolled or had completed at the same institution. Students described these courses as more flexible, more interactive, and as having more instructional materials provided for them than in other courses.

Roughly $58 \%$ of students included in the study, or 22 of 38 , stated that they learned more in BIOL 115 and BIOL 593 than in other courses at the same institution. Students attributed this to a number of factors including active learning, the use of instructional technology, and the variety of materials. 
Approximately $16 \%$ of the students included in the study, or 6 of 38 , reported that they learned about the same amount in this course as in other courses at the same institution. The reasons they provided were related to AP coursework completed in high school and the lab done outside of the course.

A little more than $18 \%$ of the students included in the study, or 7 of the 38 , stated that they learned less in this course than in other courses at the same institution. Students attributed this to not being able to hear the instructor, inability to understand the instructor, a desire for additional delivery formats, not seeing relevance in the material, and a displeasure with the teaching methods.

Chapter 5 provides (a) interpretations of the data, (b) significance of the study, (c) recent literature, (d) implications, (e) recommendations for best practices in teaching, (f) limitations, and $(\mathrm{g})$ suggestions for future research. 


\section{Chapter 5}

\section{Conclusions}

While the body of literature on Universal Design for Learning (UDL) continues to increase, adequate research has not been conducted on the application of UDL techniques in higher education. In an effort to expand the current body of knowledge and literature possessed on this topic, a case study was conducted to answer to the following research questions: (a) how and to what extent are Universal Design for Learning techniques being implemented in the college classroom, and (b) what are the student perceptions of how Universal Design for Learning techniques affect their learning.

Data was gathered through direct observations conducted in the classroom, via communication with participants involved with the courses, and through a study of archived documents. An iterative process of data collection was used throughout the investigation to maintain consistency and to ensure that similar information was obtained while various approaches were utilized to facilitate the accurate collection of data. Triangulation was done to both reinforce and validate the interpretation of the data, and reduce any potential bias that might exist. Content analysis was then completed on all of the data collected using Klaus Krippendorff's six components of data analysis as described in chapter 4 (2004). Again, an iterative process of examination was maintained while content analysis was performed on the transcripts of interview conversations, observation notes, textbook materials, and other materials to ensure consistency and credibility.

Chapter 5 is separated into the following sections: (a) interpretations, (b) significance of the study, (c) recent literature, (d) implications, (e) recommendations for best practices in teaching, (f) limitations, and (g) suggestions for future research. 


\section{Interpretations}

\section{Research question: How and to what extent are Universal Design for Learning} techniques being implemented in the college classroom. The instructor practices Scientific Teaching and had never heard of Universal Design for Learning (UDL) prior to this study, yet her teaching practices met each of the three principles for UDL and all eight performance indicator categories.

Multiple means of representation. According to Rose and Meyer, multiple means of representation refers to providing learners various ways of acquiring knowledge, skills, and information by offering multiple, flexible methods of presentation (2002). As explained in prior chapters, both the performance indicator categories delivery methods and information resources and technology are aligned with multiple means of representation as they are both defined by information delivery. Instructors who practice UDL do not limit their delivery to lecture and printed materials, as these are not often the most engaging methods (Rose \& Meyer, 2006). The instructor exercised a variety of UDL delivery methods in her classroom by

- $\quad$ addressing multiple learning styles;

- delivering information in multiple formats;

- $\quad$ keeping expectations consistent with her syllabus;

- presenting new information in a consistent method;

- using a variety of teaching methods; and

- $\quad$ using visuals to enhance interest.

The instructor used a range of teaching methods to reach a diversity of students in her classroom. Classroom discussion, think-pair share, mini-maps, brainstorming, and other such active learning strategies are used by many practitioners of UDL in the classroom as these are 
constructivist methods of forcing the learner to actively become involved with the education process. Collaborative learning strategies including group work, peer critiquing, and student-led presentations are UDL techniques that help to motivate and engage students (Burgstahler, 2007). Providing students with review sessions, study guides, online notes, and online games and quizzes are all examples of Universal Design for Learning (UDL) strategies that are used as scaffolding tools to aid learners as they progress toward understanding (Burgstahler, 2007). Using Clicker questions as part of a lecture to engage students in active learning is often cited as one of the most common examples of a way to begin integrating UDL techniques into the classroom. In fact, the Clicker 5 website boasts that the company offers a range of curriculum and accessibility support based on the principles of UDL. Modeling a process or strategy for students is also a UDL technique (Council for Exceptional Children, 2005).

Many of the teaching styles and techniques exercised by the instructor can be used to address multiple learning styles, which is a vital consideration for UDL. The instructor utilized these techniques to address multiple learning styles in her classroom, as this is a goal for Scientific Teaching. She was unaware that addressing multiple learning styles and using a wide variety of teaching methods is key to providing students with multiple means of representation, expression, and engagement.

The instructor used a wide variety of information resources and technology in her classrooms by

- providing electronic equivalents of class resources;

- making required reading assignments (other than the textbook) available online;

- using a variety of instructional technologies; and

- using a web page to provide course materials. 
She employed everything from the traditional chalkboard and textbook to Clickers and online resources to disseminate information to her learners. All media have their advantages and their limitations, and no media are experienced equally by all learners (Rose \& Meyer, 2002). The instructor's use of Blackboard and E-campus to give students access to all the PowerPoint slides and handouts used during classroom lectures, her integration of the Clicker personal response technology system into lectures, and the use of digital technologies to engage learners' multiple senses are all examples of Universal Design for Learning (UDL) techniques. "The flexibility of new media opens new doors to diverse learners," (Rose \& Meyer, 2006, p. 66). Instructors can use these new technologies for effective UDL implementation to reach a diverse audience as they both present information and provide access to materials in a variety of ways.

If the instructor were to decide to consciously adopt UDL into her repertoire of teaching strategies, this area of course design could be strengthened with the adoption of textbooks that are also available online. While the instructor stated that she purposely selects many readings that are accessed online, to the best of her knowledge, none of the textbooks she uses are currently available for download. The authors of Scientific Teaching, Jo Handelsman, Sarah Miller, and Christine Pfund, (along with Christine Pribbenow) have also authored a book titled Entering Mentoring: A Seminar to Train a New Generation of Scientists, which is available both as a hardcover textbook or as a portable document file that can be downloaded from the Internet.

Multiple means of expression. Rose and Meyer define multiple means of expression as providing learners with options for the act of demonstrating their knowledge and understanding (2002). The performance indicator assessment aligns with multiple means of expression, as the definition of assessment is to regularly assess student progress using a variety of methods and tools to determine demonstration of knowledge. 
The instructor encouraged multiple means of expression in her classrooms by

- generating assessment for higher order thinking skills;

- providing multiple tasks/wide variety of exercises and assignments other than just exams;

- providing rubrics;

- $\quad$ using assessment to inform instruction;

- $\quad$ providing students with study guides and review sessions; and

- $\quad$ using assessment as positive feedback.

In the instructor's world of Scientific Teaching, assessment is one of the keystones. The first statement the instructor gave during one interview regarding assessment was that students in any course should always be assessed on multiple tasks that are based on the learning objectives for the course. Between the student examples provided during interviews and surveys, archived document examples, and the examples witnessed during in-class observations by the researcher, the instructor provided her students with a variety of assignments for demonstrating their comprehension and application of the material. Universal Design for Learning (UDL) was once again built into her technique without her even realizing that her assessment plan incorporated UDL. Learners were assessed on assigned group work and individual work. Learners were given a wide variety of assignments from take home assignments to in-class Clicker questions to online quizzes that could be retaken until the student achieved a perfect score. Learners were given a wide range of tasks to reach various learning styles and preferences: read, write, in class presentations, labs, peer critiques, and online activities. Learners in BIOL 115 were even permitted to drop 10 of their lowest non-exam scores. All of these methods used to assess students are supported by UDL. Just as the authors of Scientific Teaching advocate for formative assessment, "UDL supports ongoing, formative assessments that inform instruction as it is 
happening, so teachers can intervene in a timely way" (Meo, 2005, p. 38). The assessment methods of Scientific Teaching - formative assessment, activities to fit learner preferences, and a variety of exercises and assessment strategies - are in alignment with those of UDL. Additionally, the instructor provided rubrics, online study guides and review sessions, all of which support a course designed with a UDL framework.

Proponents of UDL believe that if educators are to assess skill and learning in a more meaningful manner, students need options to express what they have learned (Rose \& Meyer, 2002). The instructor could strengthen her use of UDL by generating a few assignments that have options built into them. For example, she could select a few of the projects she assigns that would allow students to chose whether they submit their work as a final written research paper, edited video, or other type of creative work that demonstrates their knowledge.

Multiple means of engagement. Multiple means of engagement consists of the methods educators employ in the classroom to develop learners' interests, create appropriate challenges, and provide motivation for learners (Rose \& Meyer, 2002). Class climate, interaction, physical environment, feedback, and accommodation are all aligned with multiple means of engagement because each of these relate directly to how an instructor develops relationships and motivates learners in the classroom.

The instructor supported multiple means of engagement through class climate by

- being approachable and available to students;

- identifying students and their interests; and

- creating a class climate in which diversity was respected.

A welcoming classroom where learners feel they are respected is vital. Universal Design for Learning (UDL) advocates propose that instructors should adopt practices that reflect both 
diversity and inclusiveness" (Rose \& Meyer, 2002). Proponents of UDL suggest encouraging the sharing of many perspectives, demanding mutual respect, avoiding stereotypes, being approachable and available, and addressing students by name. The instructor did all of these to make students in her classes feel welcome and then some. Students referred to the instructor's classroom as a friendly, relaxed, open class environment.

While in class, her focus was on learner needs, as her class was very student-centered. If students needed or wanted to spend more time covering a particular topic, she would adjust the schedule to allow more time on the subject matter. She also took time to learn her students' names. Even in BIOL 115, a large lecture section, students commented that the instructor took the time to address students by their names. UDL research indicates that learners are positively motivated when instructors call on them using their names. Students feel encouraged because they feel as if the professor cares, and knows them as more than just an anonymous body in a class (Burgstahler, 2008).

The instructor celebrated diversity. As previously shared, three BIOL 593 classes were devoted to discussion of diversity in the classroom and the students completed various activities and gave teaching presentations on diversity. During one discussion, the instructor asked the learners if they should treat all their students the same and the class all seemed to think that was a wise idea - before they discussed diversity. The instructor explained that celebrating diversity means recognizing student differences and observing these differences equally; therefore, treating each student as a unique individual. The students nodded realizing that everyone wants to be recognized as a unique individual in one way or another. In BIOL 115, the instructor attempted to break traditional ethnic and gender stereotypes through the examples she provided in her lectures and on the materials she disseminated to students. She used examples that 
presented females in predominately male roles and individuals from various minority cultures in roles that traditionally are dominated by the white majority.

The instructor supported multiple means of engagement through interaction by

- $\quad$ expressing enthusiasm for the subject;

- valuing interaction and collaboration;

- offering contact time with students outside of class in flexible formats;

- $\quad$ valuing the inclusion of all students; and

- $\quad$ valuing student engagement.

Everyone was encouraged to participate in class discussions and be engaged members in the class. Students were given the opportunity to ask questions and encouraged to introduce topics of their own interests for discussion. There was an expectation of interaction.

Interaction and communication are essential in any classroom. These components are equally critical when using Universal Design for Learning (UDL). Learners need to know that their voices are heard and that their role in the classroom is important. Employing interactive teaching techniques, like Clickers and discussion buzz groups or think-pair-share, engages students and promotes interaction in the classroom (Burgstahler, 2008). The instructor used a variety of active learning methods, including discussion, group activities, modeling, think-pairshare, mini-mapping (a form of concept mapping), and others to maintain a high level of student engagement in her courses. Student feedback and direct observations indicated that the instructor maintained effective communications with her students. Students were encouraged to contact her through e-mail, during her office hours, or by appointment if they had questions or needed assistance. According to a few students in BIOL 115, and again by direct observation, she was willing to stay after class to talk with students who had questions or wanted additional 
clarification. The instructor was also willing to meet with students during office hours to discuss exams or provide other feedback related to assignments.

The instructor supported multiple means of engagement through feedback by

- aligning assessment with learning objectives;

- providing immediate and instructive feedback;

- posting grades on website to provide students access;

- providing formative assessment throughout; and

- scaffolding assignments.

Providing students with regular feedback throughout the semester and opportunities to correct errors is essential in a universally designed classroom (Burgstahler, 2008). Students indicated that the instructor provided feedback in a variety of manners. In both courses, the majority of students expressed that they were provided regular feedback throughout the course. The instructor posted individual grades online for both courses so students could access their grades at their convenience. She had set office hours and made appointments with students who were unable to meet during her scheduled hours.

Students in BIOL 115 were provided with class updates on averages during class and had access to individual scores on E-campus. Both students and the instructor stated that they were able to visit her during office hours if they wished to go over an exam or they could e-mail her or see her after class if they had needed feedback on an assignment. Students in BIOL 115 were given corrective opportunities on each of their online quizzes as they may retake every quiz until they achieved a perfect score. Additionally, students reported that the instructor took time to review assignments in class and give students feedback on their responses. 
BIOL 593 students could access their individual grades on Blackboard. Students in this course felt that they were given a great deal of immediate, relevant feedback on everything they submitted. According to the instructor, students were given both written and oral feedback on every project they completed. Corrective opportunities were also built into BIOL 593. In addition to receiving feedback from the instructor, learners received constructive feedback from their peers on all their projects. In this fashion, scaffolding was built into BIOL 593. Learners would submit a draft of their work to their peers, would receive feedback from everyone in the course, would revise based on the feedback, and then would submit the final product for a grade. Scaffolding is often used in the Universal Design for Learning (UDL) classroom as it supports the building of knowledge and mastery of skill development (Rose \& Meyer, 2006).

According to Scientific Teaching, assessment should be used to provide both students and the instructor with information about what the students are learning, but it can also be used to “engage students and help shape their learning behaviors" (Handelsman et al., 2007). As a practitioner of Scientific Teaching, the instructor was using assessment, scaffolding, and providing corrective opportunities as feedback for her students to engage her students; simultaneously, she was meeting a principle of Universal Design for Learning (UDL).

The two least developed areas of the eight performance indicator categories were physical environment and products and accommodations. These are areas that are often addressed on an as-needed basis.

The authors of Scientific Teaching address the issue of the physical environment in a couple of chapters. In chapter 2 , the authors discuss the need for classrooms that are designed to be inclusive. "The best classrooms integrate mobile chairs and tables that accommodate flexible arrangements and facilitate discussions" (Handelsman et al., 2007, p. 44). In Chapter 4, the 
authors discuss that in order for an inclusive class to support diversity it should be held in a wheelchair accessible room. This chapter also shares that instructors teaching in large lecture halls should use a microphone to ensure that everyone can hear (Handelsman et al., 2007).

The instructor supported multiple means of engagement through physical environment and products by

- $\quad$ being aware of student needs (like color blindness) and making provisions; and

- $\quad$ using a microphone so all student could hear.

According to the instructor and students in BIOL 115, she did use a microphone for both her lectures and for student responses so that everyone could hear and participate. The rooms used for her courses were both wheelchair accessible, and the room used for BIOL 593 had mobile chairs that could accommodate flexible arrangements. During BIOL 593, the instructor and her students discussed physical limitations during a class session. As mentioned in a prior chapter, the subject of color-blindness was discussed in relation to the development of digital materials. Students were advised to always write out the words for all names of colors in addition to the use of the actual color on PowerPoint slides as students who are colorblind can read the name of the color but may not be able to "see" the true color. Additionally, the instructor chose readings for her courses that were available online so her students would have digital access to them. Providing students access to digital materials allows learners choice and flexibility in how they acquire information - a fundamental concept in Universal Design for Learning (Rose \& Meyer, 2006). Students can read the information on the screen, enlarge the text, have a screen reader read to them, or they can print the material and read it from the printed page. Providing students with options gives them a sense of "ownership of their learning since they can approach tasks in ways that work best for them" (Coyne, et al., 2006, p. 8). 
While the performance indicator category physical environment and products is not as well developed as most of the others, the instructor gave attention to this area and measures were taken to consider students with diverse needs. To improve this area, she might add captions to some of the videos she used in class and add more text to some of her PowerPoint slides that have only visual images and vice versa. Accommodations, such as having sign language interpreters available in a classroom, should also be considered as part of the physical environment (Burgstahler, 2008).

The instructor supported multiple means of engagement through accommodation by - including an accommodation statement in her syllabi.

To address accommodations, the instructor included a disability statement in her syllabi (see Appendices A \& B for copies the syllabi). In these statements, she encouraged students who require accommodations to contact the Office of Disability Services to make the necessary arrangements. The instructor also asked students to inform her of accommodations, when possible, during the first week of class. She expressed that she would meet students during office hours or by appointment to discuss the arrangements. During the discussion of color blindness in BIOL 593, the instructor expressed to her students that some learners would be forthright concerning disabilities, other learners will not. She pointed out that some accommodations should be made regardless of whether the instructor knows they are needed. This belief is in alignment with Universal Design for Learning (UDL). When an instructor can generate materials that will better benefit everyone regardless of ability level, these materials should be created with the sense of universality that is a driving force behind UDL.

Handlesman, Miller, and Pfund address accommodation in Scientific Teaching in chapter 4. The authors explain that good professors are able, and willing, to alter teaching strategies that 
they identify as barriers to learning in order to accommodate a diversity of students' needs in their classrooms. "Teaching methods need to accommodate a wide range of styles, preferences, and experiences" (2007, p. 78).

According to Sheryl Burgstahler (Equal Access: Universal Design of Instruction, 2008), knowing campus protocol for accommodations and planning to accommodate students whose learning needs are not met by the instructional design are the two main factors in meeting the criteria for this performance indicator category. The instructor met both of these basic criteria. However, as the classroom population continues to diversify, this is a subject where the instructor will need to devote more attention.

The instructor's goal was to create a safe and open environment for a diverse student population where students could interact with one another, collaborate in teams, give and receive feedback, and exchange ideas without being hindered by fear of judgment or criticism. She used a constructivist approach, which focused on delivering information to students using a variety of teaching methods to engage a wide range of students. She employed teaching techniques like active learning through group problem solving, Clickers in the classroom, brainstorming, minimaps, and case studies. The instructor celebrated diversity and believed that a classroom should be inclusive of every student. She believed in giving learners multiple tasks based on learning objectives to demonstrate their knowledge and understanding. She felt assessment was feedback and feedback should be given on everything so students could correct their "kilunkers" and continually improve. The instructor practiced Scientific Teaching methods (Scientific Teaching, 2007).

All of these practices align with Rose and Meyer's belief that UDL strategies should support the learning styles and needs of an entire diversity of learners in a classroom, not a single 
student or group of students within a class. As one reads the description of the instructor's classroom, one could easily be reading about an instructor practicing Universal Design for Learning (UDL). A "Universally Designed curriculum provides students with a wide range of abilities, disabilities, ethnic backgrounds, language skills, and learning styles multiple means of representation, expression, and engagement" (Center for Applied Special Technology, 1999). Because Universal Design for Learning (UDL) techniques are common strategies that can be easily implemented in the classroom when planned, the instructor was employing UDL techniques in each of the three principle areas and eight performance indicator categories though she had never before heard of UDL.

The instructor's use of many UDL techniques without having ever been exposed to the theories of UDL is not entirely without precedent. In 2002, Renton Technical College, located in Renton, Washington, initiated a pilot program to learn how using UDL in the college classroom would change the way instructors assist students in the classroom (Jenner \& Culwell, 2006). Many of the instructors involved in the pilot program reported that they were intuitively using UDL strategies, even though they could not explain why. As Bridget M. de la Garza, of San Diego State University shares in her Introduction to Universal Design for Learning (2007) regarding faculty, "Without realizing it, most are already doing so to a certain extent because universal teaching is, arguably, a combination of good teaching, common sense, and the intention of make one's teaching accessible to all students." The results of this study support the belief that using many UDL techniques intuitively occurs through good teaching and the desire to reach a diversity of students. 


\section{Research question: What are student perceptions of how Universal Design for Learning techniques affect their learning.}

Data was collected from both students in BIOL 593 and from students who had completed BIOL 115 regarding their perceptions of how UDL techniques affect their learning.

What did you like most about the course? The data collected during this case study indicates that the majority of students involved identified UDL techniques that they liked and their responses spanned the principles of UDL.

Students liked

- active learning strategies;

- a variety of formats used to delivery information in class;

- the use of Internet technology for homework and quizzes;

- a generous amount of relevant feedback;

- leniency and flexible exam times;

- $\quad$ reviews and study guides;

- the class atmosphere;

- the instructor's enthusiasm and availability;

- the interactivity and student-centered nature of the class; and

- that they were challenged to think for understanding versus merely memorization.

Students from BIOL 593 liked acquiring knowledge of active learning strategies, modeling the methods, and practicing teaching. They felt that the information presented to them was relevant and they were pleased with the amount of feedback they received. Students were positive about the student-centered nature of the course and the class atmosphere. 
Students in BIOL 115 also reported positive reactions to many Universal Design for Learning (UDL) techniques. Students in BIOL 115 stated that they liked active learning, Clicker questions, the class environment, the reviews and study guide, the instructor's availability during office hours and after class, the flexibility to drop 10 absences or assignments, flexible times for talking exams, the interactivity of the class, the variety of teaching methods used in the course, and unlimited opportunities on the online courses to name a few. One student appreciated the teaching methods in BIOL 115 so much he or she made the statement, "I would have the same method of teaching carry on to BIOL 117."

What would you change about the course? Regardless of what strategy a professor employs, students will almost always have suggestions.

Students suggested

- putting more emphasis on the textbook;

- having more traditional lecture;

- posting the PowerPoint slides before class;

- providing a more detailed syllabus, more study materials, and more online assignments;

- giving exams on paper instead of online;

- giving a defined grade on every project;

- making the class smaller;

- assigning less group work and holding less student led discussions;

- the instructor should not assume students have prior knowledge of subject matter; and

- more course times should be offered to accommodate non-traditional students. A pair of students from BIOL 593 suggested defined, or solid, grades on every project. Unbeknownst to the students who were interviewed, the instructor addressed the issues of grades 
during one of the interviews. Individual grades for every project were posted on Blackboard. Students were given written feedback and comments on the rubric sheets used during class, and had to access their individual grades online. These two students must have been unaware of the online grades.

A number of students in BIOL 115 reported negative reactions to some Universal Design for Learning (UDL) techniques. Students stated that they would have liked more traditional lecture, a more detailed syllabus, more focus on the textbook, more materials to study, less group work, less student participation, no use of Clickers, and PowerPoint slides posted before class.

According to the instructor, the biology department at the institution offers some traditional lecture sections. Not every professor in the biology department has adopted Scientific Teaching. The instructor explains her use of Scientific Teaching on day one of the semester. This allows students plenty of time to change their schedules if they would prefer a different lecture section.

The instructor stated during an interview that she is quite accustomed to facing limited student resistance. She always has a small number of students who wish to remain passive learners. They want the material spoon-fed to them. They want to sit quietly, listen submissively, and take notes so they can memorize them for the exam. She reported that this group of students complains that they do not want to learn how to teach themselves because that is what she is paid to do. During the coding of the BIOL 115 survey results, I found a few of these comments attached to the desire for traditional lecture and focus on the textbook.

One of the purposes of Universal Design for Learning (UDL) is to create a group of students who are expert learners - learners who actively engage with course material, take responsibility for their own learning, are motivate to initiate opportunities to learn, learners who 
know not only what to learn, but how to learn (National Center on Universal Design for Learning, 2010). Passive learners wish to remain at rest and often must have some force used before they will become active, engaged, expert learners. Students who are only accustomed to passive learning methods and are unfamiliar with active classroom techniques like peer-led discussion, collaborative projects, think-pair-share, and other similar teaching strategies, may have a difficult transition when required to take responsibility for their own learning.

There was no one response that repeated enough to create a trend in students' dislikes. The most common response to the question was that students would not change anything. Overall, the majority of the criticisms and suggestions shared by these respondents appeared to revolve around the desire for a course where they could be passive learners. Based upon the number of positive comments, and the fact that a couple of the suggestions were made by students who also had positive comments to share, these students were in the minority of those who responded.

How would you describe this course in comparison to other courses you have taken or are currently taking at this institution? The positive perceptions of Universal Design for Learning (UDL) techniques were double those reported that were negative perceptions. Students compared courses saying this course

- was more flexible and interactive;

- used more instructional materials and technologies;

- promoted a more social atmosphere;

- had a greater focus on concepts and less on memorization; and

- was challenging and engaging. 
All of the students in BIOL 593 had very positive perceptions of the course and the Universal Design for Learning (UDL) techniques used in the course. Students found the course to be more flexible, more interactive, and more challenging and engaging.

Students in BIOL 115 reported mixed perceptions of the course, however the perceptions of the UDL techniques discussed in this section were all positive. Students stated they liked that there was group work in this course unlike other large lectures they were enrolled in where the professor just "talked to them the entire time." The course was also described as having a fun, friendly and open atmosphere. These factors create a social atmosphere for a course. One student wrote, "This course was very different in that I have never been in a huge lecture class where the teacher actually got the people to participate and where it was fun to learn. Usually that rapport only happens in a small group setting." The students also stated that they liked that there was more interaction in this course than in others in which they have been enrolled. Specifically, a couple of students cited the use of Clickers and PowerPoint slides during the class lectures as a positive difference. Another student pointed out that this course offered more materials to learn from than other courses in which he was enrolled. He said that he really appreciated all the online quizzes and study guides that were available. A number of students were pleased the course focused on concepts and knowledge rather than merely memorization.

A small number of students responded that the course was harder than most courses. These students stated that the course required more studying and had more work than most other courses. There was a direct correlation between this small group of students and the students seeking a passive lecture course.

\section{Do you feel you learned less/the same/or more in this course than in other courses at}

this institution? $57.9 \%$ of the students who participated in the study reported that they learned 
more in their courses with the instructor than in other courses at this institution. Students stated this was because

- the course used active learning;

- the class was fun;

- they were highly motivated;

- the course used instructional technology;

- the course was interactive;

- the course delivered relevant material; and

- of the variety of materials and discussion.

All five of the women enrolled in the BIOL 593 class responded that they learned more in this course than in other courses they have taken at the institution. One young woman said, "I learned more simply because of the level of activity, it was fun. Though there was constantly work, I enjoyed doing it." Others reported that they learned more because the material was immediately relevant in their lives and other coursework. They could easily integrate the concepts into their classrooms or assignments. A student stated, "I learned way more in this course. In fact, I've learned more in this course than any course I've taken at this institution. Between the variety of the materials and the discussion, this course was very helpful to me." Both the high level of activity and the variety of materials and discussions relate to Universal Design for Learning (UDL) techniques.

Seventeen students from BIOL 115 , or approximately $52 \%$ of the respondents, stated that they learned more in BIOL 115 than in other courses at the institution. The reasons stated that relate to UDL techniques included: active learning methods, students felt highly motivated to do well in the course, the instructional technologies assisted students, and students appreciated the 
teaching methods. One student stated, "I learned way more. Because I was able to do stuff, I learned the material better than just taking exams." Another said, "I learned more. The instructor took great pains to present the material in a way that made you question the concepts with a variety of teaching methods."

Six respondents from BIOL 115, or 18\%, said they learned the same amount in BIOL 115 as in their other courses at the institution. Four respondents merely stated that they learned the same amount and did not provide a rationale for their answer. One student stated that while she felt she learned far less in her labs, she learned more in the course, therefore these discrepancies balanced out to a response of the same. Another student said that BIOL 115 was not different enough from AP biology.

Seven students, or $21 \%$ of the respondents from BIOL 115, stated that they learned less in BIOL 115 than in other courses at the institution. The reasons stated that relate to Universal Design for Learning (UDL) techniques include: students did not like the teaching methods, desired additional delivery formats, could not hear or understand the instructor, and did not see the relevance of material. A student stated, "I learned less because too many questions were asked and the material wasn't really covered during lecture." Another said, "I feel like I've learned less because her teaching skills were not effective at all. I went to class, read the book, and studies, and I needed more lecture from the teacher."

Three students, or $9 \%$, did not respond to this question.

There is no one size fits all approach to education that ever will make every student in a classroom delighted with the instructor all of the time. While some students will report they appreciate a professor taking the extra time to create a well planned PowerPoint presentation that has a great deal of material, as a few students did in this study, another learner will present the 
opposing argument and state extreme dislike for PowerPoint presentations because they simply do not introduce enough material, as a student did in this same study. Viewing the larger picture, however, the instructor's teaching methods worked for the majority of her students. In fact, all of her students in BIOL 593 had very positive perceptions of the Universal Design for Learning (UDL) techniques utilized and the majority of students surveyed in BIOL 115 responded with positive reactions to the UDL strategies used. The data collected during this study indicates that the majority of students involved liked the variety provided through the use of UDL techniques and $57.9 \%$ of the students responded that they learned more in their classes than in other classes in which they were enrolled at the same institution.

Research indicates the positive perceptions of UDL will only increase in the future as the classroom continues to diversify and a new wave of $21^{\text {st }}$ century learners begin to fill our institutions of higher education. The new $21^{\text {st }}$ century learner will demand options, expect flexibility, technology, and curricula that are designed to meet their learning style(s). The new student believes that "learning should be personalized based on the students' desires and how they best learn" (Van Der Werf \& Sabatier, 2009, p. 9). UDL techniques allow an instructor to meet these needs with intuitive strategies that are seamlessly woven into the curriculum to provide both students and instructors with materials and lessons that students are able to use and learn (Rose \& Meyer, 2002).

\section{Significance of the Study}

The language in the No Child Left Behind legislation, can easily be interpreted as a prescription for Universal Design for Learning (UDL). The No Child Left Behind Act (NCLB) describes a new, more flexible approach that embraces the use of instructional technology to provide multimodal educational experiences and opportunities for students (U.S. Department of 
Education, 2004). Equally historic and notable to establish Universal Design for Learning's (UDL) significance is the Individuals with Disabilities Education Act (IDEA) legislation amendments that establish a Commission on Universal Design and the Accessibility of Curriculum and Instructional Materials “ to study, evaluate, and make appropriate recommendations to Congress and to the Secretary on universal design and accessibility of curriculum and instructional materials for use by all children" (Izzo and Murray, 2003, p. 30).

A growing number of states, including West Virginia, are now emphasizing $21^{\text {st }}$ Century Skills and the importance of learning and innovation skills, information and technology skills, and life/career skills, which are in alignment with NCLB and UDL (Partnership for $21^{\text {st }}$ Century Skills, 2004). The Partnership for $21^{\text {st }}$ Century Skills seeks to align with NCLB, Science, Technology, Engineering, and Math (STEM) initiatives, and other reforms that will promote rigorous coursework for students to prepare them for college and career challenges. The Partnership for $21^{\text {st }}$ Century Skills believes that every child in the United States should have the knowledge and skills necessary for tomorrow's global world, a belief shared by UDL advocates (Partnership for $21^{\text {st }}$ Century Skills, 2004).

In 2006, a National UDL Task Force, consisting of over 25 representatives from national disability and education organizations, was formed "to improve instruction and assessment for all students by incorporating UDL into policy and to promote UDL through grants, technical assistance and a communication campaign (Sopko, 2009, p. 1). The National UDL Task Force works to recommend "legislative language for upcoming reauthorization of federal education laws and communicate the importance of UDL to national organizations" (Sopko, 2009, p. 5). The National UDL Task Force shares the belief that Universal Design for Learning (UDL) "is applicable to all students and recommends funding for UDL research" (Sopko, 2009, p. 5). This 
collaborative seeks to help government and education agencies recognize that UDL is not a special education practice; UDL is an effective practice for everyone (Sopko, 2009).

Recently, "the definition for UDL was included in the reauthorization of the Higher Education Act 2008 (HEA) which is called the Higher Education Opportunity Act (HEOA)" (Sopko, 2009, p. 1). The National UDL Task Force was instrumental in having the definition of UDL added to the HEOA. UDL proponents believe "the inclusion of UDL in the reauthorization of the HEA demonstrates its escalating importance in the education field" (Sopko, 2009, p.1).

According to the HEOA, recipients of 'teacher quality partnership grants' and 'teach to reach grants" are required to prepare their instructors to use "strategies consistent with the principles of universal design for learning” [P.L. 110-315, §202(d)(1)(A)(ii)], "to integrate technology effectively into curricula and instruction, including technology consistent with the principles of universal design for learning [P.L. 110-315, §204(a)(G)(i)], and to incorporate UDL into both evaluation and performance measures" (Sopko, 2009, p. 3). Proponents view this as colossal forward progress, as this language may serve as the impetus needed for changing the language in other education policy to include UDL (Sopko, 2009).

Universal Design for Learning (UDL) is being implemented in select K-12 schools throughout the United States and now faculty and administrators at postsecondary institutions are beginning to recognize the significance of using UDL in the college classroom. Faculty at institutions including the Ohio State University, Colorado State University, the University of Maine, the University of New Hampshire, the University of Massachusetts, the University of Washington, Emory University, San Francisco State University, the University of Minnesota, the University of Arkansas, and the University of Nevada, are all utilizing Universal Design for Learning (UDL) in their classrooms. 
Every year more students with special needs enter into the world of higher education. Some of these students are minorities for whom English is a second language. Some of these students have invisible disabilities. Some of these students have special needs they have not yet even come to realize. Instructors are expected to reach as many students as is possible through solid course delivery and also to retain students in the program. At nearly every college and university in the United States, the rate of student retention is an area of immense significance. There is pressure on instructors from every angle: students, parents, and administration. Parents and students want success. Administration seeks retention. "The continuing diversification of the college-going population will put pressure on many aspects of postsecondary education to adapt" (Van Der Werf \& Sabatier, 2009, p. 14). Instructors need to recognize the changes and be willing to modify their techniques if they are going to retain students and help students succeed. The world of higher education is in the midst of a major transition and the entire institution needs to be ready to accommodate a non-traditional student body (Van Der Werf \& Sabatier, 2009).

The modern student's concept of higher education is not the same vision from only a decade ago. "Educators are increasingly finding that students want to design their own curricula and find ways to learn in their own style" (Van Der Werf \& Sabatier, 2009, p. 7). Students are demanding, "learning should be personalized based on the students' desires and how they best learn" (Van Der Werf \& Sabatier, 2009, p. 9). Learning styles, flexibility, and student options are integral components of Universal Design for Learning that make it a seemingly ideal pedagogy for the "new" and ever-diverse university classroom.

The data collected in this study supports prior research that UDL strategies are effective, best practice methods for instructing a diverse classroom. The data gathered during this study also reveals that the implementation of UDL in the college classroom is more than mere theory; 
the application of the UDL framework and principles are practical. This case study demonstrates the use of UDL principles operationalized in a college classroom. Currently, there are many texts that provide a wealth of theoretical information regarding the history and basic information about UDL. However, there are no textbooks dedicated to assisting college instructors who seek to identify practical strategies for implementing UDL in higher education. The data collected in this study should serve as a catalyst to produce practical, usable materials from which instructors can benefit.

\section{Recent Literature}

While "Universal Design for Learning (UDL) is a growing practice across the nation, one that is increasingly referenced in education policy briefs, research literature, teacher professional development, and books and articles for educators, UDL policies and practices are not yet broadly integrated into all education policy (Sopko, 2009, p. 1). In December of 2008, Project Forum at the National Association of State Directors of Special Education held a policy caucus where representatives from all levels of education, including institutions of higher education, were called upon to "identify challenges to UDL implementation and then develop policy recommendations to address those challenges" (Sopko, 2009, p. 1). After the conclusion of the presentations and meetings, a report, Universal Design for Learning: Policy Challenges and Recommendations, was prepared by Dr. Kim Sopko to present the findings of the collaboration (2009). The panel representatives from the institutions of higher education conveyed that the United States Department of Education, Office of Postsecondary Education had awarded funding to "over 30 institutions of higher education to ensure that students with disabilities receive a quality higher education" (Sopko, 2009, p. 6). When the Office of Postsecondary Education 
provided individuals at these institutions technical assistance training, UDL was recommended as the "appropriate activity to improve teaching methods and strategies" (Sopko, 2009, p. 6).

The representatives from the institutions of higher education also shared that at many postsecondary institutions, the term Universal Design for Learning (UDL) is often confused with other terms like Response to Intervention (RTI), inclusion, and PBS (Positive Behavioral Supports). Some institutions have courses specifically dedicated to teaching UDL and others have instructors who model UDL principles, but few institutions (if any) have policies in place to support the University-wide use of UDL. These representations suggest that UDL terminology be included in mission statements and University policy if educators are to incorporate it into course design, instruction, and assessment (Sopko, 2009).

Why must higher education transform itself and step away from the "traditional" model? According to Martin Van Der Werf and Grant Sabatier (2009) in their report, The College of 2020: STUDENTS, the traditional model has built-in educational barriers that today's student protests and tomorrow's student will simply elect to "shop elsewhere". The face of the college classroom has changed and will continue to undergo drastic transformations. "It should come as no surprise that student bodies will increasingly be made up of members of minority groups. At some point, probably just after 2020, minority students will outnumber white students on college campuses for the first time" (p. 5). Increasing numbers of students with disabilities, adults seeking retraining, first-generation college students from diverse cultural backgrounds, highschool dropouts, and students with perfect ACT and/or SAT scores all will be sitting in the college classroom or signing up to take online classes. "The students of 2020 will demand an education on their terms" (p. 52). Universal Design for Learning (UDL) removes the barriers and provides built-in flexibility so students can learn in the style that best suits their needs. While 
there is no "magic band-aid" that will fix every situation that could arise in a postsecondary classroom, UDL provides options that can minimize student discontentment and provide maximum learning opportunities for everyone in the classroom.

\section{Implications}

The research study conducted indicates that in the instructor's classroom, the active learning strategies of Scientific Teaching, met each of the three guiding principles of Universal Design for Learning and had criteria that fit into each of the eight performance indicator areas. Prior to this study, the instructor had not heard of Universal Design for Learning, yet she was practicing UDL teaching methods and using UDL techniques.

During the observations of the instructor's class, one of her BIOL 593 students asked why she has students in her large lectures do so many in-class activities. The instructor responded by explaining that it encourages her students to be accountable for their own learning, and by doing so allows her to get rid of the passive observers in her classroom. She then proceeded to explain the process she uses in her large lecture, BIOL 115, Principles of Biology. She will most frequently begin a topic by presenting students with a problem or puzzle they can solve, most often in a collaborative group. Then, she will provide them with new information and knowledge about the topic to support what they have already figured out on their own, or to help them unravel what they may not have been able to completely understand. After new knowledge is presented, she will introduce another similar problem. This second problem will test their level of understanding to see if they merely attempted to memorize or if they truly comprehend the material. The instructor explained that while she may use an assortment of techniques for this activity, her goal is always to engage learners and help them comprehend the material being presented. 
The activity described by the instructor was created as an active learning in-class group experience using the strategies of Scientific Teaching. However, this activity is also an excellent example of Universal Design for Learning (UDL). Both UDL and Scientific Teaching follow a constructivist approach to instructional design.

UDL is often used in tandem with other pedagogical approaches like Differentiated Instruction as it complements other constructivist models (Rose \& Meyer, 2007). "Because it emphasizes developing flexible learning environments through multiple learning means, UDL creates a framework that other (district) initiatives can hang from” (Rose \& Meyer, 2007, p. 35). In this case study, UDL complemented Scientific Teaching very well. The two approaches blended seamlessly together due to their vast similarities including: constructivist approach, belief of how students learn, learner-centered, use of scaffolding, focus on diversity, focus on goals before activity design, and a belief in the need for multiple tasks, multiple teaching approaches, and engagement. As both UDL and Scientific Teaching are both relatively new paradigms in teaching, this study may be the first time these two approaches have been documented as having been used together.

During discussions with the instructor, she talked of the scientific research and analysis she was conducting to assess the outcomes of various teaching strategies used in her classroom. Over the years, she has compared her students' achievement using various teaching techniques, and the evidence provided her with a compelling argument for using Scientific Teaching as the pedagogy in her classroom. She observed improvement on exam scores and saw drastic improvement from midterm to the end of the semester. A trend supported by the data collected from the students in the instructor's fall BIOL 115 class for this study. 
The majority of student perceptions regarding the use of Universal Design for Learning (UDL) techniques in the classroom were positive. As stated earlier, the positive responses to the techniques of UDL are likely to increase in the future as the $21^{\text {st }}$ century learner begins to pervade our postsecondary institutions. These new learners will bring with them demands for options, flexibility, technology, and curricula that are designed to meet their learning style(s) and needs. The new student believes that "learning should be personalized" (Van Der Werf \& Sabatier, 2009, p. 9) and that institutions of higher education are businesses created to cater to the customer. The UDL techniques, used by the instructor through Scientific Teaching, were intuitively woven into her course design to reach a diversity of learners. Many of the students who participated in this study complemented the instructor for her willingness to go the extramile to assist them in learning. Students were appreciative of her online PowerPoint slides, study guides, review sessions, willingness to meet them after class or during office hours, enthusiasm for learning, and various teaching methods. Tomorrow's students will expect all of these things from all of their instructors.

\section{Recommendations for Best Practices in Teaching}

A more diverse student population has begun to overwhelm the world of postsecondary education, and institutions of higher education need to evolve. Curriculum design is one vital facet of education that must be revised to meet the ever-changing needs of the modern student body. Universal Design for Learning (UDL) is an instructional design model that has the power to transform traditional curricula into designs that are flexible enough to meet the widely divergent needs of exceedingly diverse audiences. UDL is a research-based approach to education that addresses learner diversity in the first phase of course design to ensure that all students in a classroom are able to learn and remain engaged. UDL is about how educators 
define their teaching goals, methods, materials, and assessments. Through the use of UDL techniques, educators can embed learning options and flexibility into their curriculum from the initial planning stage instead of needing to modify their instructional design for individual student needs later (Rose \& Meyer, 2002). "The goal of a UDL classroom is maximizing options - both for students and teachers - in order to enable students to learn content and skills in the most effective way" (Rose \& Meyer, 2006, p. 34). Thus, the center of UDL is the assertion that added flexibility and options assist all learners in the classroom. UDL provides a framework for instructors to practice "good teaching at its best" (Rose \& Mayer, 2006, p. 35).

If one surveyed every institution of higher education across the United States, and asked what their top goals were, some of the most common responses would be increased recruitment of high quality students, improvement of academic achievement, retention of students, and improved graduate rates. These are universal concerns regardless of an institution's size or focus. Another trend the survey would reveal is that colleges and universities are growing increasingly more diverse. According to The College of 2020: Students, a report written by Martin Van Der Werf and Grant Sabatier (2009) of Chronicle Research Services, The U.S. Department of Education has projected postsecondary enrollment numbers through 2017. "While the overall numbers are trending upward, the characteristics of the student body are changing significantly" (p. 19). The student population that once consisted primarily of white, upper class eighteen year old high school graduates will soon shift dramatically. Teenagers enrolling in college will be on a steady decline, while nontraditional students returning to school will be on the rise and "more heavily weighted toward women" (p. 19). Additionally, institutions will see an increase in minority students and students with special learning needs. "The continuing diversification of the college-going population will put pressure on many aspects of postsecondary education to adapt" 
(p. 14). The grand goals of the administrators at the vast majority of postsecondary institutions, coupled with the drastic changed in student demographics, leaves many educators asking for a solution to this seemingly unsolvable dilemma. An answer can be found in the best practice use of Universal Design for Learning (UDL).

UDL is gaining traction in the world of education, "the worm has turned," according to David Rose, co-executive director of the Center for Applied Special Technology (CAST) (Universal Design for Learning Gains Traction, 2002). Rose released this statement in 2002 after the establishment of the National Center on Accessing the General Curriculum. In this same release, Rose also states that educational publishers who once had to be harassed about UDL were now initiating conversations about it. In 2004, CAST was funded by the United States Department of Education, Office of Special Education Programs to lead The National Instructional Materials Accessibility Standard (NIMAS) Development Center. The center's staff was to develop a national instructional resources standard file format to be used for the electronic distribution of all digital materials. In 2006, a National UDL Task Force was formed "to improve instruction and assessment for all students by incorporating UDL into policy and to promote UDL through grants, technical assistance and a communication campaign (Sopko, 2009, p. 1). The National UDL Task Force believes that Universal Design for Learning (UDL) "is applicable to all students and recommends funding for UDL research" (Sopko, 2009, p. 5). This collaborative seeks to help government and education agencies recognize that UDL is not a special education practice; UDL is an effective practice for everyone (Sopko, 2009). The National UDL Task Force was able to get UDL language into educational policy, the Higher Education Opportunity Act (HEOA), at the federal level for the first time in 2008. UDL is gaining traction in the world of education. While the progress may be slow, UDL is on its way. 
UDL techniques are intuitive and already being used by many instructors though they may not recognize them as UDL (Jenner \& Culwell, 2006), UDL can be used with a multitude of other pedagogical approaches (Rose \& Meyer, 2007), and when used at the front end of course design, UDL can save an instructor an infinite amount of time and frustration in the end (Jenner \& Culwell, 2006). As this case study shows, UDL and Scientific Teaching align well due to the vast number of similarities they share.

According to the authors of Scientific Teaching, "the goal of Scientific Teaching is to make teaching more scientific. Embedded in this undertaking is the challenge to all scientists to bring to teaching the critical thinking, rigor, creativity, and spirit of experimentation that defines research. Scientific Teaching also posits that the teaching of science should be faithful to the true nature of science by capturing the process of discovery in the classroom (Handelsman et al., 2004, as cited in Handelsman et al, 2007, p. 1). While the authors of this passage refer only to the undergraduate science classroom, there is no reason this level of rigor, creativity, and spirit of experimentation should not pervade every undergraduate classroom. The constructivist philosophies of Scientific Teaching - backward design, active learning, a focus on diversity, etc., could be easily applied to other fields of study. The pedagogy proposed by Scientific Teaching is applicable across the curriculum, not just in the science classroom.

Proponents of UDL believe that Universal Design for Learning “is the intersection where all” educational initiatives - "integrated units, multi-sensory teaching, multiple intelligences, differentiated instruction, use of computers in schools, performance-based assessment, and others" - that are designed to improve the traditional classroom for the benefit of all learners come together (Rose and Meyer, 2002, p. 4). 
Both Universal Design for Learning (UDL) and Scientific Teaching recognize education's greatest impediment to learning: a rigid curriculum. Often, the curriculum is structured in such a manner that it cannot meet the needs of a diverse population of students. Advocates for both UDL and Scientific Teaching both want students to learn how to learn. When the pedagogy is flexible, UDL strategies can be interwoven into the curriculum to work with the system that is already being implemented. Utilized in tandem with other constructivist approaches, like Scientific Teaching, UDL is "best practice" teaching.

Neuroscience indicates that no two students learn the same way or experience the same event with identical observations; responses are as unique as our fingerprints or DNA. As educators, our instruction must meet the needs of these unique and diverse learners. UDL assists instructors to meet a diversity of needs through a single curriculum design.

In December of 2008, the Center for Applied Special Technology (CAST) published a set of nine UDL guidelines to correspond with their three principles (see Table 15). These guidelines are version 1.0 because they are a first draft, to be used as a flexible set of strategies for generating "maximum learning opportunities for all students" (CAST, 2008, p. 9).

Table 17

UDL Guidelines (2008)

\begin{tabular}{|c|c|c|}
\hline $\begin{array}{l}\text { Provide Multiple Means of } \\
\text { Representation }\end{array}$ & $\begin{array}{l}\text { Provide Multiple Means of } \\
\text { Action and Expression }\end{array}$ & $\begin{array}{l}\text { Provide Multiple Means of } \\
\text { Engagement }\end{array}$ \\
\hline $\begin{array}{l}\text { 1. Provide options for } \\
\text { perception }\end{array}$ & $\begin{array}{l}\text { 4. Provide options for } \\
\text { physical action }\end{array}$ & $\begin{array}{l}\text { 7. Provide options for } \\
\text { recruiting interest }\end{array}$ \\
\hline $\begin{array}{l}\text { - Options that customize the } \\
\text { display of information }\end{array}$ & $\begin{array}{l}\text { - Options in the mode of } \\
\text { physical response }\end{array}$ & $\begin{array}{l}\text { - Options that increase } \\
\text { individual choice }\end{array}$ \\
\hline - Options that provide & - Options in the means of & and autonomy \\
\hline alternatives for auditory & navigation & - Options that enhance \\
\hline inforn & - Op & rel \\
\hline - Op & tool & and authenticity \\
\hline $\begin{array}{l}\text { alternatives for visual } \\
\text { information }\end{array}$ & logies & $\begin{array}{l}\text { - Options that reduce threats } \\
\text { and distractions }\end{array}$ \\
\hline
\end{tabular}




\begin{tabular}{|c|c|c|}
\hline $\begin{array}{l}\text { 2. Provide options for } \\
\text { language and } \\
\text { symbols } \\
\text { - Options that define } \\
\text { vocabulary and symbols } \\
\text { - Options that clarify syntax } \\
\text { and structure } \\
\text { - Options for decoding text } \\
\text { or mathematical notation } \\
\text { - Options that promote } \\
\text { cross-linguistic } \\
\text { understanding } \\
\text { - Options that illustrate key } \\
\text { concepts non-linguistically }\end{array}$ & $\begin{array}{l}\text { 5. Provide options for } \\
\text { expressive skills } \\
\text { and fluency } \\
\text { - Options in the media for } \\
\text { communication } \\
\text { - Options in the tools for } \\
\text { composition and problem } \\
\text { solving } \\
\text { - Options in the scaffolds } \\
\text { for practice and } \\
\text { performance }\end{array}$ & $\begin{array}{l}\text { 8. Provide options for } \\
\text { sustaining effort and } \\
\text { persistence } \\
\text { - Options that heighten } \\
\text { salience of goals } \\
\text { and objectives } \\
\text { - Options that vary levels of } \\
\text { challenge and support } \\
\text { - Options that foster } \\
\text { collaboration and } \\
\text { communication } \\
\text { - Options that increase } \\
\text { mastery-oriented feedback }\end{array}$ \\
\hline $\begin{array}{l}\text { 3. Provide options for } \\
\text { comprehension } \\
\text { - Options that provide or } \\
\text { activate background } \\
\text { knowledge } \\
\text { - Options that highlight } \\
\text { critical features, big ideas, } \\
\text { and relationships } \\
\text { - Options that guide } \\
\text { information processing } \\
\text { - Options that support } \\
\text { memory and transfer }\end{array}$ & $\begin{array}{l}\text { 6. Provide options for } \\
\text { executive functions } \\
\text { - Options that guide } \\
\text { effective goal-setting } \\
\text { - Options that support } \\
\text { planning and strategy } \\
\text { development } \\
\text { - Options that facilitate } \\
\text { managing information and } \\
\text { resources } \\
\text { - Options that enhance } \\
\text { capacity for monitoring } \\
\text { progress }\end{array}$ & $\begin{array}{l}\text { 9. Provide options for self- } \\
\text { regulation } \\
\text { - Options that guide } \\
\text { personal goal-setting and } \\
\text { expectations } \\
\text { - Options that scaffold } \\
\text { coping skills and strategies } \\
\text { - Options that develop self- } \\
\text { assessment and reflection }\end{array}$ \\
\hline
\end{tabular}

These guidelines were not used as the basis for this case study because number one, they were not published when this study was initiated, and number two, they are not complete. The authors state that these guidelines will be updated on a regular basis. As one reviews the guidelines, one might note that some appear quite complicated. While most of these statements break down with many options and techniques for use in the classroom at multiple levels of education, some are quite abstract and difficult to grasp upon a first reading. There are numerous instructors in postsecondary education who have never taken a course in education and therefore, do not have a complete understanding of the terminology and language. Many of these educators are not going to adopt a set of complicated guidelines for which they need an interpreter before 
they can begin to modify their instructional designs. These guidelines should be simplified and concrete examples should be provided before they are used in a classroom. Guidelines should help streamline a process, to make the application of UDL principles straightforward, not create such obscurities that one is deterred from their practice.

Based upon this study, UDL techniques can be implemented in the college classroom through many strategies that are intuitive, as these techniques are viewed as good teaching methods. Table 18 is a set of proposed practical guidelines for college educators. These guidelines may serve as a checklist for instructors who wish to implement UDL principles in their classrooms.

Table 18

Proposed UDL Guidelines for the College Instructor

\begin{tabular}{|c|c|c|c|c|}
\hline & Objectives & $\begin{array}{l}\text { Assessment } \\
\text { Methods }\end{array}$ & $\begin{array}{l}\text { Teaching } \\
\text { Methods }\end{array}$ & $\begin{array}{l}\text { Instructional } \\
\text { Materials }\end{array}$ \\
\hline $\begin{array}{l}\text { Provide } \\
\text { Multiple } \\
\text { Means of } \\
\text { Representation }\end{array}$ & $\begin{array}{l}\text { Create } \\
\text { expectations } \\
\text { that are } \\
\text { consistent with } \\
\text { learning } \\
\text { objectives } \\
\text { stated in } \\
\text { syllabus } \\
\text { Use authentic, } \\
\text { relevant } \\
\text { material to } \\
\text { challenge } \\
\text { learners at an } \\
\text { appropriate } \\
\text { level }\end{array}$ & & $\begin{array}{l}\text { Deliver } \\
\text { information in a } \\
\text { variety of } \\
\text { formats (e.g., } \\
\text { text, video, } \\
\text { graphically) } \\
\text { Deliver } \\
\text { instruction using } \\
\text { a variety of } \\
\text { methods (e.g., } \\
\text { Clickers, } \\
\text { discussion, } \\
\text { lecture, group } \\
\text { work) } \\
\text { Deliver material } \\
\text { in a consistent } \\
\text { manner } \\
\text { (PowerPoint } \\
\text { slides with } \\
\text { verbal } \\
\text { reinforcement }\end{array}$ & $\begin{array}{l}\text { Use } \\
\text { instructional } \\
\text { technology } \\
\text { Provide } \\
\text { electronic } \\
\text { equivalents of } \\
\text { all class } \\
\text { resources } \\
\text { Use texts } \\
\text { available in } \\
\text { both print and } \\
\text { digital formats } \\
\text { Use a visual } \\
\text { learning } \\
\text { environment } \\
\text { system (e.g., e- } \\
\text { Campus, } \\
\text { Blackboard) to } \\
\text { provide access } \\
\text { to course }\end{array}$ \\
\hline
\end{tabular}




\begin{tabular}{|c|c|c|c|c|}
\hline & & & $\begin{array}{l}\text { during lecture, } \\
\text { followed with } \\
\text { discussion, } \\
\text { slides posted } \\
\text { online for } \\
\text { reference) } \\
\text { Address } \\
\text { multiple } \\
\text { learning styles } \\
\text { Use } \\
\text { visuals/images } \\
\text { to enhance } \\
\text { interest } \\
\text { Provide relevant } \\
\text { descriptions for } \\
\text { images, } \\
\text { graphics, and } \\
\text { videos used in } \\
\text { materials } \\
\text { Open each } \\
\text { lecture with an } \\
\text { outline of } \\
\text { material to be } \\
\text { discussed and } \\
\text { conclude with a } \\
\text { summary of key } \\
\text { points. }\end{array}$ & $\begin{array}{l}\text { materials in } \\
\text { digital formats } \\
\text { (e.g., syllabi, } \\
\text { PowerPoint } \\
\text { slides, class } \\
\text { notes, handouts, } \\
\text { research } \\
\text { articles) } \\
\text { When } \\
\text { possible/needed, } \\
\text { provide captions } \\
\text { for audio/video }\end{array}$ \\
\hline $\begin{array}{l}\text { Provide } \\
\text { Multiple } \\
\text { Means of } \\
\text { Expression }\end{array}$ & $\begin{array}{l}\text { Set high } \\
\text { expectations } \\
\text { for your } \\
\text { students, and } \\
\text { be willing to } \\
\text { be flexible and } \\
\text { provide them } \\
\text { with options } \\
\text { that are } \\
\text { relevant to } \\
\text { their needs and } \\
\text { interests. }\end{array}$ & $\begin{array}{l}\text { Use of } \\
\text { assessment to } \\
\text { inform } \\
\text { instruction } \\
\text { Create } \\
\text { assessments } \\
\text { that address } \\
\text { higher order } \\
\text { thinking skills } \\
\text { Provide } \\
\text { flexibility and } \\
\text { choice in } \\
\text { activities to } \\
\text { demonstrate }\end{array}$ & & \\
\hline
\end{tabular}




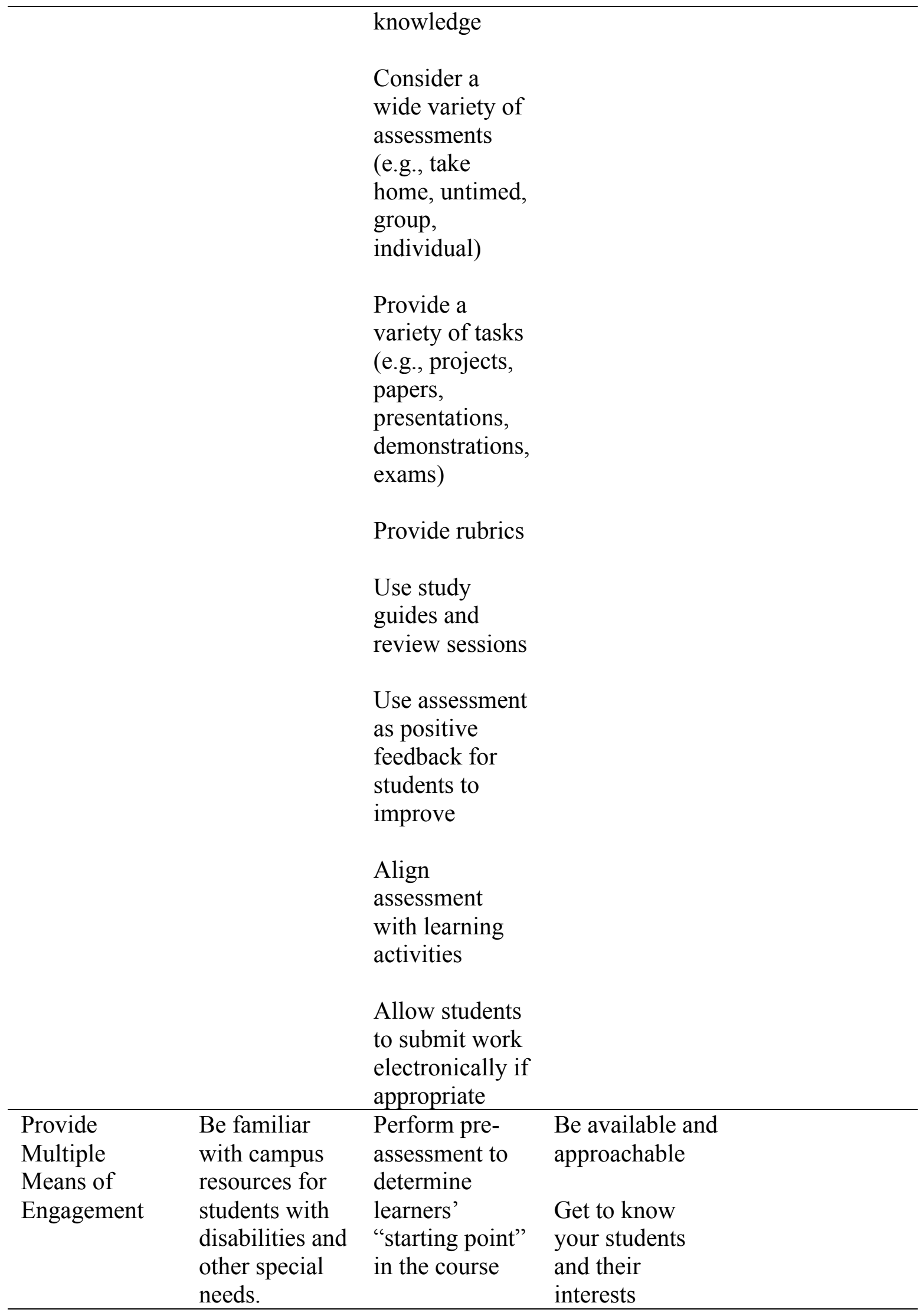




\section{Provide \\ formative \\ assessment to \\ keep students \\ motivated}

Create a class

climate where

diversity is

celebrated

Plan interactive

and

collaborative

learning

Model the

enthusiasm and

engagement you

expect from you

students

Be aware of

special needs

students may

have and the

accommodations

they may require

Consider using

scaffolding,

drafts and

revisions, to

give

opportunities for

continual

improvement

and to

encourage the

use of prior

knowledge

Consider using

peer review

Use active

learning

strategies

Ask for student

feedback 
Note: Based on UDL principles devised by Rose \& Meyer, 2002, performance indicator categories established by Burgstahler, 2007, and current research study.

\section{Limitations}

The case study method is exploratory, rather than explanatory, and therefore, no controlled conditions existed to allow absolute conclusions about cause-effect relationships. Phenomena and related behaviors are described, not explained; however, correlations and data are revealed that warrant and encourage further research of Universal Design for Learning (UDL) and Scientific Teaching in the college classroom.

Because case studies often rely on the descriptive data provided by individuals, instead of experimental data, some researchers feel there is greater room for error and for important information to be overlooked (Yin, 2003). In an effort to gather thorough and valid descriptive data, in-depth interviews were conducted and open-ended survey questions were used. Both the interview questions and the survey questionnaire were constructed in a manner to eliminate as much bias as possible.

Only adult students, those who are 18 and older, were asked to participate in this research study. Students enrolled in BIOL 115 who are under the age of 18 were excluded from the survey data.

Content analysis was completed on all of the data collected using Klaus Krippendorff's (2004) six components, or stages, of data analysis. The first four stages comprise the datamaking phase where one is "creating computable data from raw or unedited texts," (2004, p. 83). After a researcher has data, then deductions can be made about the observed phenomena, inferences that are supported by the data collected. The final stage is to present a detailed narrative explanation of the data (Krippendorff, 2004). The six phases of analysis are not always linear in nature. "A content analysis may include iterative loops - the repetition of particular 
processes until a certain quality is achieved" (Krippendorff, 2004, p. 85). The repetition involved enables the researcher to support their interpretations by weaving in quotations, construct parallelisms, and engage in triangulation of data sources to add credibility to their study. The content analysis, and the repetition of data analysis, can present challenges when working with sources of variable natures. For this case study, the researcher had interview notes, field notes, survey responses, and course materials of different types all of which required multiple cycles through the content analysis stages.

When developing a coding instrument for this study, the investigator used priori coding to provide increased reliability, credibility, generalizability, and replicability. Priori coding was based on pre-established UDL principles and indicator categories to increase the dependability of the data interpretation. Using open coding, on the other hand, would afford one the benefit of potentially discovering unexpected emergent results.

Content analysis software programs exist that will assist researchers with the transcription of audio and video files, data management and organization, create files searchable using a variety of variables, graphically display variables in relation to one another, and create unlimited coding possibilities including overlapping variable codes that may produce emergent themes. The coding for this study was completed manually. As there were small data sets collected at a single site, and human coding is more effective for interpreting perception and colloquial use of terminology, manual coding was deemed suitable for this study.

\section{Suggestions for Future Research}

If institutions of higher education are to succeed in meeting the demands of the next generation and successfully educate the $21^{\text {st }}$ century learner, educators will need to apply 
innovative strategies to the traditional classroom model and continue to do research to assess the outcomes of our teaching strategies.

The instructor in this study was instinctively employing the principles of Universal Design for Learning (UDL) techniques in her classroom without ever having heard of UDL. Due to the intuitive, best practice nature of UDL, a survey of the institution's faculty to inquire about the teaching methods and instructional techniques beings used in their classrooms would most likely produce results indicating many professors at the institution are using some level of UDL in their classroom without knowledge. Possessing this data would be beneficial for a number of reasons. First, the study would identify which instructors at the institution are already practicing UDL techniques and to what degree. Second, the study would identify what methods are being implemented most at the institution and in which departments. Third, and finally, the study would provide an expansive view of the institution's pedagogy as a whole.

Using the information from a survey study of faculty, further research could be conducted to determine how best to pilot a professional development program for the institution's faculty. Who would be the most receptive? Who is already using the most UDL in their classrooms? How does one begin to train instructors on how to implement UDL into their curriculum? There are multiple training programs in existence at other colleges and universities. A study should be conducted to learn what these other institutions are already doing and how they began their programs.

Additionally, a limited number of institutions of higher education throughout the United States are already encouraging faculty to use the UDL framework to design their courses. A study to identify the institutions that are promoting UDL, why these institutions have elected to encourage the use of UDL, the faculty who are using UDL, and how they are implementing 
UDL, would provide useful information to inform all and all other UDL research. An investigation should be conducted in a university classroom where UDL has been intentionally planned into the design of the course. The use of video to capture each element of UDL would allow a researcher to intricately review how an instructor implemented the principles and also retrieve fine details that cannot be captured by notes.

At the present, there are virtually limitless opportunities in UDL research in higher education. While there is much literature devoted to the definition of Universal Design for Learning (UDL) and the theories of using UDL in the classroom, there are few publications dedicated to the practical application of UDL that provide concrete information for educators who desire to create a universally designed curriculum. There are very few publications that discuss UDL in higher education. A canvas of available literature produced only one result concerning student perceptions of UDL and only a small number of sources that specifically discuss UDL as it applies to postsecondary education. UDL is a relatively modern paradigm of instruction that warrants further investigation to expand to the body of knowledge and literature currently possessed.

Universal Design for Learning (UDL) is truly inclusion through design; a no-step entrance to student success. UDL offers instructors a flexible, barrier free framework for all learners in a classroom. The landscape of postsecondary education is projected to continue to transform rapidly, and as educators we will need approaches that reach our ever-changing population of students. UDL is our best practice, research-based solution. 


\section{References}

Bowe, F. (1999). Universal design in education: Teaching non-traditional students.

Westport, CT: Greenwood Press. Retrieved September 7, 2006 from

http://www.udeducation.org/teach.teaching_techniques/bowe.asp

Burgstahler, S. E. (2008). Equal access: Universal design of Instruction. DO-IT

University of Washington. Retrieved October 26, 2008 from

http://www.washington.edu/doit/Brochures/Academics/equal_access_udi.html

Burgstahler, S. E. (2008). Universal design in higher education. In S. Burgstahler \& R.

Cory (Eds.), Universal design in higher education: From principles to practice (pp. 3-

20). Cambridge, MA: Harvard Education Press.

Burgstahler, S. E., \& Cory, R. C. (Eds.). (2008). Universal design in higher education:

From principles to practice. Cambridge, MA: Harvard Education Press.

Center for Applied Special Technology. (1999). CAST: What is universal design for learning?

Retrieved November 12, 2003 from http://www.cast.org/udl

CAST. (2008). Universal design for learning guidelines version 1.0. Wakefield: MA.

Center for Universal Design. (1997). The principles of universal design. Raleigh,

NC: North Carolina State University.

Council for Exceptional Children. (2005). Universal design for Learning: A guide for

teachers and education professionals. Alexandria, VA: Pearson Custom Publishing.

Coyne, P., Ganley, P., Hall, T., Meo, G., Murray, E. \& Gordon, D. (2006). Applying Universal

Design for Learning in the classroom. In D. Rose \& A. Meyer (Eds.), A practical reader in universal design for learning (pp. 1-13). Cambridge, MA: Harvard Education Press.

De la Garza, B. M. (2007). Introduction to Universal Design for Learning. San Diego State 
University. Retrieved October 15, 2009 from http://highered.sdsu.edu/UDL.htm

Depaolo, C. \& Mclaren, C. H. (2006). The relationship between attitudes and performance in business calculus. INFORMS Transactions on Education. 6(2), 8-22. Retrieved March 1, 2010 from http://ite.pubs.informs.org/Vol6No2/DepaoloMclaren/

Faculty Ware. (2002). University of Connecticut Center on Postsecondary Education and Disability. Retrieved September 7, 2006 from http://www.facultyware.uconn.edu

Handelsman, J., Lauffer, S. M., \& Pfund, C. (2006). Scientific teaching: A guide to transforming undergraduate biology education. New York, NY: W.H. Freeman.

Handelsman, J., Lauffer, S. M., \& Pfund, C. (2007). Scientific teaching. New York, NY: W.H. Freeman.

Henderson, C. (2001). College freshmen with disabilities: A biennial statistical profile. Washington, DC: American Council on Education.

Hussar, W. J., \& Bailey, T. M. (2008). Projections of Education Statistics to 2017 (NCES 2008-078). Washington, DC: National Center for Education Statistics, Institute of Education Sciences, U.S. Department of Education.

Individuals with Disabilities Education Act (IDEA) of 1990, 20 United States Congress 1412 ([a] [5]), Reauthorized 1997. Reauthorized 2004.

Izzo, M., \& Murray, A. (2003). Applying universal design for learning principles to enhance achievement of college students. Learning Objectives: Context and Connections. Ohio State University. 29-42.

Jenner, C., \& Culwell, C. (2006). Using universal design for learning in community and technical colleges. Renton, Washington: Renton Technical College.

Kortering, L., McClannon, T., \& Braziel, P. (2005). What algebra and biology students 
have to say about universal design for learning. National Center on Secondary Education and Transition, 4(2).

Krippendorff, K. (2004). Content analysis: An introduction to its methodology. Thousand Oaks, CA: Sage Publications.

Liddell, M. J., \& Davidson, S. K. (2004). Student attitudes and their academic performance: is there any relationship? Medical Teacher, 26(1), 52-56.

McGuire, J. M., Scott, S. S., \& Shaw, S. F. (2006). Universal design and its applications in educational environments. Remedial and Special Education, 27(3), 166-175.

Meo, G. (2005). Frequent questions about universal design for learning. In D. Rose \& A. Meyer (Eds.), A practical reader in universal design for learning (pp. 33-38). Cambridge, MA: Harvard Education Press.

Müller, E., \& Tschantz, J. (2003). Universal design for learning: Four state initiatives. Quick Turn Around. Project FORUM at the National Association of State Directors of Special Education, Inc. Alexandria, VA.

National Center on Universal Design for Learning. (2010). UDL guidelines. Retrieved September 25, 2009 from http://www.udlcenter.org/aboutudl/udlguidelines/introduction\#intro_learners

No Child Left Behind. (NCLB). (2002). United States Department of Education. Retrieved September 10, 2005 from http://www.ed.gov/policy/elsec/leg/esea02/beginning.html\#sec1

O’Donnell, V. L., \& Tobbell, J. (2007). The transition of adult students to higher education: Legitimate peripheral participation in a community of practice? Adult Education Quarterly, 57(4), 312-328. 
Orkwis, R. (1999). Curriculum access and universal design for learning. ERIC Clearinghouse on Disabilities and Gifted Education (ERIC EC), \#E586. Retrieved March 12, 2003 from http://ericec.org/digest/e586.html

Partnership for $21^{\text {st }}$ Century Skills. (2004). Retrieved September 25, 2007 from http://www.21stcenturyskills.org/

Punch, K. F. (2005). Introduction to social research: Quantitative and qualitative approaches. London: Sage Publications Ltd.

Rose, D. H. et al. (2008). Universal design for learning in postsecondary education: Reflections on principles and their applications. In S. Burgstahler \& R. Cory (Eds.), Universal design in higher education: From principles to practice (pp. 45-59). Cambridge, MA: Harvard Education Press.

Rose, D. \& Meyer, A. (Eds.). (2006). A practical reader in universal design for learning. Cambridge, MA: Harvard Education Press.

Rose, D. \& Meyer, A. (2002). Teaching every student in the digital age: Universal design for learning. Association for Supervision \& Curriculum Development. Alexandria, VA.

Scott, S. S., McGuire, J. M., \& Shaw, S. F. (2001). Principles of universal design for instruction. Storrs: University of Connecticut, Center on Postsecondary Education and Disability.

Scott, S. S., McGuire, J. M., \& Shaw, S. F. (2003). Universal design for instruction: A new paradigm for adult instruction in Postsecondary Education. Remedial and Special Education, 24(6), 369-379.

Sheehan, K. (2001). E-mail survey response rates: A review. Journal of Computer 
Mediated Communication, 6(2), Retrieved July 10, 2006 from

http://www.ascusc.org/jcmc/vol6/issue2/sheehan.html

Sopko, K. M. (2009). Universal design for learning: Policy challenges and recommendations. Project Forum at National Association of State Directors of Special Education. United States Office of Special Education Programs. Alexandria, VA.

Story, M. F., Mueller, J. L., \& Mace, R. L. (1998). The universal design file: Designing for people of all ages and abilities. The Center for Universal Design: North Carolina State University.

Universal design for learning gains traction. (2002). Heller Report on Educational Technology Markets, 14(1), 9-12.

University of Guelph. UID principles. Retrieved September 7, 2006 from http://www.tss.uoguelph.ca/uid/uidprinciples.cfm

University of Maryland Survey Research Center. (2000). Web and e-mail surveys. Retrieved April 12, 2001 from http://www.bsos.umd.edu/src

U.S. Department of Education. (2007). Grant award database. Retrieved September 13, 2007 from http://wdcrobcolp01.ed.gov/CFAPPS/grantaward/start.cfm U.S. Department of Education, Office of Educational Technology. (2004). Toward a golden age in American education: How the internet, the law and today's students are revolutionizing expectations. Washington, DC: U.S. Department of Education.

Van Der Werf, M., and Sabatier, G. (2009). The college of 2020: Students. Washington, DC:

Chronicle Research Services, a division of The Chronicle of Higher Education, Inc.

Wiggins, G., and McTighe, J. (2005). Understanding by design (2nd ed.). Alexandria, VA: Association for Supervision and Curriculum Development. 
Yin, R. K. (2003). Case study research: Design and methods. Applied Social Research Methods Series. Vol. 5. Thousand Oaks, CA: Sage Publications. 
Appendix A

\section{Institution of Higher Education in Louisiana \\ Department of Biological Sciences \\ Spring Semester 2007 \\ Biol 1202 \\ Course Assistant: \\ Office: \\ Office hours: \\ Phone: \\ Email:}

Instructor:

Office:

Office hours

Phone:

Email:

Course Information:

Course Description: Biol 1202 Biology for Science Majors II (3 credit hours), Prereqs: Biol 1201.General concepts in evolution, ecology, and the function of organisms. Primarily for students in science, agriculture, or education. Credit will not be given for this course AND BIOL1002.

\section{Times and locations:}

Section 1, MWF, 1:40-2:30, Williams 102

Section 3, MWF, 9:40-10:30, Coates 143

Course objectives: In this course you will learn core concepts in ecology, evolution and organismal biology. In addition, you will practice critical thinking and science skills such as analyzing figures, designing experiments, and applying information to solve problems and make predictions.

Course methods: In this course, we will use mini-lectures, active learning, clickers, group work, and formative assessments to capture the nature of science in the classroom.

Course Website: All information about this course's policies, schedules, assignments, etc., can be accessed at all times on the class Blackboard website.

\section{Course Requirements:}

Text: Biology $7_{\text {th }}$ Edition, by Campbell and Reece, Pearson-Benjamin Cummings, publishers Clicker: Turning Technologies Radio Frequency student response device.

3x5 notecards: you will need about 15-20 note cards for homework and in-class work.

Class Attendance and Participation: Students are expected to attend class regularly. Your participation will be assessed using online quizzes, homework, daily in-class clicker questions and/or individual and group in-class exercises.

Course Content and Organization: (A detailed schedule is on the class Blackboard site) Ecology: Conservation, Communities, Ecosystems \& Populations, Chpts: 50, 52-55

Evolution: Natural Selection, Population Genetics, Speciation, Origin of Life, Chpts: 22-24, 26

Biodiversity: Systematics, Prokaryotes, Protists, Plants, Fungi and Animals, Chpts: 25, 27-34 Anatomy/Physiology: Homeostasis, Transport and Gas Exchange, Plant Form \& Function, 
Transport and Gas Exchange, Animal Nutrition and Excretion, Chpts: 40, 42, 35, 36, 41, 44

Reproduction: Animal and Plant Reproduction, Chpts 46, 47 and 38.

Class Conduct:

Class Civility: Since every student is entitled to full participation in class without interruption, all students are expected to be in class and prepared to begin ON TIME. All pagers, cellular phones, electronic games, radios, tape or CD players or other sound-generating devices must be turned off when you enter the classroom. Disruption of class, whether by latecomers, noisy devices or inconsiderate behavior, will not be tolerated. Respect for individual differences and alternative viewpoints will be maintained at all times.

Academic Integrity: Scholarly activity is marked by honesty, fairness, and rigor. A scholar does not take credit for the work of others, does not take unfair advantages of others, does not perform acts that frustrate the scholarly efforts of others. The violation of any of these principles is academic dishonesty. Academic Dishonesty includes giving, taking or presenting of information or material by a student with the intent of unethically or fraudulently aiding oneself or another person on ay work which is to be considered in the determination of a grade or the completion of academic requirements. Academic Dishonesty will be handled by the Dean of Students as outlined in the institution's Code of Student Conduct, available online at...

Disability Statement: Any student who, because of a disabling condition, may require accommodations, please see a Coordinator in the Office of Disability Services so that such accommodations may be arranged. After you receive your Accommodation Letters, please meet with someone in that office to discuss the provisions of those accommodations as soon as possible.

\section{Grades:}

Final grades are based on a 500 point scale: 80 points come from homework, in-class exercises and online quizzes; 310 come from four semester exams; 110 points come from a final exam. I round up from 0.50 , i.e. $89.50=\mathrm{A}, 89.49=\mathrm{B}$.

\section{DO NOT NEGOTIATE GRADES!}

\section{Final Grade $\quad$ Percentage $\quad$ Minimum points}

\begin{tabular}{|c|c|c|}
\hline A & $90-100$ & 448 \\
\hline $\mathrm{B}$ & $80-89$ & 398 \\
\hline $\mathrm{C}$ & $70-79$ & 348 \\
\hline $\mathrm{D}$ & $60-69$ & 298 \\
\hline $\mathrm{F}$ & $<60$ & $<298$ \\
\hline
\end{tabular}

Exam Policy: (A detailed exam schedule is on the class Blackboard site)

All exams are computer-based and will be taken outside of class. Class will be held during exam weeks, so do not schedule exams during class times. All exams have 35 questions on new material. The first semester exam will not have cumulative questions, but the 2 nd -4 th semester exams will have 5 cumulative questions each. The final exam will have 20 cumulative questions from material across the semester. Exams will be made up of multiple-choice, multiple response, ranking and $\mathrm{T} / \mathrm{F}$ questions.

Scheduling: You MUST schedule your exam using a web-based scheduler 
prior to taking the exam. Once you have scheduled your exam you will receive a confirmation email letting you know the location of the exam. Failure to schedule and take an exam will result in a zero. Student ID is REQUIRED for all exams.

Make-up policy: (A detailed make-up exam schedule is on the class Blackboard site)

Make-up exams: Paper exams w/ multiple choice, multiple response, ranking, fill-in-the-blank and short answer questions, covering the same topics as the missed exam. Students must fill out AND turn in a make-up exam request form (found on the class webpage) and be granted permission to take the make-up exam before the make-up exam date. Failure to do so will result in a zero.

Participation points: Make-ups will not be given for participation assignments (in-class clicker questions, exercises or homework assignments). Students will be able to drop a total of six participation points without affecting their grade. These drops will be used for participation points missed due to University-approved absences. 
Biology 115 Principles of Biology

Institution of Higher Education in West Virginia

Biology Department

Fall Semester 2009

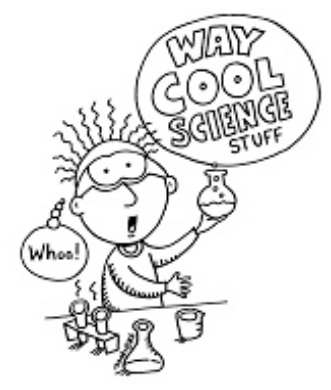

Instructor:

Office:

Phone

Email:
Sections: $\mathrm{H} 03$ and 013

Meeting times: Tue/Thurs 2:30-3:45

Location: Brooks Hall 202

Office hours: Wed 1-3 pm or by appt.

Course Description: BIOL 115 (4 cr) An introductory biology course presenting basic principles of modern. This course represents the first in a four-course, integrated sequence required of biology majors. You must register for both a lecture section and a laboratory section. This course fulfills GEC Objective 2: Basic Math \& Scientific Inquiry.

Learning objectives: Upon successful completion of the course, students will be expected to:

1) Understand and apply fundamental concepts in cellular and molecular biology, genetics and evolution;

2) Work collaboratively to analyze and interpret figures, formulate hypotheses, design experiments, and applying critical thinking and knowledge of the fundamentals of biology to solve problems and make predictions.

Course methods: In this course, we will use mini-lectures, active learning, clickers, group work, and formative assessments to capture the nature of science in the classroom.

\section{Required Materials:}

Text: Biological Science 3rd edition, by Freeman, S. Pearson-Benjamin Cummings, publishers Section 013 - Biology 115 Laboratory Manual 2008-2009.

Section H03 will pick laboratory manual up from lab class.

Clicker: We will use the PRS system and you will be assigned a clicker that you will get from lockboxes in the classroom each class period.

3x5 notecards: you will need about 15-20 note cards for homework and in-class work.

Course Website: All information about this course's policies, schedules, assignments, etc., can be accessed at all times on the class eCampus website.

Class Attendance and Participation: Students are expected to attend class regularly. Your participation will be assessed using online quizzes, homework, daily in-class clicker questions and/or individual and group in-class exercises.

Course Content: In this course, students will learn fundamental concepts in Scientific Method, Chemistry of Life, Cellular Basis of Life, Molecular Basis of Life, Genetics, and Evolution. 
Class Civility: Since every student is entitled to full participation in class without interruption, all students are expected to be in class and prepared to begin ON TIME. All pagers, cellular phones, electronic games, radios, tape or CD players or other sound-generating devices must be turned off when you enter the classroom. Disruption of class, whether by latecomers, noisy devices or inconsiderate behavior, will not be tolerated. Respect for individual differences and alternative viewpoints will be maintained at all times.

Grades: While Biology 115 is one course, we expect you to pass both the lecture and the laboratory sections. Should you receive an $F$ on either the laboratory or the lecture you will receive an $F$ for the entire course. If you receive an $F$ and you wish to $D / F$ repeat the course you must retake the entire course not just the part (lecture or laboratory) you failed.

Relative contribution of exams, non-exam points and lab to overall course grade.

\begin{tabular}{|l|c|}
\hline Midterm Exam 1 & $\mathbf{8 \%}$ \\
\hline Midterm Exam 2 & $\mathbf{1 2 \%}$ \\
\hline Midterm Exam 3 & $\mathbf{1 2 \%}$ \\
\hline Midterm Exam 4 & $\mathbf{1 2 \%}$ \\
\hline Final Exam & $\mathbf{1 8 \%}$ \\
\hline Non-exam points & $\mathbf{1 5 \%}$ \\
\hline Lab Grade & $\mathbf{2 3 \%}$ \\
\hline Total & $\mathbf{1 0 0 \%}$ \\
\hline
\end{tabular}

\section{Grade Calculation}

Final Grade Percentage

$\begin{array}{ll}\text { A } & 90-100 \\ \text { B } & \mathbf{8 0 - 8 9} \\ \text { C } & 70-79 \\ \text { D } & 60-69 \\ \text { F } & <60\end{array}$

Exams: All exams are computer-based and will be taken in the third floor computer lab of the Life Sciences Building. Class will be held during exam weeks, so do not schedule exams during class times. All exams, except the first, will be cumulative. Exams will be made up of multiplechoice, multiple response, ranking and T/F questions. You MUST schedule your exam using the web-based scheduler prior to taking the exam. Failure to schedule and take an exam will result in a zero. Student ID is REQUIRED for all exams.

Exam Schedule

\begin{tabular}{|l|l|l|l|}
\hline Number & Days & Date & \# of questions \\
\hline Exam 1 & Tue-Fri & $9 / 7-9 / 10$ & 25 \\
\hline Exam 2 & Mon-Fri & $9 / 28-10 / 2$ & $35+5$ cumulative \\
\hline Exam 3 & Mon-Fri & $10 / 19-10 / 23$ & $35+5$ cumulative \\
\hline Exam 4 & Mon-Fri & $11 / 19-11 / 13$ & $35+5$ cumulative \\
\hline Final Exam & Mon-Fri & $12 / 7-12 / 11$ & $35+25$ cumulative \\
\hline
\end{tabular}


Make-up exams: Make-up exams will be given to students who miss the original exam for a University excused absence only. Make up exams will be given on the Wednesday following the original exam week at $3 \mathrm{pm}$ in my office (XXX 4110). Students must inform me of the exam absence and be granted permission to take the make-up exam before the make-up exam date.

Failure to do so could result in a zero.

Students will be able to drop a total of 10 non-exam activities (i.e. an online quiz or an in-class assignment is equivalent to one activity) without affecting their grades. These drops will be used for non-exam points missed due to University-approved absences.

Academic Integrity: Scholarly activity is marked by honesty, fairness, and rigor. A scholar does not take credit for the work of others, does not take unfair advantages of others, does not perform acts that frustrate the scholarly efforts of others. The violation of any of these principles is academic dishonesty. Academic Dishonesty includes giving, taking or presenting of information or material by a student with the intent of unethically or fraudulently aiding oneself or another person on ay work which is to be considered in the determination of a grade or the completion of academic requirements. Academic Dishonesty will be handled through the office of the Dean of Students.

Disability Statement: Any student who, because of a disabling condition, may require accommodations, please contact the Office of Disability Services (XXX-XXXX) so that such accommodations may be arranged. Please inform your instructor of the accommodations during the first week of class, if possible, during office hours or by appointment.

Social Justice: This institution is committed to social justice. The instructors of this course concur with this institution's commitment and expect to maintain a positive learning environment based upon open communication, mutual respect and nondiscrimination. Our institution does not discriminate on the basis of race, sex, age, disability, veteran status, religion, sexual orientation, color or national origin. Any suggestions as to how to further such an environment will be appreciated and given serious consideration. 


\begin{tabular}{|c|c|c|c|}
\hline Date & Topic & Quiz/Homework & Due \\
\hline \multicolumn{4}{|c|}{ Nature of Science } \\
\hline \multicolumn{4}{|c|}{ Week 1: How is science a way of knowing? Chpt 1 section 4} \\
\hline Tue $8 / 25$ & How does this class work? & & \\
\hline Thu $8 / 27$ & $\begin{array}{l}\text { Nature of science: What does it } \\
\text { mean to be evidence-based? }\end{array}$ & OL quiz 1 & \\
\hline \multicolumn{4}{|c|}{ Week 2: How do scientists use experiments to answer questions? } \\
\hline Tue $9 / 1$ & $\begin{array}{l}\text { Experimental Design and data } \\
\text { representation }\end{array}$ & & \\
\hline Thu $9 / 3$ & What does it mean to be alive? & & \\
\hline \multicolumn{4}{|c|}{ Cellular Basis of Life } \\
\hline \multicolumn{4}{|l|}{$\begin{array}{l}\text { Week 3: } \\
\text { Exam 1 }\end{array}$} \\
\hline Tue $9 / 8$ & Transport across cell membranes & OL quiz 2 (chpt $6+2)$ & \\
\hline Thu 9/10 & Dynamic cell structure/function & Quiz 3 & \\
\hline \multicolumn{4}{|c|}{ Energy } \\
\hline \multicolumn{4}{|l|}{ Week 4: } \\
\hline \multicolumn{4}{|l|}{ Tue $9 / 15$} \\
\hline \multicolumn{4}{|l|}{ Thu 9/17 } \\
\hline \multicolumn{4}{|l|}{ Week 5: } \\
\hline \multicolumn{4}{|l|}{ Tue $9 / 22$} \\
\hline \multicolumn{4}{|l|}{ Thu 9/24 } \\
\hline \multicolumn{4}{|l|}{ Week 6: } \\
\hline \multicolumn{4}{|l|}{ Tue $10 / 6$} \\
\hline \multicolumn{4}{|l|}{ Thu $10 / 8$} \\
\hline \multicolumn{4}{|l|}{ Week 7: } \\
\hline \multicolumn{4}{|l|}{ Tue $10 / 13$} \\
\hline \multicolumn{4}{|l|}{ Thu $10 / 15$} \\
\hline \multicolumn{4}{|l|}{$\begin{array}{l}\text { Week 8: } \\
\text { Exam } 3\end{array}$} \\
\hline \multicolumn{4}{|l|}{ Tue $10 / 20$} \\
\hline \multicolumn{4}{|l|}{ Thu 10/22 } \\
\hline \multicolumn{4}{|l|}{ Week 9: } \\
\hline \multicolumn{4}{|l|}{ Tue $10 / 27$} \\
\hline \multirow{2}{*}{\multicolumn{4}{|c|}{$\begin{array}{l}\text { Thu 10/29 } \\
\text { Week 10: }\end{array}$}} \\
\hline & \multirow{2}{*}{\multicolumn{3}{|c|}{ Week 10: }} \\
\hline \multicolumn{3}{|l|}{ Tue $11 / 3$} & \\
\hline \multicolumn{4}{|l|}{ Thu 11/5 } \\
\hline \multicolumn{4}{|l|}{$\begin{array}{l}\text { Week 11: } \\
\text { Exam } 4\end{array}$} \\
\hline Tue $10 / 10$ & & & \\
\hline
\end{tabular}




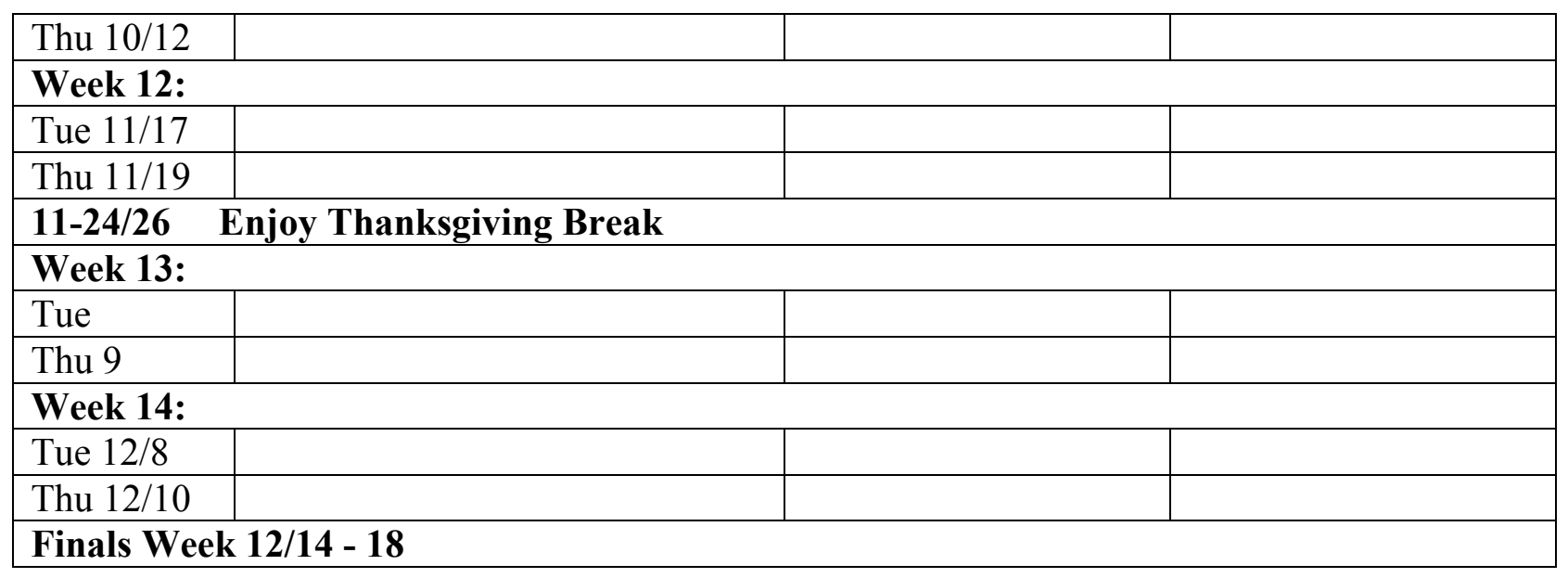


Appendix B

\section{Biol 593E Scholarly Teaching for Future College Faculty Institution of Higher Education in West Virginia Spring 2009}

\author{
Instructor: \\ Office: \\ Phone \\ Email:
}

\author{
Meeting times: Tue/Thurs 2:30-3:45 \\ Location: Life Sciences Building 5001 \\ Office hours: By appointment.
}

Text: Scientific Teaching, J. Handelsman, S. Miller and C. Pfund, W. H. Freeman and Company, 2007.

Selected readings from: a) primary literature, b) National Research Council reports, b)

Pathways to Scientific Teaching, D. Ebert-May and J. Hodder, Sinauer Associates, 2008. and c)

Classroom Assessment Techniques, T. Angelo and K. Cross, Jossey-Bass Publishers, 1993.

Course Management System: eCampus www.ecampus.wvu.edu

Course Description and Format: Biol 593E (3cr) is a graduate course on the theory and practice of Scientific Teaching. This course is designed to model the teaching practices about which we are learning. Each day is designed to offer experiences, knowledge and discussions about teaching and learning. In addition you will gain hands-on experience with the techniques being modeled.

\section{Learning Outcomes}

By the end of this course, we will:

1. know: (knowledge)

a. the core concepts in scientific teaching, active learning, assessment, and diversity

b. the role of student learning is paramount in the classroom

2. be able to: (skills)

a. apply the core concepts of scientific teaching to your own teaching

b. choose teaching methods based on evidence

c. create an inclusive classroom

d. design and implement assessment tools that gauge learning and teaching

e. use instructional resources, technology, and literature in the development of new materials

f. give and receive feedback on teaching materials and teaching philosophies

3. have created: (products)

a. teaching materials that address a knotty problem in an undergraduate course (at the "comprehensive" level) and that engage students in thinking

b. a network of colleagues in teaching that is grounded in problem solving, peer review, and mutual respect

c. a toolbox of ideas, materials, and resources for teaching

d. a peer-reviewed teaching philosophy 


\section{Course Schedule \\ Date Topic \\ 1/13 Introductions, Syllabus \\ 1/15 Scientific Teaching \\ 1/20 No Class: Inauguration \\ 1/22 Teachable Units, Course Design, Syllabus I, RAT 1}

1/27 Teachable Units, Course Design, Syllabus II

1/29 Assessment I; RAT 2

2/3 Formative Assessment Tidbit presentation I

2/5 Formative Assessment Tidbit presentation II

2/10 Assessment II; RAT 3

2/12 Active Learning; RAT 4

2/17 Active Learning - Tidbit Presentation I

2/19 Active Learning - Tidbit Presentation II

2/24 No Class: NASI Mtg

2/26 Diversity; RAT 5

3/3 No Class: Va Tech Talk

3/5 Diversity - Tidbit Presentation I

3/10 Diversity - Tidbit Presentation II

3/12 Teachable Unit Production

3/17 - 19 No Class: Spring Break

3/24 How to write a teaching philosophy

3/26 No Class: Teaching Workshop

3/31 From Assessment to Research

\section{Reading/ Assignment}

Chpt 1: Scientific Teaching

Chpt 2: "How People Learn", NRC report.

Chpt 5: Scientific Teaching

"The Complete Syllabus"

"Syllabus Planning Workbook: A Decision Guide" Lynn Evans

Turn in Syllabus, review first draft of syllabus and topic/learning objectives for TU

Chpt 3: Scientific Teaching

"Nine Principles of Good Practice for Assessing Student Learning" (AAHE)

Peer review

Peer review

"Biology in Bloom: Implementing Bloom's Taxonomy to Enhance Student Learning in Biology" Crowe et al., CBELSE (2008)

Chpt 2: Scientific Teaching

Peer review

Peer review

Chpt 4: Scientific Teaching

Peer review

Peer review,

Critique class in your discipline

Readings: "Bridging the pathway from instruction to research". Batzli et al.

"Designing research to investigate student learning." Ebert-May et al.

Turn in Teaching Philosophy - first draft and class critique 
4/2 Teachable Unit Production Peer review teaching philosophies

II

4/7 Teachable Unit Production Get back peer-reviewed Teaching Philosophies

4/9 No Class: Case Western Talk

4/14 Teachable Unit Presentations - preliminary

4/16 Teachable Unit Presentations - preliminary

4/21 Teachable Unit Presentations - preliminary

4/23 Teachable Unit Presentations -

4/28 Teachable Unit Presentations - final

4/30 Teachable Unit peer review Presentations - final

peer review, Turn in Teaching Philosophy- final draft

peer review

peer review

peer review

peer review

5/8 Turn in final TU and TU Presentation documents

Learning Assessment/Evaluation:

Your grade for this course will be determine by the following activities

$\begin{array}{ll}\text { Assignment } & \text { \% of total grade } \\ \text { Reading assessment team (RAT) presentation } & \mathbf{5} \\ \text { Syllabus } & \mathbf{1 5} \\ \text { Teachable Tidbit presentations } & \mathbf{1 5}(\mathbf{5} \text { each x 3) } \\ \text { Teachable Unit } & \mathbf{2 5} \\ \text { Teachable Unit Presentation } & \mathbf{1 0} \\ \text { Class critique } & \mathbf{5} \\ \text { Teaching Statement/Philosophy } & \mathbf{1 5} \\ \text { Peer-review of assignments } & \mathbf{5} \\ \text { Participation in class discussion and activities } & \mathbf{5}\end{array}$

Reading assessments. Pairs of classmates will develop and lead an activity or series of activities that (a) engages the other classmates in applying the material and (b) assesses whether the other classmates understand the material. For ideas, refer to pp. 52-58 in Scientific Teaching. Page 58 is especially useful. Each team will do ONE reading assessment during the course.

Teachable Tidbits. A "teachable tidbit" is a 10-15 minute activity that (a) engages students in learning a specific concept or series of concepts and (b) assesses learning.

\section{Grade Distributions}
A $\quad 90-100$
B $\quad 80-89$
C $\quad 70-79$
D $\quad 60-69$
F $<60$ 
Class Attendance and Participation: Students are expected to attend class regularly. Your participation in the learning activities provided during class and out of class is important to your learning success in this course. Participation will be assessed using daily discussions and learning exercises.

Class Civility: Since every student is entitled to full participation in class without interruption, all students are expected to be in class and prepared to begin on time and remain for the duration of the class period. All pagers, cellular phones, electronic games, radios, tape or CD players or other sound-generating devices must be turned off when you enter the classroom. Disruption of class, whether by latecomers, noisy devices or inconsiderate behavior, will not be tolerated. Respect for individual differences and alternative viewpoints will be maintained at all times.

Course Syllabus Modifications: Modifications to this Course Syllabus will be made as to the selection of reading assignments, learning assignments and due dates in consultation with students. The schedule and procedures in this course are subject to change in the event of extenuating circumstances.

Academic Integrity: Scholarly activity is marked by honesty, fairness, and rigor. A scholar does not take credit for the work of others, does not take unfair advantages of others, does not perform acts that frustrate the scholarly efforts of others. The violation of any of these principles is academic dishonesty. Academic Dishonesty includes giving, taking or presenting of information or material by a student with the intent of unethically or fraudulently aiding oneself or another person on ay work which is to be considered in the determination of a grade or the completion of academic requirements. Academic Dishonesty will be handled through the office of the Dean of Students.

Disability Statement: Any student who, because of a disabling condition, may require accommodations, please contact the Office of Disability Services (XXX-XXXX) so that such accommodations may be arranged. Please inform your instructor of the accommodations during the first week of class, if possible, during office hours or by appointment.

Social Justice: The institution is committed to social justice. The instructor of this course concurs with the institution's commitment and expect to maintain a positive learning environment based upon open communication, mutual respect and nondiscrimination. Our institution does not discriminate on the basis of race, sex, age, disability, veteran status, religion, sexual orientation, color or national origin. Any suggestions as to how to further such an environment will be appreciated and given serious consideration.

\section{Giving and Receiving Constructive Feedback}

The Teachable Unit Review Rubric (pp. 86-87 in Scientific Teaching) provides guidelines for developing instructional materials and teaching practice. The rubric describes the important components of a teachable unit and provides descriptions for the caliber of the unit ("comprehensive," "intermediate," and "cursory.") Use the rubric as a guide for the development of your materials and as a framework for giving feedback. 
You can best benefit from your teaching practice if you receive clear feedback. This requires an open and caring atmosphere in which your fellow participants feel comfortable enough to offer honest feedback, motivated by your willingness to receive it. Feedback provides you with information about how you affect others and how well your behavior and activities match your intentions; it helps you identify your strengths and areas for improvement.

Constructive feedback is descriptive rather than evaluative. By describing one's own reaction and avoiding evaluative language, the individual receiving feedback is less likely to react defensively. Constructive feedback has the following characteristics:

1. It is specific rather than general.

2. It considers the needs of the receiver and giver.

3. It is directed toward behavior that the receiver can change. Frustration is generated when a person is reminded of a shortcoming s/he cannot control.

4. It is solicited rather than imposed. Feedback is most useful when the receiver has a question the observers can answer.

5. It is given immediately after the event.

6. It is checked to ensure clear communication. Have the receiver rephrase the feedback.

7. Both giver and receiver can check with others on the accuracy of the feedback; is this one person's impression or a shared impression? 


\section{Appendix C}

1. How would you describe the demographic characteristics of your class population?

2. Do you know if you have any students with disabilities who have gone to disability services and asked for accommodations?

3. Do you have any students for whom English is their second language?

4. What majors enroll in your course?

5. What formats do you use to present information to your students?

6. How do you share learning objectives/expectations with the students?

7. Describe a typical lecture.

8. Do you select readings that are available online?

9. What is the role of instructional technology in your classroom?

10. How do you provide feedback to students?

11. How do you communicate with students directly?

12. How do you motivate students?

13. How are students assessed?

14. How would you describe your teaching?

15. What techniques do you feel are the most effective in helping your student to learn the material?

16. What have been some of the definitive outcomes of using these techniques?

17. What do you perceive as the student reaction to your course?

18. What do you know about Universal Design for Learning?

19. How did you get involved with Scientific Teaching

20. How did you use Scientific Teaching methods to construct your course?

21. How did your course evolve as a result of using Scientific Teaching? What methods did you being implanting first, etc. 


\section{Appendix D}

1. Throughout this course, how did the instructor present information to the class? Describe a typical lecture.

2. What instructional technologies were used during lectures?

3. Describe your level of interest in this course - did you enjoy attending the course? How did the instructor keep you motivated?

4. How did you receive feedback on your assignments?

5. In what ways were you expected to demonstrate your understanding of the material? (In other words, what was your grade based upon?)

6. Were the instructor's expectations consistent with the learning objectives stated in the course syllabus?

7. What did you like most about this course?

8. What would you change about this course?

9. At midterm, what grade did you receive in this course?

10. What final grade do you expect to receive in this course?

11. How would you describe this course in comparison to other courses you have taken or are currently taking at this institution? How are they similar? How are they different?

12. Do you feel you learned less/the same/or more in this course than in other courses at this institution? Why or why not? Please explain. 
Demographic information

Student gender: Male

Freshman

$18-22$

Age:

I am a student with a disability:

English is my second language:

Are you an Honors student?
BIOL 115 Questions

Year:

\section{Appendix E}

Female

Sophomore

Junior

Senior

23-30

$30-45$

45-60

True

False

True

False

How would you describe your race/cultural background?

What is your major?

1. In BIOL 115, how did the instructor present information to the class?

2. What instructional technologies were used during BIOL 115 lectures?

3. Describe your level of interest in BIOL 115 - did you enjoy attending the course? How did the instructor keep you motivated?

4. How did you receive feedback on your assignments?

5. In what ways were you expected to demonstrate your understanding of the material? (In other words, what was your grade based upon?)

6. Were the instructor's expectations consistent with the learning objectives stated in the course syllabus?

7. What did you like most about BIOL 115 ?

8. What would you change about BIOL 115 ?

9. At midterm, what grade did you receive in BIOL 115 ? 
10. What final grade did you receive for BIOL 115 ?

11. How would you describe BIOL 115 in comparison to other courses you have taken or are currently taking at this institution? How are they similar? How are they different?

12. Do you feel you learned less/the same/more in BIOL 115 than in other courses at this institution? Why or why not? Please explain.

13. If I should need more information, would you be willing to participate in an interview? 
Appendix F

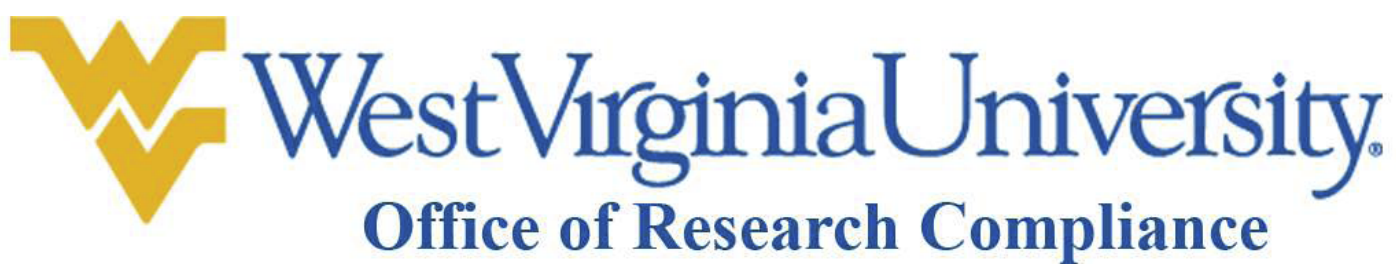

The above-referenced study was reviewed by the Institutional Review Board and was granted exemption on 2/3/2009 in accordance with 45 CFR 46.101(1,2).

While no action is required on your part, the IRB made the following findings:

The following documents have been approved and validated for use in this study and are available in the BRAAN system:

This protocol was reviewed using the following:

Exemption Checklist (210r)

BIOL593InterviewRequestLetteronLetterhead.doc

Letter to request interviews on letterhead

BIOL593Letter.rtf Letter to request interviews (will be on letterhead)

Guided interview questions for instructor

Interview questions for instructor

Questions for Graduate Student

Interviews.rtf

Graduate student interview question set

Reference Pages.rtf References

Student Survey Question Set.rtf Survey question set for e-mail

Miscellaneous Attachments

Attachments

BIOL593InterviewRequestLetteronLetterhead.rtf

Once you begin your human subject research the following regulations apply:

1. Unanticipated or serious adverse events/side effects encountered in this research study must be reported to the IRB within five (5) days.

2. Any modifications the study protocol or informed consent form must be reviewed and approved by the IRB prior to implementation.

3. You may not use a modified informed consent form until it has been approved and validated by the IRB.

Thank you

Letter Sent By: Board Designee, 2/3/2009 1:39 PM 